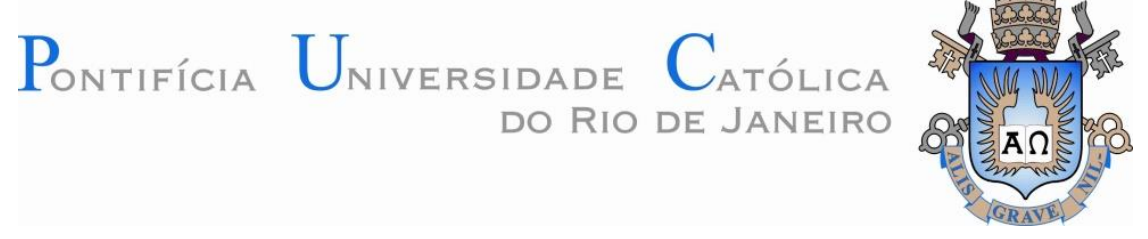

Javier Linkolk Lopez Gonzales

\title{
Simulação dos Preços de Energia no Leilão de Eficiência Energética no Brasil
}

Dissertação de Mestrado

Dissertação apresentada como requisito parcial para obtenção do título de Mestre pelo Programa de PósGraduação em Metrologia (Área de concentração: Metrologia para Qualidade e Inovação) da PUC-Rio.

Orientador: Prof. Reinaldo Castro Souza Co-Orientador: Prof. Rodrigo Flora Calili 
Javier Linkolk Lopez Gonzales

\title{
Simulação dos Preços de Energia no Leilão de Eficiência Energética no Brasil
}

\begin{abstract}
Dissertação apresentada como requisito parcial para obtenção do título de Mestre pelo Programa de PósGraduação em Metrologia (Área de concentração: Metrologia para Qualidade e Inovação) da PUC-Rio. Aprovada pela Comissão Examinadora abaixo assinada.
\end{abstract}

Prof. Reinaldo Castro Souza

Presidente/Orientador Departamento de Engenharia Elétrica (PUC-Rio)

Prof. Rodrigo Flora Calili Co-Orientador Programa de Pós-Graduação em Metrologia (PUC-Rio)

Dr. João Carlos de Oliveira Aires Universidade Santa Úrsula (USU)

Dra. Gheisa Roberta Telles Esteves

IICA/Eletrobras

Prof. Jose Eugênio Leal Coordenador Setorial de Pós-Graduação do Centro Técnico Científico (PUC-Rio)

Rio de Janeiro, 25 de março de 2015 
Todos os direitos reservados. É proibida a reprodução total ou parcial do trabalho sem autorização da universidade, do autor e do orientador.

Javier Linkolk Lopez Gonzales

Formado em Engenharia Informática e Estatística na Universidade Peruana Unión no ano de 2010.

Ficha Catalográfica

Gonzales, Javier Linkolk Lopez

Simulação dos Preços de Energia no Leilão de Eficiência Energética no Brasil / Javier Linkolk Lopez Gonzales; Orientador: Reinaldo Castro Souza; CoOrientador: Rodrigo Flora Calili - 2015.

107 f.: il. (color) ; $30 \mathrm{~cm}$

Dissertação (mestrado) - Pontifícia Universidade Católica do Rio de Janeiro, Programa de Pós-Graduação em Metrologia para a Qualidade e Inovação, 2015. Incluí referências bibliográficas.

1. Metrologia - Teses; 2. Metrologia. 3. Dissertação. 4. Leilão Eficiência Energética. 5. Preço de Energia; 6. Simulação. 7. Energia. 8. MCMC I. Souza, Reinaldo Castro. II. Calili, Rodrigo Flora. III. Pontifícia Universidade Católica do Rio de Janeiro. Programa de Pós-Graduação em Metrologia para a Qualidade e Inovação. IV. Título

CDD: 389.1 


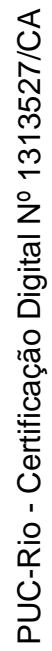

Aos meus pais

A minha faculdade 


\section{Agradecimentos}

A Deus pelo cuidado ao longo desse tempo.

Aos meus orientadores os professores Reinaldo Castro Souza, Rodrigo Flora Calili pela parceria, todos os ensinamentos e a orientação durante o decorrer desta empreitada.

À PUC-Rio pelos auxílios concedidos, sem as quais esta dissertação de mestrado não poderia ter sido concluída.

Ao meu coordenador do Programa Prof. Mauricio Frota, pela grande oportunidade de permitir-me cursar o mestrado com todas as facilidades possíveis, e pela pro atividade que ele tem um exemplo a seguir.

Aos professores e funcionários do Programa de Metrologia, Qualidade, Inovação e Sustentabilidade da PUC-Rio, pelos ensinamentos e ajuda em todos os momentos durantes estes 2 anos de estudo e pesquisa.

Aos meus queridos pais, Javier e Maribel, por sempre estarem comigo e me apoiando em todas as minhas decisões, mesmo que isto ocasionasse em distância, como foi o caso de eu vir aqui.

As minhas irmãs Shany Mavet e Lizeth Priscila, por sempre me darem seu ânimo constante estando longe.

À minha vô, Elsa Guzmán, a quem considero a pessoa mais generosa e com muita capacidade de saber administrar o que tem um exemplo que sempre levo na minha vida.

Aos meus amigos Ivan e Sindy que sempre estiveram pertos e me acolheram como parte da sua família.

Aos meus amigos brasileiros Felipe e Laura, que foram muito acolhedores enquanto estive aqui no Rio.

À Universidad Peruana Unión (UPeU) pelo apoio econômico, espiritual e pela facilidade que me deram de poder realizar os estudos de mestrado fora do meu país de origem. 


\section{Resumo}

Gonzales, Javier Linkolk Lopez; Souza, Reinaldo Castro (Orientador); Calili, Rodrigo Flora (Co-Orientador). Simulação dos Preços de Energia no Leilão de Eficiência Energética no Brasil. Rio de Janeiro, 2015. 107 p. Dissertação de Mestrado - Programa de Pós-Graduação em Metrologia (Área de concentração: Metrologia para Qualidade e Inovação), Pontifícia Universidade Católica do Rio de Janeiro.

A Eficiência Energética (EE) pode ser considerada sinônimo de preservação ambiental, pois a energia economizada evita a construção de novas plantas de geração e de linhas de transmissão. O Leilão de Eficiência Energética (LEE) poderia representar uma alternativa muito interessante para a dinamização e promoção de práticas de EE no Brasil. Porém, é importante mencionar que isso pressupõe uma confiança na quantidade de energia reduzida, o que só pode se tornar realidade com a implantação e desenvolvimento de um sistema de Medição e Verificação $(\mathrm{M} \& \mathrm{~V})$ dos consumos de energia. Neste contexto, tem-se como objetivo principal simular os preços de energia do Leilão de Eficiência Energética no ambiente regulado para conhecer se a viabilidade no Brasil poderia se concretizar. A metodologia utilizada para realizar as simulações foi a de Monte Carlo, ademais, antes se utilizou o método do Kernel com a finalidade de conseguir ajustar os dados a uma curva através de polinômios. Uma vez conseguida a curva melhor ajustada se realizou a análise de cada cenário (nas diferentes rodadas) com cada amostra $(500,1000,5000$ e 10000) para encontrar a probabilidade dos preços ficarem entre o intervalo de $\mathrm{R} \$ 110$ e $\mathrm{R} \$ 140$ (preços ótimos propostos no LEE). Finalmente, os resultados apresentam que a probabilidade de o preço ficar no intervalo de $\mathrm{R} \$ 110$ e $\mathrm{R} \$ 140$ na amostra de 500 dados é de 28,20\%, na amostra de 1000 é de 33,00\%, na amostra de 5000 é de $29,96 \%$ e de 10000 é de $32,36 \%$.

\section{Palavras-chave}

Metrologia; Leilões Eficiência Energética; Preço de Energia; Simulação; Energia; MCMC. 


\section{Abstract}

Gonzales, Javier Linkolk Lopez; Souza, Reinaldo Castro (Advisor); Calili, Rodrigo Flora (Co-Advisor). Energy Price Simulation in Brazil through Demand Side Bidding. Rio de Janeiro, 2015. 107 p. MSc. Dissertation Programa de Pós-Graduação em Metrologia (Área de concentração: Metrologia para Qualidade e Inovação), Pontifícia Universidade Católica do Rio de Janeiro.

The Energy Efficiency (EE) is considered a synonymous of environmental preservation, because the energy saved prevents the construction of new generating plants and transmission lines. The Demand-Side Bidding (DSB) could represent a very interesting alternative for the revitalization and promotion of $\mathrm{EE}$ practices in Brazil. However, it is important to note that this presupposes a confidence on the amount of reduced energy, which can only take reality with the implementation and development of a measurement system and verification $(\mathrm{M} \& \mathrm{~V})$ the energy consumption. In this context, the main objective is to simulate of the prices of the demand-side bidding in the regulated environment to meet the viability in Brazil that could become a reality. The methodology used to perform the simulations was the Monte Carlo addition, prior to the Kernel method was used in order to be able to adjust the data to a curve, using polynomials. Once achieved the best-fitted curve was carried out through an analysis of each scenario (in different rounds) with each sample (500, 1000, 5000 and 10000) to find the probability of the price falling between the RS110 range and R \$ 140 (great prices proposed by the DSB). Finally, the results showed that the probability of staying in the price range from $\mathrm{R} \$ 110$ and RS 140 data 500 in the sample is $28.20 \%$, the sample 1000 is $33.00 \%$, the sample 5000 is $29.96 \%$ and 10000 is $32.36 \%$.

\section{Keywords}

Metrology; Demand-Side Bidding; Energy price; Simulation; Energy; MCMC. 


\section{Sumário}

1 Introdução 17

1.1. Experiências de eficiência energética em outros Países 19

1.2. Definição do problema de pesquisa 21

1.3. Objetivos: geral e específicos 22

1.4. Motivação 23

1.5. Organização do trabalho 24

2 Proposta do leilão de eficiência energética 25

2.1. Experiências internacionais 25

2.1.1. Estados unidos 25

2.1.1.1. Descrição da demanda dos mercados de resposta mecânica 27

2.1.1.2. Diferentes abordagens para alcançar a resposta da demanda 29

2.1.2. África do Sul 30

2.1.3. Noruega 32

2.1.3.1. Mercado do dia anterior 32

2.1.3.2. Mercado em tempo real 33

2.2. Proposta inicial no Brasil 34

2.2.1. Compradores 41

2.2.2. Vendedores 41

2.2.3. O governo 42

2.3. Proposta para o Leilão de Eficiência Energética no Brasil 42

3 Medição e Verificação $\quad 47$

3.1. Definição de M\&V 48

3.2. A relação entre a M\&V e as ESCOs 50

3.3. Definição de Baseline 53

3.3.1. Contrato de performance $\quad 54$

3.4. Opções de M\&V

3.5. Validação de M\&V 
4 Simulação do leilão de Eficiência Energética $\quad 60$

4.1. Ambiente de contratação para a simulação do LEE 60

4.2. Método de Kernel 62

4.3. Aproximação por polinômios 64

4.4. Método de Monte Carlo via cadeias de Markov 65

4.5. Simulação 66

4.5.1. Simulação Estatística $\quad 67$

4.5.2. Simulação de Monte Carlo 69

4.5.3. Geração de números aleatórios 70

5 Metodologia 72

5.1. Considerações iniciais $\quad 72$

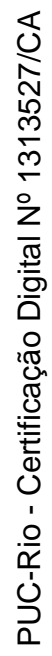

5.2. Simulação no ambiente de contratação regulado 72

5.2.1. A distribuição dos dados foi obtida usando o método Kernel e aproximação polinomial 73

5.2.2. Utilização do MCMC 73

5.2.3. Geração de amostras usando o algoritmo de MetropolisHastings

6 Resultados $\quad 75$

6.1. Funcionamento do Leilão de Eficiência Energética 75

6.2. Resultados das rodadas para o ambiente regulado 82

7 Conclusões e recomendações 103

8 Referências bibliográficas 105 


\section{Lista de figuras}

Figura 1: Ranking internacional de eficiência energética - $2014 \quad 20$

Figura 2: Organizações Regionais de Transmissão nos Estados Unidos 26

Figura 3: Administração das ORTs 27

Figura 4: Matriz do Balance sheet 30

Figura 5: Tecnologia completa do Balance sheet 31

Figura 6: Possíveis Fases do LEE 36

Figura 7: Cenários para a inserção do LEE 37

Figura 8: Modelo de mercado do LEE 38

Figura 9: Passos para a implementação do LEE 39

Figura 10: Condutores que interagirão no LEE 43

Figura 11: Proposta do Leilão de Eficiência Energética 45

Figura 12: Funcionamento da estrutura do PROESCO 51

Figura 13: Passos de um PEE

Figura 14: Descrição de Baseline $\quad 54$

Figura 15: Resumo dos ambientes de contratação $\quad 60$

Figura 16: ACR e ACL $\quad 61$

Figura 17: Histograma dos dados originais sem aplicar a inflação 82

Figura 18: Histograma dos dados originais aplicando a inflação 84

Figura 19: Estimativa da densidade pelo Kernel 85

Figura 20: Histograma com Kernel e MCMC de 500 iterações 86

Figura 21: Histograma com Kernel e MCMC de 1000 iterações 86

Figura 22: Histograma com Kernel e MCMC de 5000 iterações 87

Figura 23: Histograma com Kernel e MCMC de 10000 iterações 87 


\section{Lista de quadros}

Quadro 1: Opções do PIMVP 56

Quadro 2: Características e opções do projeto da AEE 57

Quadro 3: Comparações entre os cenários 98

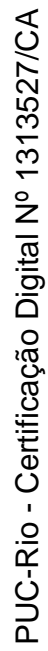




\section{Lista de tabelas}

Tabela 1: Geração total, preços e arranjo contratual no ano t 76

Tabela 2: Geração total, preços e arranjo contratual no ano $\mathrm{t}+1$ sem EE 78

Tabela 3: Geração total, preços e arranjo contratual no ano $t+1$ com EE (Real) 79

Tabela 4: Geração total, preços e arranjo contratual no ano t+1 com EE(Virtual) 81

Tabela 5: Preços sem inflação $\quad 82$

Tabela 6: Análise descritiva do preço sem inflação 83

Tabela 7: Preços com inflação $\quad 83$

Tabela 8: Análise descritiva do preço sem inflação 83

Tabela 10: Cenário 1 (A500) 88

Tabela 11: Cenário 1 (A1000) 88

Tabela 12: Cenário 1 (A5000) 88

Tabela 13: Cenário 1 (A10000) 88

Tabela 14: Cenário 2 (A500) 89

Tabela 15: Cenário 2 (A1000) 89

Tabela 16: Cenário 2 (A5000) 89

Tabela 17: Cenário 2 (A10000) 89

Tabela 18: Cenário 3 (A500) 90

Tabela 19: Cenário 3 (A1000) 90

Tabela 20: Cenário 3 (A5000) 90

Tabela 21: Cenário 3 (A10000) 90

Tabela 22: Cenário 4 (A500) 91

Tabela 23: Cenário 4 (A1000) 91

Tabela 24: Cenário 4 (A5000) 91

Tabela 25: Cenário 4 (10000) 91

Tabela 26: Cenário 5 (A500) 92

Tabela 27: Cenário 5 (A1000) 92

Tabela 28: Cenário 5 (A5000) 92

Tabela 29: Cenário 5 (A10000) 92

Tabela 30: Cenário 6 (A500) 93

Tabela 31: Cenário 6 (A1000) 93 
Tabela 32: Cenário 6 (A5000) 93

Tabela 33: Cenário 6 (A10000) 93

Tabela 34: Cenário 7 (A500) 94

Tabela 35: Cenário 7 (A1000) 94

Tabela 36: Cenário 7 (A5000) 94

Tabela 37: Cenário 7 (A10000) 94

Tabela 38: Cenário 8 (A500) 95

Tabela 39: Cenário 8 (A1000) 95

Tabela 40: Cenário 8 (A5000) 95

Tabela 41: Cenário 8 (A10000) 95

Tabela 42: Cenário 9 (A500) 96

Tabela 43: Cenário 9 (A1000) 96

Tabela 44: Cenário 9 (A5000) 96

Tabela 45: Cenário 9 (A10000) 96

Ð Tabela 46: Cenário 10 (A500) 97

Tabela 47: Cenário 10 (A1000) 97

Tabela 48: Cenário 10 (A5000) 97

Tabela 49: Cenário 10 (10000) 97

Tabela 50: Conclusões das amostras $\quad 98$

Tabela 51: Probabilidade no Cenário 1

Tabela 52: Probabilidade no Cenário $2 \quad 99$

Tabela 53: Probabilidade no Cenário $3 \quad 99$

Tabela 54: Probabilidade no Cenário $4 \quad 100$

Tabela 55: Probabilidade no Cenário 5

Tabela 56: Probabilidade no Cenário $6 \quad 100$

$\begin{array}{ll}\text { Tabela 57: Probabilidade no Cenário } 7 & 101\end{array}$

Tabela 58: Probabilidade no Cenário $8 \quad 101$

Tabela 59: Probabilidade no Cenário $9 \quad 101$

Tabela 60: Probabilidade no Cenário $10 \quad 102$ 


\section{Lista de Siglas}

\section{Símbolo Descrição}

h Comprimento dos intervalos

$f(x) \quad$ Função da densidade

$\pi(\mathrm{x}) \quad$ Distribuição estacionaria

$\sqrt{n} \quad$ Erro absoluto de estimação

r $\quad$ Espaços de dimensão

$\hat{f}_{h}(x) \quad$ Estimativa para $f$

K Função Kernel

MWh Megawatt-hora

$k \quad$ Número de intervalos

n Número de observações

$p(x) \quad$ Polinômio de aproximação

$\mathrm{P}(\mathrm{x}) \quad$ Probabilidade de uma observação cair no intervalo

x Variável aleatória

$\mathrm{C}_{\mathrm{j}} \quad$ Variável que permite construir os intervalos

\section{Unidade}

Adimensional

Adimensional

Adimensional

Adimensional

Adimensional

Adimensional

Adimensional

$\mathrm{J}(1 \mathrm{MWh}=3,6 \mathrm{GJ})$

Adimensional

Adimensional

Adimensional

Adimensional

Adimensional

Adimensional 


\section{Lista de Abreviações}

ABESCO - Associação Brasileira das Empresas de Serviços de Conservação de Energia

ACEEE - American Council for an energy-efficient economics

$\mathrm{ACL}$ - Ambiente de Contratação Livre

ACR - Ambiente de Contratação Regulada

ADENE - Agência para Energia em Portugal

AEE - Ações de Eficiência Energética

ANEEL - Agência Nacional de Energia Elétrica

BNDES - Banco Nacional de Desenvolvimento Econômico e Social

CCEE - Câmara de Comercialização de Energia Elétrica

CMVP - Certified Measurement and Verification Professionals

CUSD - Contrato de Uso da Rede de Distribuição

CUST - Contrato de Uso da Rede de Transmissão

DSB - Demand Side Bidding

EE - Eficiência Energética

EPE - Empresa de Pesquisa Energética

ESCOs - Energy Service Companies

EUA - Estados Unidos de América

EVO - Efficiency Valuation Organization

FEMP - Federal Energy Management Program

INEE - Instituto Nacional de Eficiência Energética

INMETRO - Instituto Nacional de Metrologia

LEE - Leilão de Eficiência Energética

LEED - Leadership in Energy and Environmental Design

$\mathrm{M} \& \mathrm{~V}$ - Medição e Verificação

MME - Ministério de Minas e Energia

ONS - Operador Nacional do Sistema Elétrico

ORT - Organizações Regionais de Transmissão

OSI - Operador do Sistema Independente

OST - Operador do Sistema de Transmissão

PEE - Programa de Eficiência Energética

PIB - Produto Interno Bruto

PIMVP - Protocolo Internacional de Medição e Verificação de Performance

PNE - Plano Nacional de Energia 
PNEf - Plano Nacional de Eficiência Energética

PROESCO - Programa de Apoio a Projetos de Eficiência Energética

PROPEE - Procedimentos do Programa de Eficiência Energética

TUSD - Tarifas para o Uso do Sistema de Distribuição

TUST - Tarifas para o Uso do Sistema de Transmissão 


\section{Introdução}

A eficiência energética (EE) é sinônimo de preservação ambiental, pois a energia economizada evita a construção de novas plantas de geração e linhas de transmissão. Recentemente, os Procedimentos do Programa de Eficiência Energética (PROPEE) foram reformulados. Entre as reformulações destaca-se a inserção de fontes incentivadas de energia, sendo de considerável apoio os projetos realizados em conjunto como Ações de Eficiência Energética (AEE) no uso final.

Segundo o Operador Nacional do Sistema Elétrico (ONS), em abril de 2014, a estimativa de estoque dos reservatórios das usinas deste subsistema caiu de $40,6 \%$ para $36,6 \%$, e a queda foi motivada principalmente pela redução da expectativa de chuvas para esse mês.

Neste contexto, estabelecer leilões de eficiência energética (energia virtual $^{1}$ ), a um custo menor que a energia real, além da vantagem econômica e do benefício ambiental, podem-se obter ganhos na esfera social uma vez que a indústria de EE gera empregos e serviços. A usina virtual é aquela que deveria ser construída para fornecer a mesma quantidade de energia economizada, e que, devido a esta redução, pode ser adiada, reduzindo os custos e os impactos ambientais. Ademais, poder-se-ia obter retirando energia do sistema, em forma de "pacotes" de energia conservada. Por exemplo, os fabricantes de equipamentos poderiam lançar no mercado produtos com tecnologia que incorporasse maior eficiência energética, cujo investimento necessário seria pago com a energia economizada vendida através do leilão (Garcia, 2009).

Os leilões podem ser utilizados como mecanismos eficazes para atender o progresso de EE. Os programas de EE, bem estruturados e com ganhos comprovados, seriam úteis no sentido de retardar a construção de novas usinas.

\footnotetext{
${ }^{1}$ A energia virtual é aquela energia reduzida com ações de eficiência energética. Ademais, esta energia poderia ser vendida no mercado de energia através de mecanismos de leilões.
} 
Haveria reduções de custos e ganhos ambientais com a utilização mais racional de recursos.

O Plano Nacional de Energia 2030 (PNE2030), incorporou a elaboração de um Plano Nacional de Eficiência Energética (PNEf), que considera que a eficiência energética pode ocorrer de duas formas: pelo progresso autônomo e também pelo progresso induzido.

$\mathrm{O}$ progresso autônomo esta sujeito às iniciativas de mercado sem interferência de políticas públicas, por meio de ações das empresas, entidades e famílias visando à redução dos custos e otimização dos recursos. No PNE2030, estima-se uma economia de 5\% em 2030 advindo em parte deste progresso, aquele que ocorrerá de qualquer maneira por causa de melhorias de equipamento.

Entretanto, o progresso induzido se apresenta através de estímulos por meio de políticas públicas visando atender questões econômicas e sociais por meio de EE, tendo como meta outros 5\% segundo o PNE2030, já que para 2030 se espera chegar aos $10 \%$ de ganhos em EE. O progresso induzido não ocorreria sem a ação do governo.

De acordo com Schaeffer (2004), são consideráveis os benefícios resultantes para o sistema elétrico brasileiro no caso de uma aposta dedicada de redução do consumo de energia através de políticas de eficiência energética.

A melhoria dos níveis de eficiência energética no sistema energético brasileiro teria também um forte impacto junto aos consumidores e empresas, que perceberiam uma redução considerável.

Esta redução resultaria não só das medidas de diminuição do consumo pelos consumidores através da substituição de lâmpadas ou de motores por outros mais eficientes, mais também, da própria redução das tarifas cobradas pelas concessionárias.

Para a indústria brasileira, a promoção da eficiência energética apresenta-se como uma grande oportunidade. O impacto do elevado custo de energia ao nível da competitividade da indústria é enorme. Assim, torna-se crucial aproveitar a oportunidade que um plano dedicado de eficiência energética pode proporcionar para tornar a economia brasileira mais competitiva.

Ao longo dos últimos dez anos, vários programas e ações foram sendo criados de modo a incentivar práticas de EE. Em particular, três programas se destacam: PROCEL, PROESCO, e PEE (Ministério de Minas e Energia, 2014). 
Neste contexto, e como parte do mercado de EE, o Leilão de Eficiência Energética (LEE) poderia representar uma alternativa muito interessante para a dinamização e promoção de práticas de EE no Brasil. Porém, é importante mencionar que isso pressupõe uma confiança na quantidade de energia reduzida, o que só pode se tornar realidade com a implantação e desenvolvimento de um sistema robusto e confiável de Medição e Verificação $(\mathrm{M} \& \mathrm{~V})$ dos consumos de energia.

Deste modo, a definição do LEE pressupõe que a entidade, ao investir em medidas de eficiência energética, tenha a possibilidade de vender a energia que passou a economizar. Assim, pode-se também considerar que, a aplicação de certa medida de eficiência energética, corresponde à criação de uma usina virtual de capacidade igual à energia que se conseguiu economizar.

\section{1.}

\section{Experiências de eficiência energética em outros Países}

Segundo a American Council for an energy-efficient economics (ACEEE) Conselho para uma economia eficiente em termos energéticos - são 16 os países que lideram o ranking mundial sobre eficiência energética, entre eles o Brasil. A ACEEE classifica os países com as maiores economias do mundo, em suas políticas e programas de eficiência energética. Os países que compõem esta lista são: Austrália, Brasil, Canadá, China, França, Alemanha, Índia, Itália, Japão, México, Rússia, Coreia do Sul, Espanha, Reino Unido, Estados Unidos e a União Europeia. São 31 indicadores de eficiência energética que a ACEEE considera para a avaliação dos diferentes países que incluem em suas políticas de governo, diversos mecanismos de eficiência energética. Entretanto, os indicadores podem ser classificados em quatro categorias diferentes, entre elas destacam-se: construções, indústria, transporte e esforço nacional, que mede indicadores gerais e transversais do uso da energia a nível nacional. 


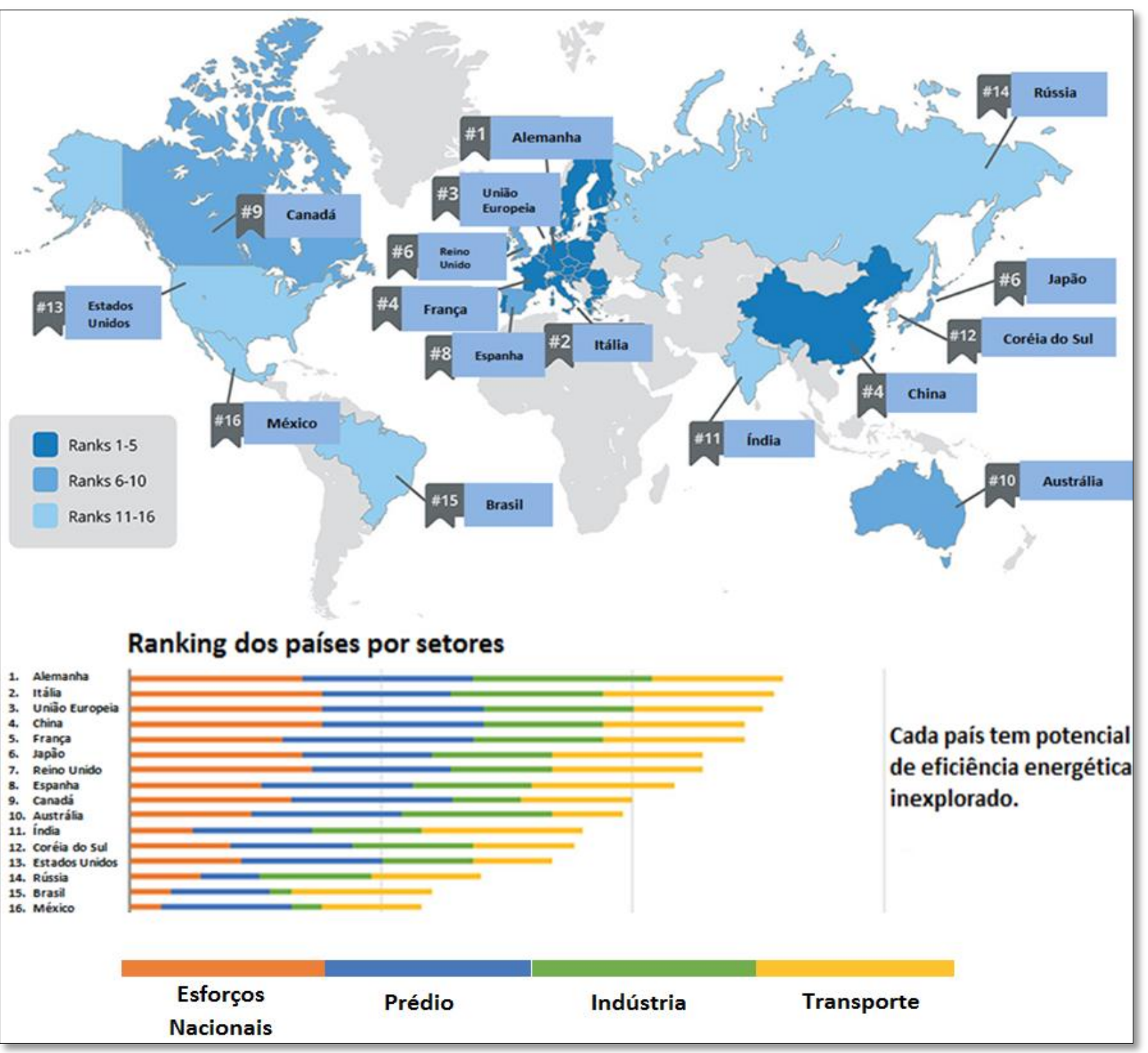

Figura 1: Ranking internacional de eficiência energética - 2014

Fonte: ACEEE (2014)

$\mathrm{Na}$ figura 1, pode-se observar que o país que lidera este ranking internacional é Alemanha, seguida da Itália, União Europeia, China, França, Japão e Reino Unido. Analisando esta realidade, observa-se que Brasil situa-se num nível muito baixo em relação aos países líderes. Não por ter uma economia ruim, senão, por ausência de mecanismos ativos de eficiência energética estimulados pelo governo. Desta forma, com apoio de organismos e instituições que tentam promover e implementar o LEE, o governo precisa rever essa situação e melhorar nos próximos anos utilizando os diversos mecanismos e políticas que permitirão situar o Brasil entre os primeiros lugares desse ranking mundial. 


\section{2. \\ Definição do problema de pesquisa}

Os leilões de energia são processos licitatórios realizados com o objetivo de contratar a energia elétrica necessária para assegurar o pleno atendimento da demanda futura no ambiente de contratação regulado (ACR).

Calili (2013) afirma que a energia elétrica é um insumo essencial na grande maioria das indústrias e que sem este insumo, nenhum país consegue se desenvolver a níveis aceitáveis. Este autor acrescenta que, quando se analisa o crescimento do Produto Interno Bruto (PIB) de um país, se verifica que este é totalmente correlacionado ao crescimento do consumo da energia.

Investir cada vez mais em fontes de energia renovável e utilizar este insumo de forma racional e eficiente é vital para o crescimento sustentável do mundo. Assim, a EE toma cada vez mais um papel fundamental para que as gerações futuras tenham garantida sua existência. Uma vez que reduz o consumo de energia, também diminui as emissões de gases de efeito estufa na atmosfera.

Neste contexto é importante dizer que com o crescimento do consumo de energia, cada vez mais fontes de geração térmicas são exigidas nos sistemas. No entanto, estas fontes são altamente poluidoras e emitem uma grande quantidade de Dióxido de Carbono $\left(\mathrm{CO}_{2}\right)$ na atmosfera.

Aumentar a eficiência no uso da eletricidade tem sido reconhecido em todo o mundo como o "recurso elétrico" mais economicamente atrativo. Economizar energia através do uso de lâmpadas, eletrodomésticos e sistemas motrizes mais eficientes é menos custoso do que investir em novos recursos de geração, independente do recurso energético utilizado (Garcia, 2009).

Assim, o caminho da EE, que pode ser fomentado pelo LEE se torna importante, pois pode reduzir o consumo previsto de energia no país (consumo base) e a emissão de $\mathrm{CO}_{2}$ na atmosfera. Também não há emissões de poluentes associadas com a economia de eletricidade obtida através de maior eficiência; isto é, maior eficiência energética reduz também os danos ambientais, ademais, pode ser considerada a "energia" mais limpa e barata.

O desafio é maximizar a adoção de medidas de eficiência viáveis economicamente, através de aparelhos domésticos, como também por mecanismos de mercado, para se atingir os benefícios econômicos desejados. As 
medidas de eficiência energética têm como foco principal diminuir o consumo total de energia a médio e longo prazo.

O conceito do LEE serve para aumentar e promover a eficiência do setor nacional. Dada a ênfase atual nos leilões de oferta no setor elétrico, os leilões de eficiência são uma estratégia de complemento que merece ser considerada minuciosamente, e vendo-se como a mesma, pode ser levada à prática considerando a estrutura legal e as instituições existentes no país. Um ponto importante do LEE é pensar em como vender a energia economizada, e como regulamentar isso. Atualmente, o país consegue conservar aproximadamente 1\% de toda energia consumida, e os $10 \%$ de conservação seria um percentual que o governo brasileiro teria como meta (Ministério de Minas e Energia, 2014).

A pesquisa realizada por Calili (2013) esboça o modelo de venda da sobra de energia proveniente de programas de eficiência. Pode-se ofertar a energia, neste caso, retirada com preço-teto definido e abaixo do custo marginal de expansão. Desta forma promove-se o leilão, e um organismo independente determinado pelo governo verificaria a sua performance.

Além disso, a viabilidade do LEE no Brasil é outro ponto importante a considerar. Nesse sentido a questão dos preços vai definir e permitir que se conheça o panorama em diferentes cenários. Utilizando os dados que correspondem aos preços de venda nos diferentes leilões nesses últimos anos, se tentará estimar o preço que a energia virtual poderia ser vendida no LEE.

\section{3.}

\section{Objetivos: geral e específicos}

Os objetivos da pesquisa científica representam, além das intenções propostas, possibilidades de obtenção de resultado. Neste sentido, a pesquisa apresentará tanto objetivo geral quanto objetivos específicos.

O objetivo geral deste trabalho é simular os preços de energia no leilão de eficiência energética.

Os objetivos específicos apresentam, de forma detalhada, as ações que se pretende alcançar e estabelecem estreita relação com as particularidades relativas à pesquisa. Dessa maneira, se considerará alguns, tendo como base o objetivo geral: 
- Simular através de ferramentas computacionais e modelos estatísticos o leilão de eficiência energética no Brasil, com vistas a obter o preço da energia neste mecanismo e verificar sua viabilidade;

- Estabelecer a partir das propostas de leilões de eficiência energética, as melhores características de um leilão de eficiência energética;

- Estudar a pertinência da medição e verificação (M\&V) no leilão de eficiência energética.

\section{4 . \\ Motivação}

São inúmeras as motivações para que um leilão de EE seja estabelecido no Brasil. Dentre eles, pode-se destacar:

- Postergação de investimento em novas usinas.

- Postergação de investimentos em linhas de transmissão.

- Viabilização de projetos de eficiência energética.

- Aumento da confiabilidade do sistema elétrico brasileiro.

- Redução da emissão de $\mathrm{CO}_{2}$ na atmosfera.

A situação energética atual do país preocupa por conta dos seus reservatórios esvaziados e das usinas que não foram planejadas, mas que ainda não foram construídas. As discussões, no entanto, têm adotado mais um viés político do que, de fato, um compromisso ou preocupação com diagnósticos e soluções para estabilizar a oferta de energia no país. Entretanto, a construção ou investimento em uma nova usina sai muito mais caro que pensar em políticas de eficiência energética, as quais contribuiriam substancialmente para o país (Calili, 2013).

O tema de eficiência energética tem tido um papel central na agenda política dos países desenvolvidos, principalmente depois do protocolo de Quioto em 1997. Como este protocolo tem por objetivo reduzir as emissões de gases de efeito estufa na atmosfera (GEE). Nesse contexto, a eficiência energética surge como uma alternativa para que os países desenvolvidos signatários atinjam as metas estabelecidas respeito aos gases. 


\section{5 .}

\section{Organização do trabalho}

O presente trabalho divide-se em sete capítulos. No capítulo 2 procede-se à revisão da literatura concernente a EE, servindo de base teórica geral para fazer a proposta do Leilão de Eficiência Energética no Brasil. Por sua vez, o capítulo 3 aborda especificamente a temática da Medição e Verificação (M\&V) que permite definir a relação entre $\mathrm{M} \& \mathrm{~V}$ e as ESCOs, como também a validação e as considerações concernentes a $\mathrm{M} \& \mathrm{~V}$.

No capítulo 4, aborda-se a parte da simulação dos preços de energia no mercado regulado utilizando o método de Kernel, assim como aproximação por polinômios que permite adequar o comportamento dos preços. Neste contexto, o método de Monte Carlo via cadeias de Markov (MCMC) permitirá gerar amostras em diferentes cenários para analisar detalhadamente o comportamento dos preços.

No capítulo 5, na parte metodológica, são examinados os passos que a pesquisa contém para desenvolver de maneira ordenada a temática abordada. Entre eles, destacam-se as considerações iniciais, aproximação dos dados com Kernel, o uso do MCMC e a geração de amostras com o algoritmo MetropolisHastings.

A linha de investigação culmina, no capítulo 6, apresentando o funcionamento do Leilão de Eficiência Energética, assim como os resultados obtidos depois de ter feito as simulações para o ambiente regulado, sendo este analisado, com rodadas para cada cenário. E, por fim, no capítulo 7, apresenta-se a conclusão do trabalho. 


\section{2 \\ Proposta do leilão de eficiência energética}

Neste capítulo será apresentada a proposta do Leilão de Eficiência Energética (LEE) a ser criado no Brasil. Este capítulo está dividido em três partes. $\mathrm{Na}$ primeira parte são apresentadas as experiências internacionais sobre o tema. $\mathrm{Na}$ segunda, é feito um resumo da proposta realizada pelos principais autores brasileiros em possível LEE no Brasil. Finalmente, são tiradas algumas conclusões e é feita uma proposta de modelo de Leilão para o Brasil, levando em consideração as especificidades do mercado de energia brasileiro.

\section{1. \\ Experiências internacionais}

Neste item serão apresentadas as experiências relacionadas ao LEE em diversos países, entre eles, Estados Unidos, África do Sul e Noruega.

\subsection{1. \\ Estados unidos}

Neste item é apresentada uma visão geral da existência do gerenciamento pelo lado da demanda (GLD) e a resposta à demanda nos mercados mais representativos dos Estados Unidos. Este mercado está centrado nas organizações regionais de transmissão (ORT), tais como: PJM (Pensilvânia, Nova Jersey e Maryland), OSI-NI (OSI-Nova Iorque), OSI-NING (ORT da Nova Inglaterra), CCET (Conselho de Confiabilidade Elétrica do Texas), OSI-CO (Operador do Sistema Independente Centro-Oeste.), e OSI-CA (OSI da Califórnia), seus programas de resposta à demanda, e seu impacto na carga máxima. A figura 2 mostra um mapa das ORTs nos Estados Unidos. 


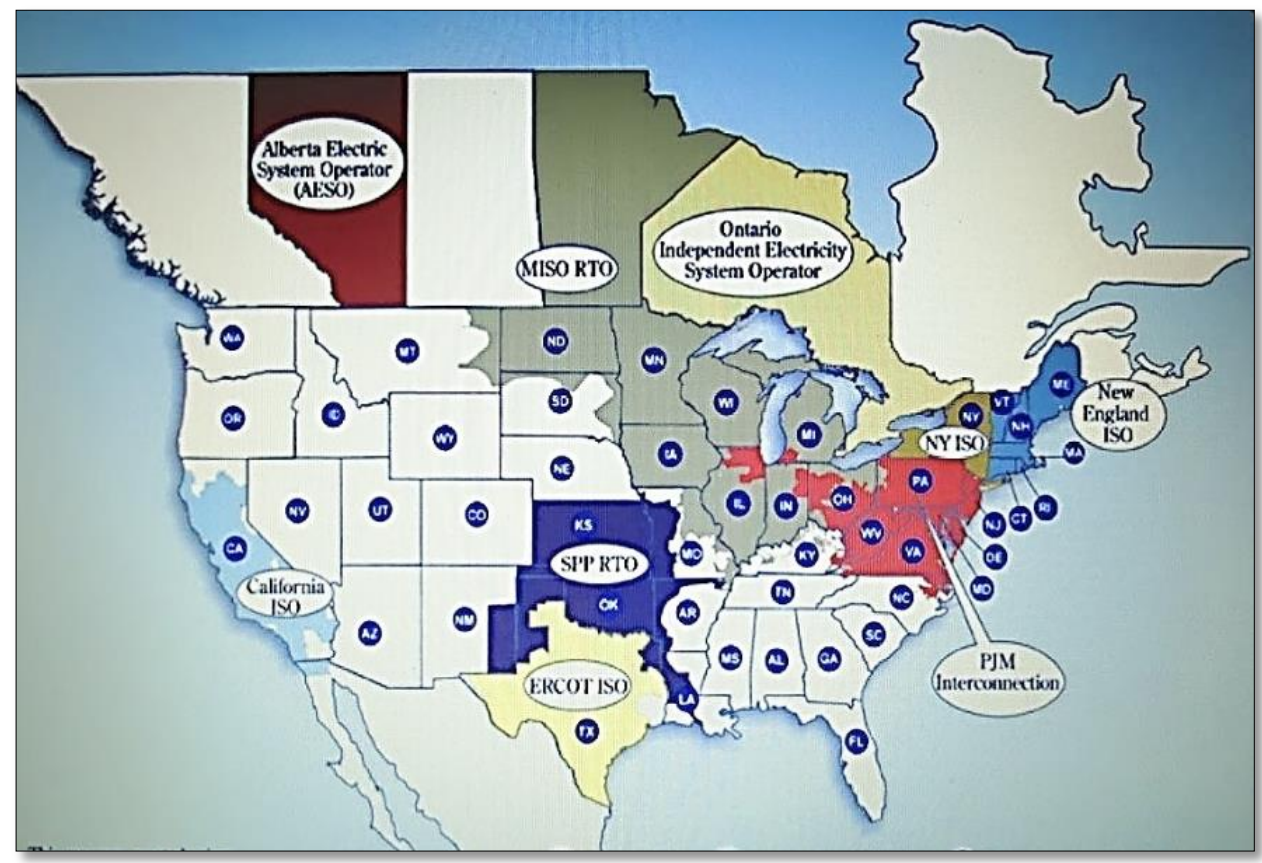

Figura 2: Organizações Regionais de Transmissão nos Estados Unidos

Fonte: (Comissão Federal Regulatória de Energia, 2007)

A figura 3 resume a administração que a ORT tem dos programas de resposta à demanda e a participação nos mercados representativos, tendo seis ORTs com presença significativa de resposta à demanda. Estes programas abordam a participação nos mercados de energia (tanto para o dia seguinte quanto para tempo real), partes dos mercados de serviços auxiliares, como também os programas de resposta à demanda especializada centrados em torno da reação às emergências do sistema. 


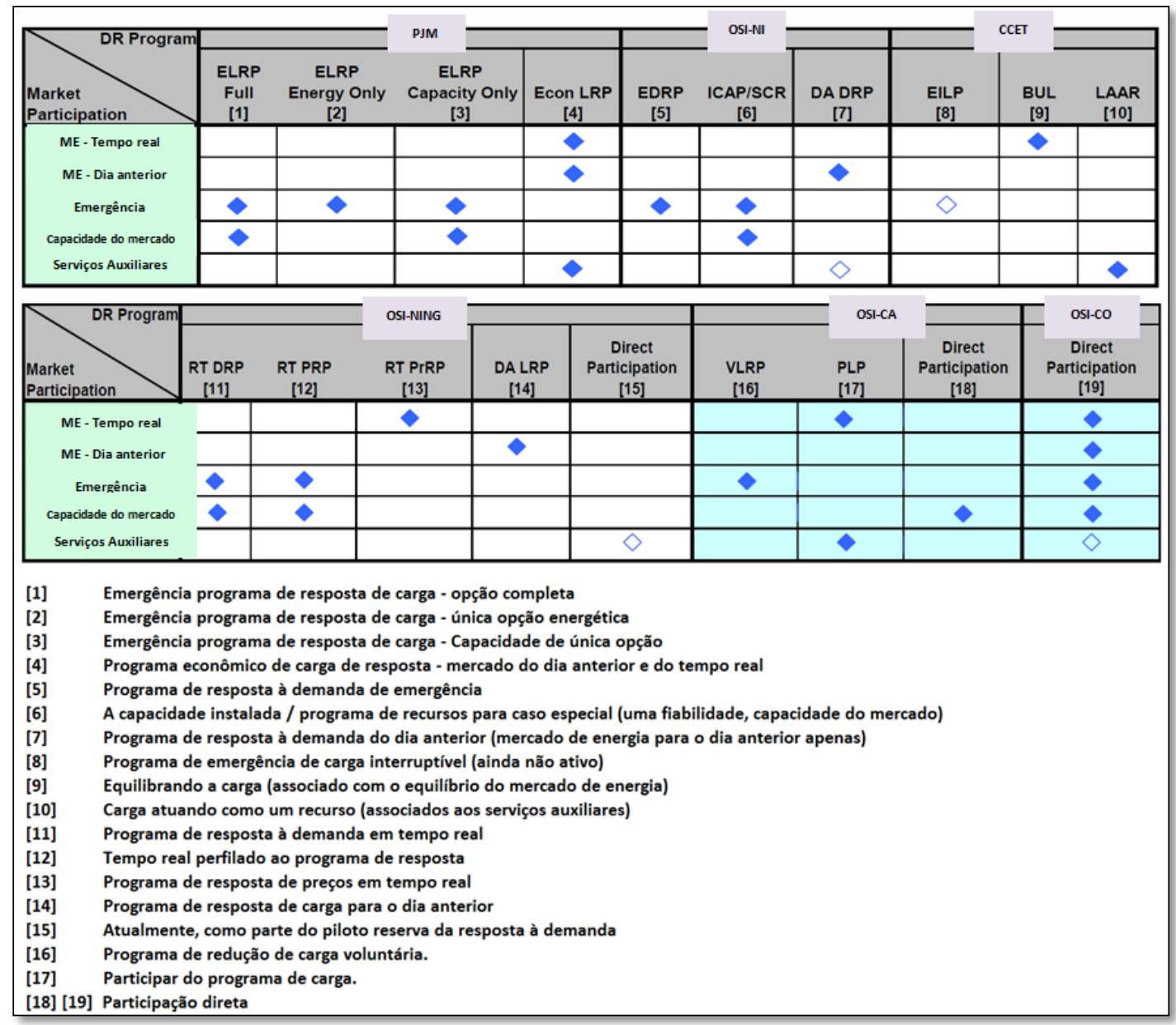

Figura 3: Administração das ORTs

Fonte: Adaptado de Earle e Faruqui (2008)

Observa-se que em quase todas as ORTs o mercado de energia em tempo real vem sendo executado (exceto em OSI-NI). Por outro lado, o mercado de energia do dia anterior também tem grande demanda (exceto em a CCET e OSICA), nesse sentido, os dois mercados são os mais importantes nos Estados Unidos. Ademais, existem outros mecanismos que garantem a resposta à demanda (emergência, capacidade do mercado, serviços auxiliares), dos quais, alguns já foram implementados e outros ainda continuam como proposta (OSI-NI, CCET, OSI-NING, OSI-CO).

\subsubsection{1. \\ Descrição da demanda dos mercados de resposta mecânica}

Uma característica dos mercados nos Estados Unidos é que funcionam com dois tipos de mecanismos: do dia anterior e o mercado em tempo real. Como 
norma geral, uma oferta pelo lado da demanda nos mercados energéticos no dia anterior consiste na capacidade de apresentar uma proposta de inclinação descendente da demanda.

Desta forma, enquanto haja aumento de preços, menor quantidade de energia será comprada do dia anterior. Um esquema típico para a licitação da demanda em um mercado de energia do dia anterior seria para os compradores (demanda) apresentarem as curvas de demanda para o meio dia, do dia anterior ao dia de funcionamento. Por cada hora operando, uma curva de demanda diferente poderia ser apresentada. Os vendedores também teriam que apresentar suas curvas de oferta nesse momento. A curva de oferta apresentada pelos compradores, tipicamente, consiste em uma sequência de pares de preço-quantidade que representariam o desejo dos compradores pagarem uma dada quantidade de energia. Por exemplo, se um comprador estava disposto a pagar US\$ 100/MWh por $1.000 \mathrm{MW}$, agora estaria disposto a pagar somente por $800 \mathrm{MW}$ já que o preço subiu a US\$ 120/MWh; o comprador apresentará os pares preço quantidade: (US\$ 120/MWh, 800 MWh) e (US\$ 100/MWh, 1.000 MW) (Earle e Faruqui, 2008).

As curvas de oferta apresentadas à ORT passariam então a ser conferidas com a curva de oferta inicial. Isso daria ao comprador uma posição que seria entregue no dia seguinte. Em tempo real, um comprador poderia fazer uma oferta para mudar a sua posição a partir da posição do dia anterior, fazendo uma nova curva de demanda. A diferença em tempo real é que o comprador tem que ser capaz de reagir em tempo real aos sinais da ORT. Todavia, para a licitação do dia anterior, a posição do comprador está fixada a um dia de antecedência e assim teria muito mais tempo para tomar em conta as medidas que são necessárias com a finalidade de aumentar ou diminuir sua carga. Os desvios no consumo da programação do dia seguinte para um comprador são normalmente resolvidos com o preço em tempo real (Earle e Faruqui, 2008).

Em contraste com o programa de energia em tempo real e do dia anterior, os programas de emergência são os utilizados pelas ORTs somente no caso de um evento predefinido de ativação que se considera ser uma emergência. Estes programas em alguns aspectos são muito similares aos programas de controle de carga tradicionais. Em troca, os participantes geralmente recebem um pagamento fixo se são chamados ou não, às vezes recebem um pagamento variável se forem 
solicitados a reduzirem o consumo. Embora os programas de resposta à demanda de emergência não sejam realmente parte da licitação pelo lado da demanda, se incluem aqui porque o seu tamanho reflete o potencial de fazer uma oferta à demanda.

Finalmente, alguns mercados nos Estados Unidos da América (EUA) têm os requisitos de capacidade que são formalizados através de um mercado centralizado para capacidade na ORT.

\subsubsection{2.}

\section{Diferentes abordagens para alcançar a resposta da demanda}

Segundo Earle e Faruqui (2008), nos Estados Unidos, a política regulatória do Estado e a política da ORT podem trabalhar juntas em três abordagens distintas para a resposta à demanda: precificação dinâmica ao nível do usuário final, entidade encarregada da carga (EEC), baseado no programa de redução de carga e o provedor de serviços de reduções (PSR), encarregada das prestações de reduções de carga.

A precificação dinâmica ao nível do usuário final obrigaria os clientes a pagarem mais pela energia que consomem quando os preços à vista são mais elevados, isto é, por meio de precificação em tempo real ou programas críticos de fixação de preços máximos. Esta é a abordagem econômica clássica que tem sido a motivação da reestruturação de energia elétrica nos Estados Unidos.

Já a entidade encarregada da carga (EEC) envolveria principalmente as taxas de varejo interruptiva e/ou controle direto de cargas de alguns clientes pela EEC (e, possivelmente, alguns preços dinâmicos). As EECs conseguem crédito para as reduções de carga, é dizer, elas simplesmente reduzem a quantidade líquida de energia e/ou capacidade de compra. A vantagem deste modelo é que ele impede que a ORT tenha que se acomodar aos PSRs, apesar das dificuldades semelhantes em medir e compensar seus clientes, as reduções de carga ainda podem ser tratadas em nível EECs.

No caso dos provedores de serviços de reduções (PSR) trabalhariam diretamente com os usuários finais para reduzir os picos de carga através de uma combinação de controle da carga direta e protocolos de comunicação. Eles recebem uma remuneração do OSI, que compartilham com seus clientes, tomando 
uma parte de valor da capacidade, assim como também dá ao cliente a maior parte do valor da energia. A vantagem do PSR é que oferecem a experiência técnica e de marketing inovador para estimular a resposta à demanda.

\subsection{2.}

\section{África do Sul}

Os mecanismos de LEE e gerenciamento pelo lado da demanda, também tem participação ativa na África do Sul, com diferentes panoramas, mas sempre em busca do mesmo objetivo, a redução no consumo da energia.

A tecnologia usada na África do Sul para analisar este sistema é o Balance sheet, a qual vem a ser uma representação gráfica das inter-relações, interdependência e confiança entre a tecnologia, os processos, os produtos e o mercado. O balanço completo de tecnologia pode ser agrupado em três matrizes distintas; a matriz de produtos-mercados; a matriz de produtos-processos e a matriz de tecnologias-processos (Grover e Pretorius, 2007).

Na figura 4 é mostrado como o gerenciamento pelo lado da demanda é representado segundo a tecnologia usada, o Balance sheet.

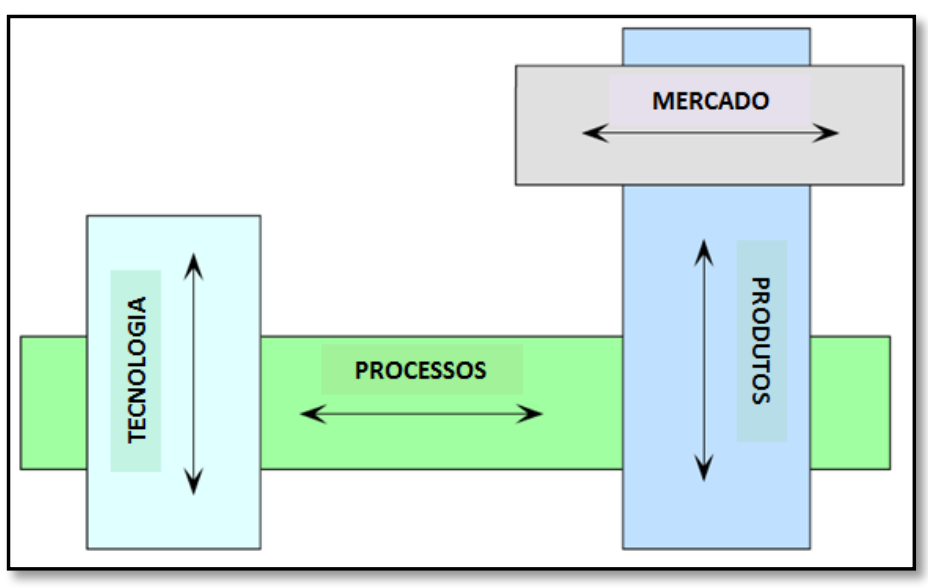

Figura 4: Matriz do Balance sheet

Fonte: Adaptado de (Grover e Pretorius, 2007)

A definição do mercado tem a ver com: o mercado de energia, o mercado de reservas, o mercado de reserva de dez minutos e o mercado de reserva suplementar. Já a definição do produto tem a ver com: a redução do pico de 
demanda, o deslocamento da carga, a confiabilidade flexível e a conservação estratégica.

Por outro lado, a definição dos processos e tecnologias tem a ver com: o agendamento de carga, o armazenamento de carga térmica, a gestão da carga, a gestão de energia e o monitoramento da carga em tempo real, em relação aos processos. E em relação às tecnologias tem-se: as tecnologias de comunicação (com fio e sem fio - wireless), as tecnologias de eficiência energética (iluminação), e tecnologias de hardware e software.

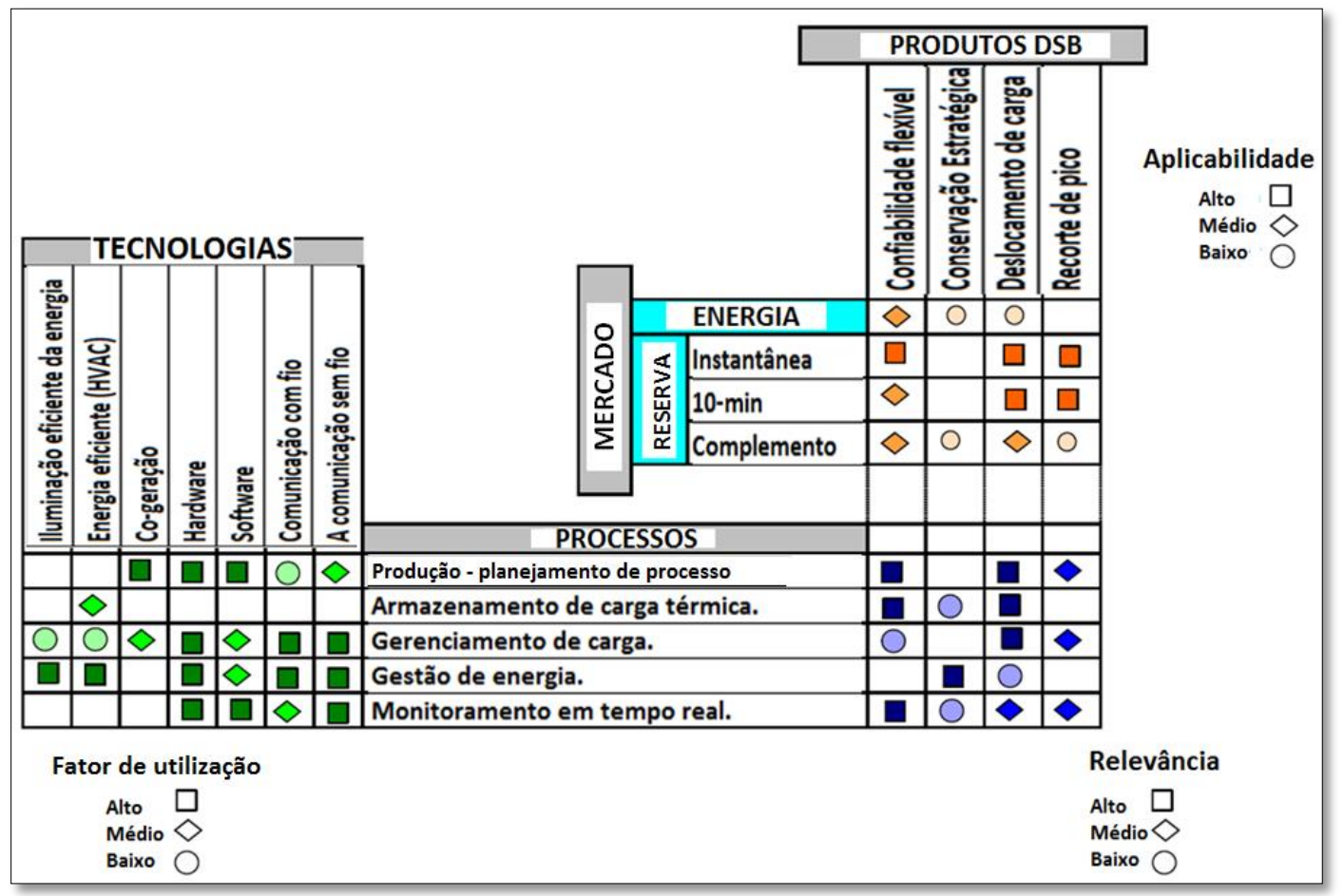

Figura 5: Tecnologia completa do Balance sheet

Fonte: Adaptado de (Grover e Pretorius, 2007)

O balance sheet mostra as inter-relações específicas entre as tecnologias, produtos, processos e mercados em um momento específico no tempo.

Note-se que na figura 5 acima, tanto o mercado Instantâneo quanto dos 10 minutos em Reserva têm a maior participação de todos os produtos de Demand Side Bidding (DSB), ademais, este é um cenário que exige atividades de carga máxima (instantâneo) de redução. Além disso, percebe-se que a aplicabilidade entre estas duas matrizes com relação ao mercado de reserva é relativamente alta. 
Já, o monitoramento em tempo real, a gestão de energia, o gerenciamento da carga e o planejamento de processos/produção se vinculam com a utilização das tecnologias em um nível alto do fator de utilização.

As tecnologias de cogeração também estão vinculadas com os processos de gerenciamento da carga e com o planejamento de processos-produção. Aqui a cogeração se considera como uma tecnologia, mas, se poderia argumentar que cogeração não é uma tecnologia, senão um incentivo; o uso de tecnologias de geração cumpre com o objetivo de "segurar" os custos da eletricidade.

Entretanto, a relação entre as matrizes de processos e produtos DSB, considera que todos os processos usam pelo menos um produto DSB com uma alta relevância. Demonstrando-se que a relação existente entre tecnologia, processos, mercado e produtos DSB é forte.

\subsection{3.}

\section{Noruega}

A Noruega utiliza dois mecanismos pelo lado da demanda, que também são utilizados nos EUA: o mercado do dia anterior e o mercado em tempo real.

\subsubsection{1. Mercado do dia anterior}

A participação no mercado do dia anterior é opcional. Tendo em conta todas as obrigações nos termos de contratos bilaterais físicos, os participantes do mercado de energia 'Elspot ${ }^{2}$ ', apresentam propostas de geração e lances de demanda na forma de uma curva de preços/volume para cada hora do dia seguinte. O Nord Pool define os preços de hora em hora na interseção das curvas de oferta e demanda agregada. As 13:30 horas no dia seguinte, Nord Pool informa que cada participante deem seus compromissos de geração ou de compra no mercado à vista, e permite aos participantes 30 minutos para verificar se a sua posição comercial líquida está de acordo com as suas propostas e ofertas. Uma vez confirmada, as quantidades de compra e venda aceitas se tornam contratos firmes de entrega física. Os participantes não têm oportunidade de rever suas propostas

\footnotetext{
${ }^{2}$ Elspot é o maior mercado do dia anterior do mundo pelo poder de negociação que tem, ademais, garante um ambiente altamente seguro e transparente na região nórdica e báltica.
} 
e/ou ofertas. Mais de $20 \%$ da demanda de Noruega se considera potencialmente preparada para satisfazer as necessidades do mercado. Entretanto, de acordo com o operador do sistema norueguês (Statnett), os incentivos econômicos para participar no dia seguinte são limitados. Por outro lado, dado que o mercado norueguês é dominado pela energia hidráulica, pode haver incentivos significativos nos anos em que há pouca precipitação. Os participantes têm a oportunidade de revisar suas ofertas. Dado que os participantes do mercado fornecem as curvas de demanda, bem como as curvas de oferta (Earle e Faruqui, 2008).

\subsubsection{2.}

\section{Mercado em tempo real}

Devido à disponibilidade de serviços de compensação de usinas hidrelétricas, as oportunidades de participação do lado da demanda nos mercados em tempo real são limitadas. Até hoje, apenas na prestação de reserva rápida e gerenciamento de restrições para o lado da demanda têm sido desenvolvidas.

Um mercado com opções reais de reserva independente existe na Noruega desde o inverno de 2000. Seu objetivo é assegurar um nível adequado de reservas que regulam a oferta durante os meses de inverno (Earle e Faruqui, 2008).

O mercado de opções de reserva provou ser popular com os consumidores, com até 1.200 MW de contratos assinados. A participação neste mercado tem sido principalmente de grandes instalações industriais (metais e produção de papel).

Estudos também têm sido realizados para explorar a participação neste mercado de cargas menores, incluindo os clientes residenciais. Estes envolvem a introdução de medidores inteligentes para permitir que os consumidores respondam aos sinais de preços e controles de redução de carga automática. Enquanto estes mecanismos apresentam a possibilidade de envolvimento do maior número de consumidores, maiores desafios tecnológicos e relacionados com os custos precisarão ser superados para incentivar a participação do maior número de consumidores (Earle e Faruqui, 2008). 


\section{2.}

\section{Proposta inicial no Brasil}

Apesar de o governo propor estudos de um mecanismo de LEE, ainda não está muito claro que este leilão deva existir. O governo tem interesse em estimular todas as propostas que possam usar de maneira mais eficiente a energia elétrica, assim, várias políticas de redução de energia pelo lado da demanda estão sendo estudadas pelo governo e, entre essas, se enquadra o LEE (Ministério de Minas e Energia, 2014).

Neste contexto existem muitos riscos inerentes à implementação de mecanismos pelo lado da demanda. Alguns destes riscos estão intrinsecamente ligados às medidas de Medição e Verificação (M\&V) adotadas. Desta forma, a construção de uma linha base bem feita é fundamental para o sucesso deste tipo de empreendimento. É muito importante que no LEE, assim como em qualquer leilão, seja encorajado o maior número de licitantes possíveis, para evitar a colusão (Calili, 2013).

Segundo Garcia (2009), em um workshop realizado pela EPE em 2006 foram sugeridos três mecanismos de Leilão de Eficiência Energética:

- O volume de projetos de Eficiência Energética (EE) seria baixo e todos aqueles qualificados e abaixo de um preço-teto (abaixo do custo marginal de expansão) poderiam ser implantados. Neste caso, não seria necessário um leilão de eficiência energética. Após a consolidação de energia reduzida com este mecanismo, o cálculo do acréscimo de mercado seria refeito e os leilões da expansão dar-seiam como antes (A-3, A-5, etc.).

- Haveria um conjunto numeroso de projetos de EE, superando o que a sociedade admitiria como risco. Após a avaliação preliminar dos projetos, se faria um leilão de eficiência energética dos projetos habilitados. Este leilão seria feito previamente ao leilão de energia nova, abatendo-se uma parcela de energia a ser contratada neste leilão.

- Todos os projetos de EE concorreriam no mesmo leilão com as demais usinas. Este seria procedimento mais simples, porém haveria produtos com características bem distintas (lado da oferta e lado da demanda).

Ademais, alguns pontos devem ser levados em conta na hora de pensar na implementação de um mecanismo de Leilão de Eficiência Energética, entre eles se destacam: 
- Muitos empreendedores estariam dispostos a utilizar diversas medidas de eficiência energética, sabendo que o LEE traria beneficio e redução do consumo de energia.

- Sabendo que o Brasil é um dos países que conta com os leilões mais sofisticados, conforme o Banco mundial e a pesquisa realizada por Maurer T. A. e Barroso (2011), a experiência pode ser usada na implementação de um mecanismo de Leilão de Eficiência Energética, através da venda de energia como usina virtual.

- Uma das maiores barreiras para a venda da eficiência energética é a comprovação da energia real conservada. Neste contexto, as medidas de $\mathrm{M} \& \mathrm{~V}$ adotadas de forma correta e transparente, lograrão que o mercado da EE se desenvolva.

Conforme Garcia (2009), a implantação do LEE poder-se-ia levar a cabo no Brasil desenvolvendo-se alguns pontos que facilitariam que a proposta se torne uma realidade, tais pontos são: oportunidade do leilão, recursos a utilizar, regionalização, operacionalização, arranjo institucional.

Cada um desses pontos será analisado no decorrer deste item. Além disso, as propostas tentam focar um dos objetivos do PNE 2030, que é o uso de mecanismos de EE para reduzir o consumo de energia.

Para a implementação do LEE se devem fazer estudos e análises que garantam a solidez deste mecanismo. Temas como a expansão do mercado elétrico no Brasil, poderiam ser uma garantia para que o leilão aconteça, já que o avanço neste mercado incorporará outras fontes de energia, além da hidrelétrica, que originarão ganhos importantes, como a redução no consumo de energia.

Outro tema de relevância é a questão ambiental, onde o PNE 2030 identifica o esgotamento do potencial hidrelétrico brasileiro. Em um sistema basicamente termelétrico como o Brasileiro, há um agravamento dos impactos ambientais causado pelos gases de efeito estufa gerados pelas termelétricas. Neste cenário os mecanismos de EE são os privilegiados para reduzir as emissões, e o leilão tem a oportunidade de intervir para interromper os impactos negativos causados pelas térmicas.

Além disso, a efetividade dos mecanismos e Ações de Eficiência Energética (AEE) converte-se num desafio que necessita ser atingido e solucionado. Neste contexto a $\mathrm{M} \& \mathrm{~V}$ tem um papel muito importante, já que implantando uma boa estrutura se poderá dar confiabilidade ao LEE. Porém, no Brasil a carência de boa avaliação é latente em programas relacionados à EE. Dessa forma, as avaliações 
de $\mathrm{M} \& \mathrm{~V}$ no momento de analisar o leilão, são fundamentais para garantir confiança neste mecanismo.

Garcia (2009) menciona que a proposta do LEE deve ser baseada em fases, já que permitiriam o funcionamento e a operacionalização por parte das concessionarias que seriam as principais responsáveis deste processo.

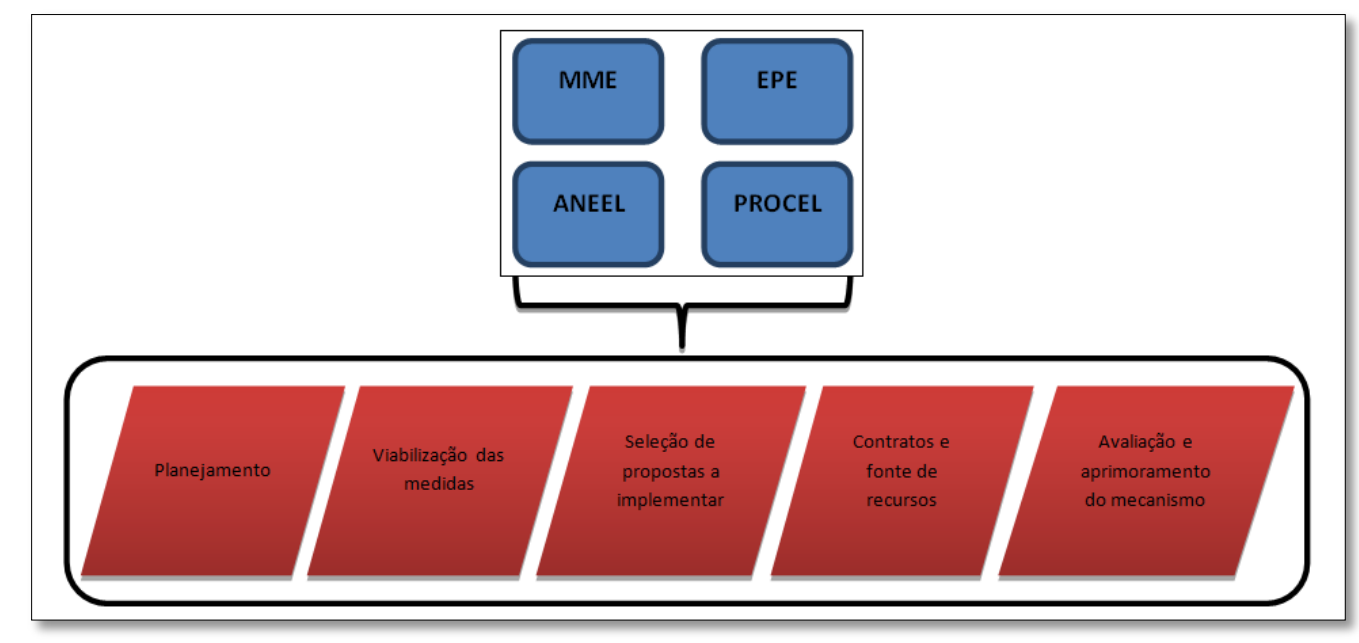

Figura 6: Possíveis Fases do LEE

Fonte: (Garcia, 2009)

Analisando a figura 6, pode-se dizer que para a implementação do LEE é necessária à relação dinâmica entre os participantes em relação às fases. Neste sentido, a inserção da EE no planejamento para conseguir a expansão do mercado de eletricidade vem sendo um objetivo principal do MME (Garcia, 2009).

Além disso, o Plano Nacional de Eficiência Energética (PNEf) considera que a EE deve ocorrer de duas formas. Primeiro, através do progresso autônomo e segundo, pelo progresso induzido. Uma visão clara do planejamento viria a partir do delineamento de três cenários que serão observados na figura abaixo e que possibilitam um melhor entendimento da inserção da EE. 


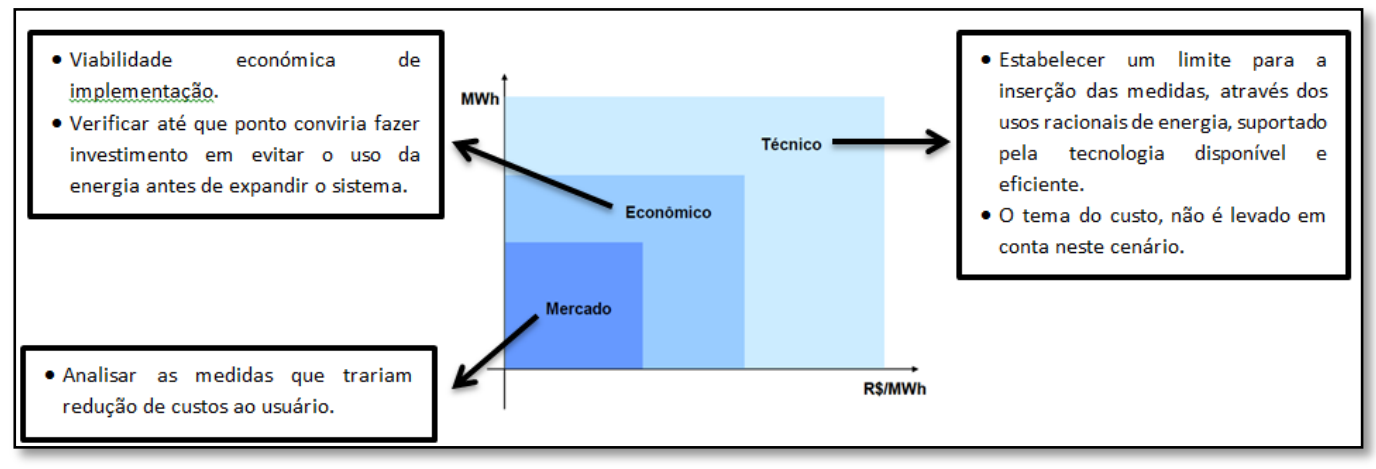

Figura 7: Cenários para a inserção do LEE

No momento da seleção das propostas, devem ser considerados alguns critérios que conduzirão ao bom desempenho e comportamento do leilão. Este aspecto é importante já que aborda os pontos que permitirão traçar a linha para fazer boas escolhas em relação às medidas de EE.

Garcia (2009) menciona detalhadamente as características que devem ser consideradas durante o processo de seleção.

- Confiabilidade: Qualidade e preço (com transparência) geram confiança.

- Colusão: Grande risco que deve ser superado. O mecanismo do leilão deve ser justo e uniforme para todas as ESCOs e participantes do leilão.

- Barreiras: A simplificação do processo e uma confiável M\&V permitirão que as barreiras desapareçam. E fará que a participação seja estimulada entre os diferentes participantes.

- Preço: A uniformidade e homogeneidade dos preços será chave.

- Diversidade: Uma divisão em blocos seria ótima, já que permitiria que diversas medidas de EE pudessem ter oportunidade no mercado.

A questão do contrato deve ser firmada entre a Câmara de Comercialização de Energia Elétrica (CCEE), ou outro órgão encarregado pela liquidação dos contratos do leilão, e os ofertantes, isso daria seriedade e transparência no momento de optar pelo uso da EE na expansão do mercado (Calili, 2013). Entretanto, como a proposta do leilão é constituir-se como uma fonte virtual de abastecimento de energia, todos os custos e gastos que possa gerar será repassado às tarifas dos consumidores, já que teria características similares com as outras usinas.

Todo projeto, antes de ser executado sempre é avaliado com um teste piloto, ou experiência piloto, que permite conhecer e detectar possíveis soluções frente a 
possíveis dificuldades. E como este caso não é a exceção, o LEE, antes de ser implantado, também deve ser submetido a um projeto piloto que ajude a visualizar os prós e os contras da sua implantação.

Em relação ao arranjo institucional, Garcia (2009) monta um modelo considerando os participantes que interagiriam com a finalidade de expandir o mercado considerando o LEE. O mercado de eficiência energética poderia ser graficamente representado pela figura 8 a seguir.

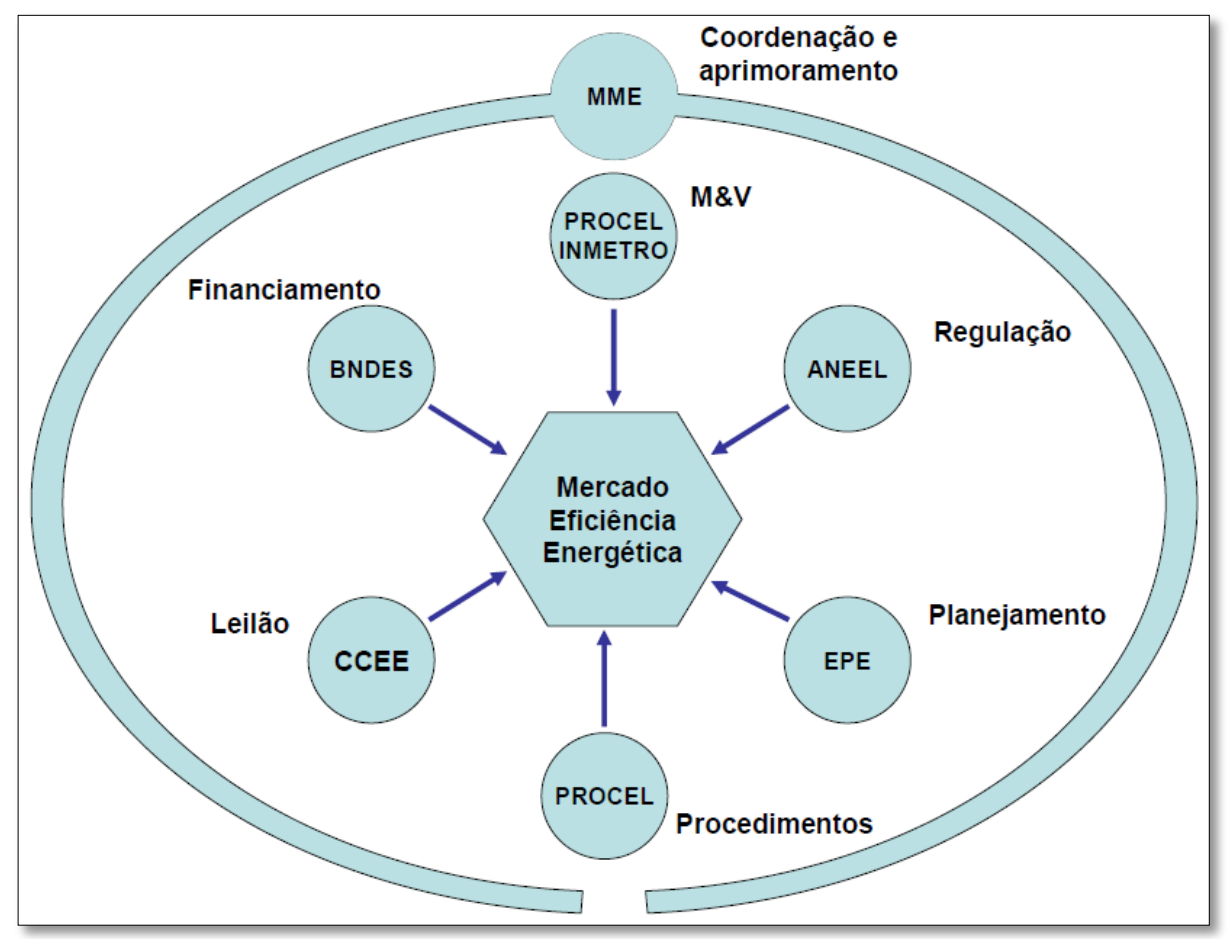

Figura 8: Modelo de mercado do LEE

Fonte: (Garcia, 2009)

Seguindo a ordem, quem tomaria conta do planejamento, como foi visto anteriormente, seria a Empresa de Pesquisa Energética (EPE), que para levar a cabo esse processo teria como aliado o Programa Nacional de Conservação de Energia Elétrica (PROCEL), já que necessitaria da experiência em pesquisas de mercado e em estimativas de potencial. No entanto, os procedimentos seriam estabelecidos e conduzidos pelo PROCEL, de forma integrada com a Agência Nacional de Energia Elétrica (ANEEL).

Os procedimentos que a $\mathrm{M} \& \mathrm{~V}$ tem, são de grande importância. Já o leilão propriamente dito, seria direcionado e realizado pela CCEE e contaria com a experiência e o apoio da EPE e PROCEL no momento da avaliação das propostas. 
Frente a todos estes procedimentos, não ficaria excluído o tema do financiamento, já que é imprescindível em todo projeto, no caso do LEE dentro da expansão do mercado.

Mesmo assim, todas as ações e medidas de M\&V estariam dirigidas pelo Instituto Nacional de Metrologia (INMETRO) e PROCEL, que fomentariam a credibilidade das atividades de $\mathrm{M} \& \mathrm{~V}$ baseados no Protocolo Internacional de Medição e Verificação de Performance (PIMVP). E, finalizando, a dinâmica do modelo proposto, os contratos, os planos e ações de $\mathrm{M} \& \mathrm{~V}$, que são parte da regulação, seriam coordenados pela ANEEL como agente encarregado do governo. Já a coordenação e o aprimoramento dos resultados deste processo seriam vistos pelo Ministério de Minas e Energia (MME), abordando todas as medidas com a finalidade da expansão do mercado de eficiência energética através do leilão (Garcia, 2009).

Na figura 9 a seguir, o mesmo autor apresenta uma série de passos para conseguir a implementação do leilão.

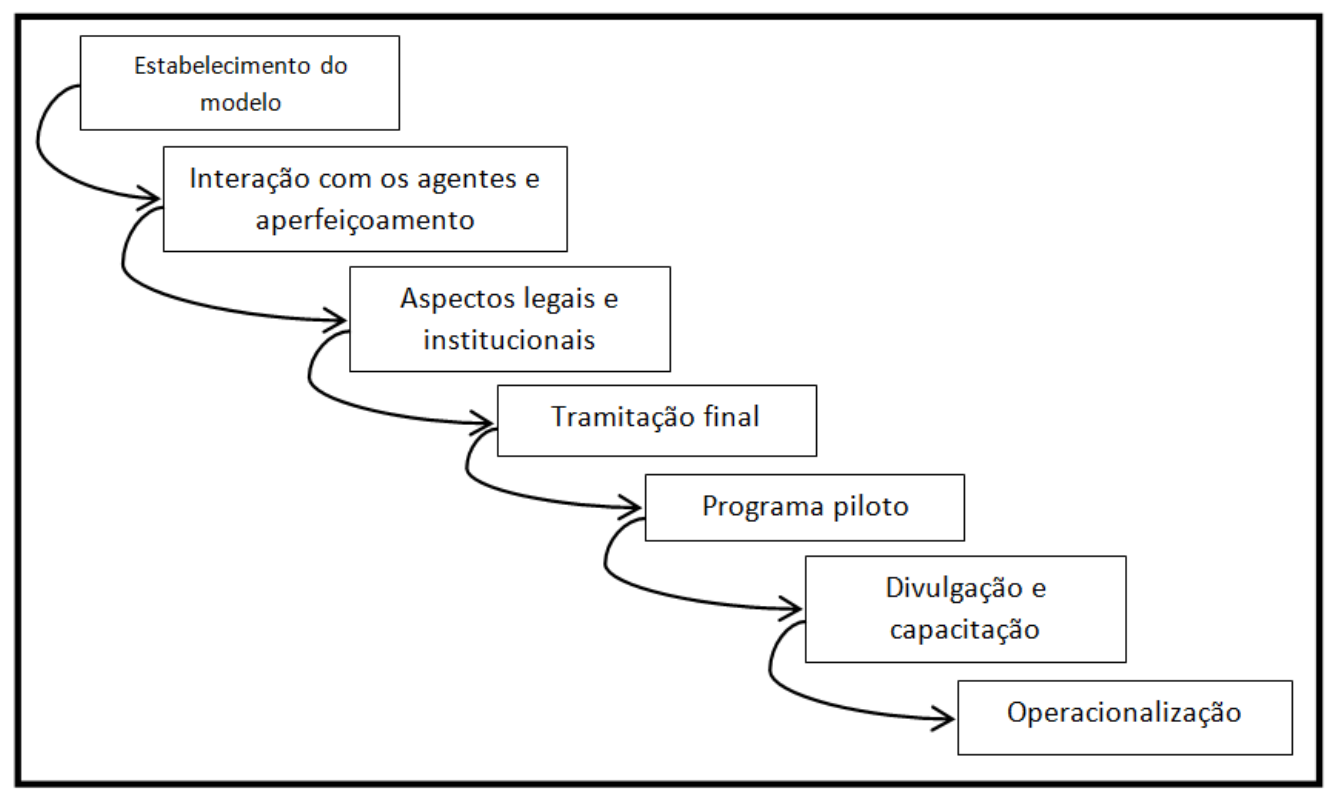

Figura 9: Passos para a implementação do LEE Fonte: (Garcia, 2009)

Em primeiro lugar é importante fazer um estudo para conseguir estabelecer e definir aspectos que facilitem determinar o modelo, o qual será chave para continuar com os demais passos que compõem a implementação do LEE. 
No seguinte passo, é conveniente negociar e discutir os processos com os diversos agentes para poder consolidar a proposta. Os diversos agentes relevantes do setor, incluindo MME, ANEEL, PROCEL, EPE, Energy Service Companies (ESCOs), consumidores de energia, distribuidoras de eletricidade e outros representantes terão parte neste passo.

Ademais, será de muita importância, portanto, realizar avaliações e revisões no contexto legal e proposições de possíveis alterações para viabilizar o LEE. Depois o projeto deverá ser encaminhado para tramitação nas instâncias governamentais, como o MME e a ANEEL. Entretanto, é recomendável fazer um projeto piloto, para avaliar e consolidar os processos operacionais. Para isso, escolher uma determinada região ou uma concessionária onde as condições de monitoramento dos resultados sejam facilitadas, seria a melhor opção. Desta forma, o leilão de projetos de eficiência poderá ser conduzido.

Assim, as diversas propostas devem ser avaliadas, assim como os contratos assinados, os projetos de eficiência energética implementados, as ações de $\mathrm{M} \& \mathrm{~V}$ efetivadas e os pagamentos pelas economias de energia efetuados. Seguido disso, deverão se desenvolver treinamentos para capacitação dos profissionais envolvidos (ESCOs, concessionárias, agentes executores do leilão, $M \& V$, etc.) e conscientização e conhecimento do processo para os tomadores de decisão envolvidos (concessionárias e donos de instalações).

Esta atividade pode ser conduzida em paralelo com o programa piloto, depois da aprovação do modelo do leilão. Finalmente, deve-se prever uma divulgação ampla do programa, para fomentar a consciência da sociedade e possa servir para o aumento da eficiência no uso da energia elétrica no Brasil. Consolidado o modelo, deve-se implantar a estrutura necessária definida e iniciar a fase operacional (Garcia, 2009).

Calili (2013) realizou uma pesquisa com oito renomados especialistas em Eficiência Energética e Planejamento Energético do Brasil. Este seguiu a metodologia baseado no livro "Making Markets" de AJIT KAMBIL e ERIC VAN HECK (Harvard Business School Press, pag 64 a 67), separando as questões em três partes referentes do ponto de vista dos players que compõem este mercado: compradores, vendedores e market makers (o governo).

As principais conclusões aportadas por Calili (2013) estão descritas nos subitens a seguir: 


\subsection{1.}

\section{Compradores}

- A energia proveniente de projetos de EE ainda não é um produto implantado no mercado.

- Assim, a ANEEL ou EPE através de audiências públicas poderiam definir este produto. Portanto, deve existir um condicionamento bem feito deste mecanismo e não replicar modelos de outros países. Por mais que os mesmos sejam benéficos para aqueles que o executam, tais benefícios não podem ser garantidos no caso específico do Brasil.

- Neste cenário, se ressalta a questão de que os vendedores sejam préqualificados para dar confiança aos compradores. Desta forma a definição de uma metodologia de $\mathrm{M} \& \mathrm{~V}$, daria confiabilidade ao processo.

- A avaliação de um projeto de EE requer conhecer todos os detalhes, incluindo o alvo, as ações a executar, o cronograma e principalmente as metodologias para estimar os benefícios. Tanto uma empresa auditora como um profissional qualificado, poderiam emitir propostas técnicas para ajudar no processo de decisão ao comprador.

\subsection{2. \\ Vendedores}

- O interesse e o nível de confiança que o mercado deve ter para adquirir energia advinda de usinas virtuais deve ser entendido e pesquisado mais a fundo para que os investidores tenham interesse neste mercado.

- Talvez a energia vendida neste leilão tenha um preço que não consiga pagar os custos do projeto de eficiência energética, pois o custo de transação do leilão se for muito alto pode inviabilizar o projeto em si. Desta forma, os vendedores devem prever um preço mínimo a que estariam dispostos a vender, já incorporando os custos de transação, e um ágio sobre esse valor pode ser considerado como ganho financeiro.

- Assegurar que o montante de energia ou demanda negociado será economizado. Como os vendedores estão encarregados de vender no leilão o seu potencial de redução, devem garantir que o projeto será executado confiavelmente para alcançar a redução de energia esperada. Um mecanismo que pode aplacar os riscos é a simplificação do processo de medição e verificação.

- Existe o risco de colusão, que em vez de competirem, os agentes conspirem secretamente para modificar os preços ou baixar a qualidade dos bens e serviços para compradores que desejem adquirir produtos ou serviços no leilão. 


\subsection{3.}

\section{O governo}

- A importância de diversos mecanismos de formação de preços, alguns de venda direta da energia de projetos de eficiência, como também os certificados brancos e o leilão propriamente dito são vistos para atrair o máximo de agentes e evitar colusão. Normalmente uma entidade independente que garante os resultados e impõe obrigações de eficiência energética, emite os certificados.

- Deve haver uma redução significativa nos valores de contrato de uso da rede de distribuição e transmissão, e nenhuma tarifa de uso deve ser cobrada à energia advinda de LEE, já que os projetos pelo lado da demanda não usam a capacidade das linhas: de transmissão e distribuição.

- A CCEE é quem faz a comercialização de energia elétrica no sistema Interligado nacional nos ambientes de contratação regulada e livre. Também quem promove os leilões de compra e venda de energia elétrica, conforme delegação da ANEEL para expansão do sistema.

- Como a CCEE efetua a contabilização e a liquidação financeira das operações realizadas no mercado de curto prazo, também ela deve definir os mecanismos dos LEE e realizar todos os procedimentos de pagamento e liquidação da energia comercializada nos leilões.

- A confiabilidade no LEE será alcançada a medida que os leilões produzam bons resultados. Assim, segundo os especialistas, um projeto piloto teria que ser realizado, para que eventuais problemas sejam solucionados e uma formatação definitiva possa ser concebida.

- Com a experiência advinda dos leilões de energia, o LEE deve ser capaz de prever mecanismos que garantam a eficácia e eficiência através da competição dos participantes durante a realização do mesmo. Inicialmente é importante comprovar que houve redução de energia e/ou demanda. Isso pode ser feito com a aplicação de metodologias de $\mathrm{M} \& \mathrm{~V}$ em todos os projetos de eficiência energética que vierem a participar do leilão.

\section{3.}

\section{Proposta para o Leilão de Eficiência Energética no Brasil}

Depois de ter visto o panorama das experiências internacionais em relação ao LEE e também as propostas sugeridas por Garcia (2009) e Calili (2013), neste item pretende-se propor um modelo de implementação do LEE adaptado à realidade brasileira.

O LEE tem tudo a ver com a participação ativa dos consumidores de energia (demanda) nos processos da fixação dos preços e a manutenção da qualidade do 
fornecimento. Tudo isso, se consegue através do fomento e a recompensa à demanda pela flexibilidade no uso da eletricidade.

O gerenciamento pelo lado demanda tem implicações importantes em termos da eficiência global do suprimento de eletricidade, tanto pelo lado econômico quanto pelo lado ambiental. No médio prazo, se evita a necessidade de recorrer a custosos investimentos em usinas, já que altera os custos do mercado.

Por outro lado, em termos de longo prazo, pode-se reduzir tanto o tamanho das linhas de transmissão quanto das usinas hidrelétricas, sendo importante para o mercado, já que os custos baixariam consideravelmente. Na maioria dos casos, os geradores produzem altos níveis de emissões de $\mathrm{CO}_{2}$, o que se tenta evitar com a implementação do LEE.

Nesse sentido o gerenciamento pelo lado da demanda é considerado como uma via de otimização de EE. Antes de apresentar o modelo de proposta da implementação do LEE, se apresentará os condutores que interatuarão no LEE. Na figura 10 se observa o dito anteriormente.

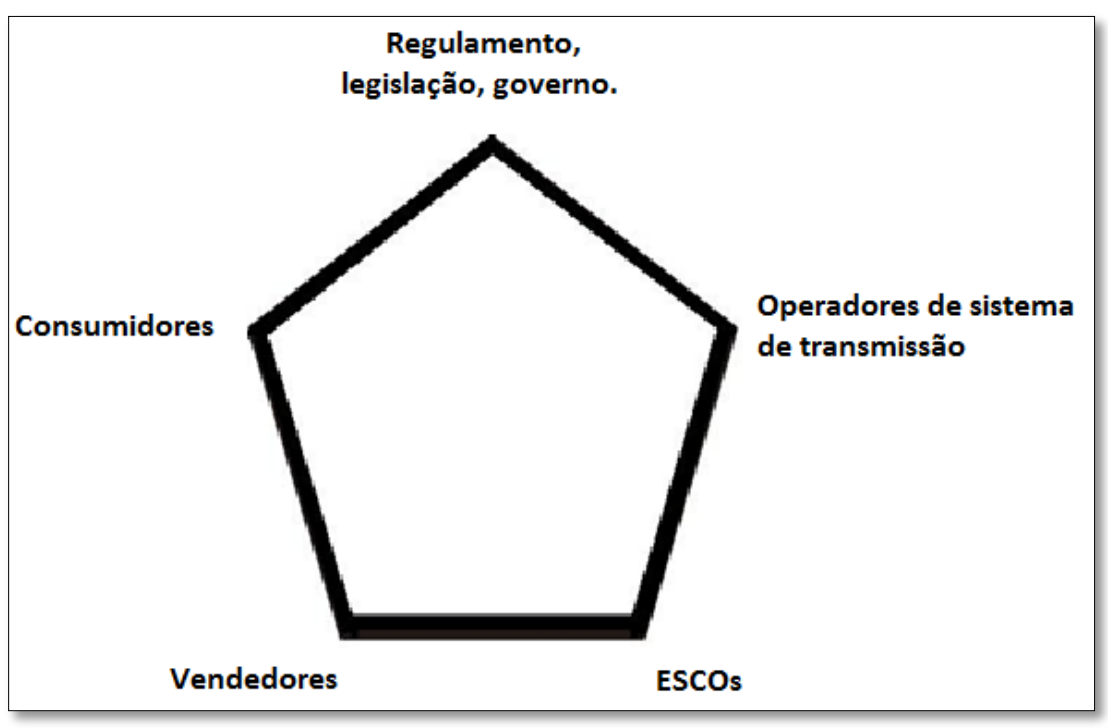

Figura 10: Condutores que interagirão no LEE

O LEE não acontecerá a menos que os diferentes participantes consigam se beneficiar mutuamente. O Operador Nacional do Sistema Elétrico (ONS) tem a responsabilidade de manter a segurança do sistema e a qualidade da oferta. A geração virtual seria mais uma fonte de energia que o ONS teria disponível para assegurar a confiabilidade do sistema. 
Nos mercados competitivos, geralmente, os provedores devem comprar a energia suficiente para satisfazer as necessidades dos seus clientes em todo momento, senão se enfrentam a punições financeiras. Tais punições, em geral, dependerão da hora durante o dia que reflita a demanda no sistema e a disponibilidade da capacidade de geração.

Os clientes que possuem maior flexibilidade em seus padrões de uso da eletricidade podem ser particularmente valiosos para os provedores, já que podem ajuda-los a evitar os períodos de pico da demanda de energia.

Os consumidores de eletricidade estão naturalmente interessados na compra de eletricidade ao menor custo, e o gerenciamento pelo lado da demanda pode ajudar neste caso. Alguns consumidores, devido à natureza do seu processo, têm mais capacidade para mudar os seus perfis de consumo do que outros.

Por outro lado, na maioria dos casos, os consumidores residenciais utilizam pouca eletricidade para que sejam elegíveis a participar do mecanismo de LEE. Portanto, em termos gerais, os consumidores individuais não são fortes impulsores da realização do LEE.

Tendo analisado os condutores que interviriam na proposta, através das etapas do LEE, tenta-se definir os conceitos baseados na opinião de especialistas na pesquisa de (Calili, 2013). Além disso, as etapas tentam incluir a adaptação e aproveitamento da tecnologia para facilitar alguns pontos. 


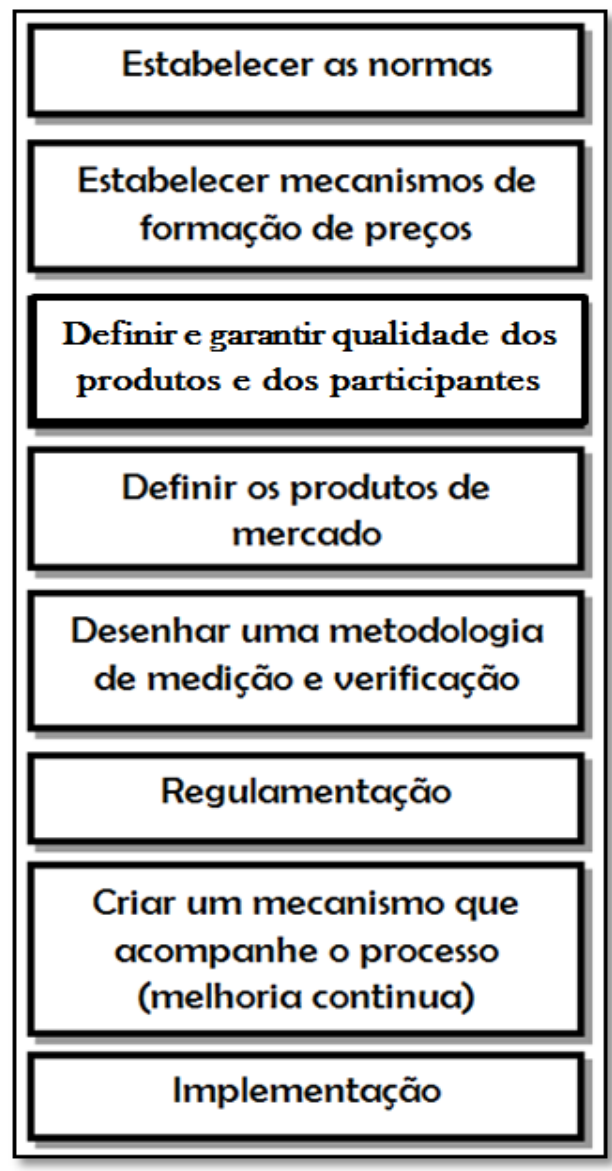

Figura 11: Proposta do Leilão de Eficiência Energética

O primeiro passo no desenvolvimento de um sistema de LEE é estabelecer as normas de governança do mercado/processo. Ademais, os mecanismos de formação de preços devem ser bem definidos, já que antes de formar o preço e definir suas políticas de vendas, um mercado deve ter o conhecimento dos elementos de formação do preço de venda dos produtos.

Atualmente, muitos mercados buscam a excelência em seus processos produtivos por meio da qualidade, no mesmo sentido, o LEE tenta envolver a definição e garantia de qualidade dos participantes.

Constantemente, as mudanças têm de estar acompanhadas de melhorias e refinamentos até que se alcance a excelência, e neste contexto não há exceção, tal é assim que refinar o produto é considerado de vital importância para levar a cabo este processo. Além disso, adaptar os produtos de licitação pelo lado da demanda também permitirá ampliar a gama de provedores, alinhando as necessidades reais dos compradores para o processamento dos provedores. Mencionando também que a concorrência de diferentes projetos menores da mesma linha que 
componham um montante de energia mínimo permitiria que a energia fosse comercializada.

Vinculado a tudo isto, o desenho de uma metodologia de $\mathrm{M} \& \mathrm{~V}$, fará que o mercado em geral transmita confiabilidade entre seus participantes.

Neste contexto torna-se imprescindível mencionar a regulamentação já que se converte em instrumento pelo qual o regulador pode se valer para estabelecer regras (direitos e obrigações) aos participantes que presta serviço. Mas, para isso, além do regulador, Calili (2013) menciona que se deve criar um mecanismo que acompanhe o processo global.

Todo processo que é considerado ótimo pode ainda ser melhorado. A melhoria contínua requer ação proativa de todos os participantes do LEE, pois as oportunidades de aperfeiçoamento surgem em todos os momentos da abordagem de processos. É indispensável que: a eficiência e a eficácia sejam avaliadas; as alternativas para soluções de problemas sejam exploradas; a melhor solução seja selecionada e implementada; a alternativa que vai eliminar a(s) causa(s)-raiz do problema e evitar a(s) sua(s) recorrência(s) seja imediatamente aplicada e monitorada, deste modo o mecanismo que acompanhe o processo será de muito proveito na implementação do LEE.

Finalmente, depois de ter estabelecido as normas, identificado os participantes e as suas necessidades, definido o produto, os quais servirão para esclarecer o panorama, se procederá a propor a implementação do LEE. 


\section{3 Medição e Verificação}

A Efficiency Valuation Organization (EVO) é responsável pela publicação do Protocolo Internacional de Medição e Verificação de Performance (PIMVP). A criação da EVO teve como objetivo a modernização de conceitos e de estrutura de modo a acompanhar as alterações ocorridas na visão da sociedade desde a aprovação do primeiro modelo de Protocolo. Além disso, a EVO desenvolve e promove o uso de protocolos padronizados, métodos e ferramentas para quantificar e gerenciar os riscos e benefícios das transações comerciais sob o regime de performance, associadas ao uso final eficiente da energia.

Este protocolo é usado como base de programas de eficiência energética e guias de Medição e Verificação (M\&V) em mais de 40 países. Alguns usuários do PIMVP são: o Federal Energy Management Program (FEMP), a Leadership in Energy and Environmental Design (LEED) nos Estados Unidos; a Agência para a Energia (ADENE) em Portugal; o Energy Savings Measurement Guide do Energy Efficiency Opportunities (Austrália), SGS-CSTC Standards Technical Services Co., Ltd. (Suíça e China) e HEP ESCO d.o.o. (Croácia). Além disso, existem treinamentos e certificações a profissionais em todo o mundo (Certified Measurement and Verification Professionals (CMVP) (Agência Nacional de Energia Elétrica, 2012).

O PIMVP fornece uma visão geral das técnicas atuais de melhores práticas disponíveis para a verificação dos resultados de eficiência energética, a eficiência da água e projetos de energias renováveis em instalações comerciais e industriais. Este protocolo também pode ser usado por operadores de instalações para avaliar e melhorar o desempenho da instalação. Ademais, algumas atividades se detalham a seguir:

- Documenta termos comuns e métodos para avaliar o desempenho energético de projetos de eficiência.

- Fornece métodos, com diferentes níveis de custo e exatidão, com a função de determinar economias para ações de eficiência energética. 
- Especifica o conteúdo de um Plano de Medição e Verificação (Plano de $M \& V)$. Este Plano de $M \& V$ adere aos princípios fundamentais de $\mathrm{M} \& \mathrm{~V}$ aceitos em todo o mundo.

A história do PIMVP remonta a 1995. Além disso, o seu desenvolvimento e a disseminação do seu uso internacional ocasionou:

- Fator alavancado do processo de pagamentos pelo desempenho energético.

- Redução dos custos de transação em um contrato de desempenho energético.

- Credibilidade internacional para relatórios de economia de energia.

- Auxílio a organizações nacionais e industriais no sentido de promover e obter o uso eficiente dos recursos e alcançar os objetivos ambientais.

A $M \& V$ dos resultados em projetos de eficiência energética desempenha um papel fundamental na avaliação das reais reduções de consumo e demanda de energia conseguida.

A ANEEL menciona que a atividade de avaliação dos resultados energéticos deverá ser baseada no PIMVP, que descreve as melhores práticas atualmente disponíveis para medir e verificar os resultados de projetos de eficiência energética do PEE.

Como a eficiência não é medida diretamente há sempre uma incerteza envolvida no resultado obtido. A ANEEL, neste contexto, sugere medições mais prolongadas, de maior número de variáveis, com maior precisão, de forma a diminuir o grau de incerteza. No entanto, o uso desse procedimento incorreria em aumento de custos. Em face disso, existe a necessidade de encontrar o equilíbrio entre precisão e custo, já que é fundamental para uma boa prática de $\mathrm{M} \& \mathrm{~V}$ (Agência Nacional de Energia Elétrica, 2012).

\section{1.}

\section{Definição de $M \& V$}

A M\&V é o processo de utilização de medições para determinar, de modo seguro, a economia conseguida por algum programa de gestão de energia. Segundo o Instituto Nacional de Eficiência Energética (INEE), para se constatar 
se a eficiência energética é ou não obtida por uma ação é preciso relacionar os resultados de redução de consumo de energia com os ganhos associados. Para garantir que os resultados obtidos sejam mantidos no longo prazo contratual, é preciso monitorar os seus valores (Agência Nacional de Energia Elétrica, 2012).

No entanto, segundo Garcia (2009), apesar da existência de guias gerais para a definição de processos de $\mathrm{M} \& \mathrm{~V}$, estas devem ser encaradas acima de tudo como um manual de boas práticas, sendo que não há acordos padrão e normas para realizar a $\mathrm{M} \& \mathrm{~V}$. Ao mesmo tempo, a $\mathrm{M} \& \mathrm{~V}$ é uma ferramenta muito útil para o controle energético em geral.

Ao elaborar um Plano de $\mathrm{M} \& \mathrm{~V}$ para uma edificação são considerados procedimentos reconhecidos internacionalmente, para permitir ao proprietário, às ESCOs, e agências financiadoras dos projetos, quantificarem as medidas de conservação de energia incorporadas à edificação e a correspondente economia obtida.

Neste caso, a metodologia adotada para a elaboração de $\mathrm{M} \& \mathrm{~V}$ inclui a coleta de informações referentes à operação e ao consumo de energia de modo sistemático, de maneira a apresentar níveis adequados de confiabilidade nos resultados obtidos. Com isso é possível identificar aspectos críticos e incrementar os níveis de eficiência; apresentar informações precisas para a elaboração de relatórios de emissões; e reduzir o custo do financiamento de projetos, devido à maior acuidade das previsões envolvendo a eficiência energética de uma nova edificação.

Além disso, permite a elaboração de um benchmarking que forneça subsídios para projetos mais eficientes e a redução dos riscos associados às previsões de consumo, e eficiência nas etapas de planejamento e projeto. Entre as vantagens da implantação de um Plano de $M \& V$, estão:

- Aumentar a precisão, confiabilidade e eficiência das medidas de conservação de energia adotadas para a edificação.

- Apresentar informações que permitam quantificar as reduções das emissões e melhorias obtidas relacionadas à qualidade ambiental.

- Determinar uma metodologia para negociar os termos contratuais que assegurem a eficiência energética do projeto atingido, ou a superação de metas e a correspondente economia financeira, através de um contrato de performance. 
Como já foi mencionada, em termos técnicos, a eficiência energética é a energia que não se consumiu, ou seja, a energia consumida após uma ação, subtraída daquela que teria sido consumida na sua ausência, é dizer, é resultado de um cálculo, uma subtração, onde um dos fatores (o subtraendo) é resultado de uma medida direta, e o outro fator (o minuendo) é uma avaliação. Para ser confiável, esta avaliação precisa ser feita não somente com base em outras medições, mas sim em um processo de preferencia padronizado e adotado internacionalmente (Agência Nacional de Energia Elétrica, 2012).

\section{2.}

\section{A relação entre a $M \& V$ e as ESCOs}

Muitas vezes o tema da energia torna-se distante nas atividades das empresas. Como o seu tratamento adequado exige conhecimentos específicos, empresas especializadas em serviços de eficiência de energia são as chamadas Empresas de Serviços de Conservação de Energia (ESCOs), e podem ser fundamentais para muitos consumidores identificarem e implementarem medidas de eficiência.

As ESCOs através de um contrato são encarregadas de monitorar as diferentes ações de eficiência energética por meio das medidas de $M \& V$ em um cliente. Além disso, conforme Calili (2013), em geral, as ESCOs não financiam o projeto de eficiência energética com seus próprios recursos, conseguem o financiamento de bancos, como por exemplo, o Banco Nacional do Desenvolvimento Econômico e Social (BNDES). Este banco conta com uma categoria de financiamento exclusiva para ESCOs, chamado Programa de Apoio a Projetos de Eficiência Energética (PROESCO), que tem o objetivo de apoiar projetos de eficiência energética. Na figura 12 se observa o funcionamento da estrutura do PROESCO. 


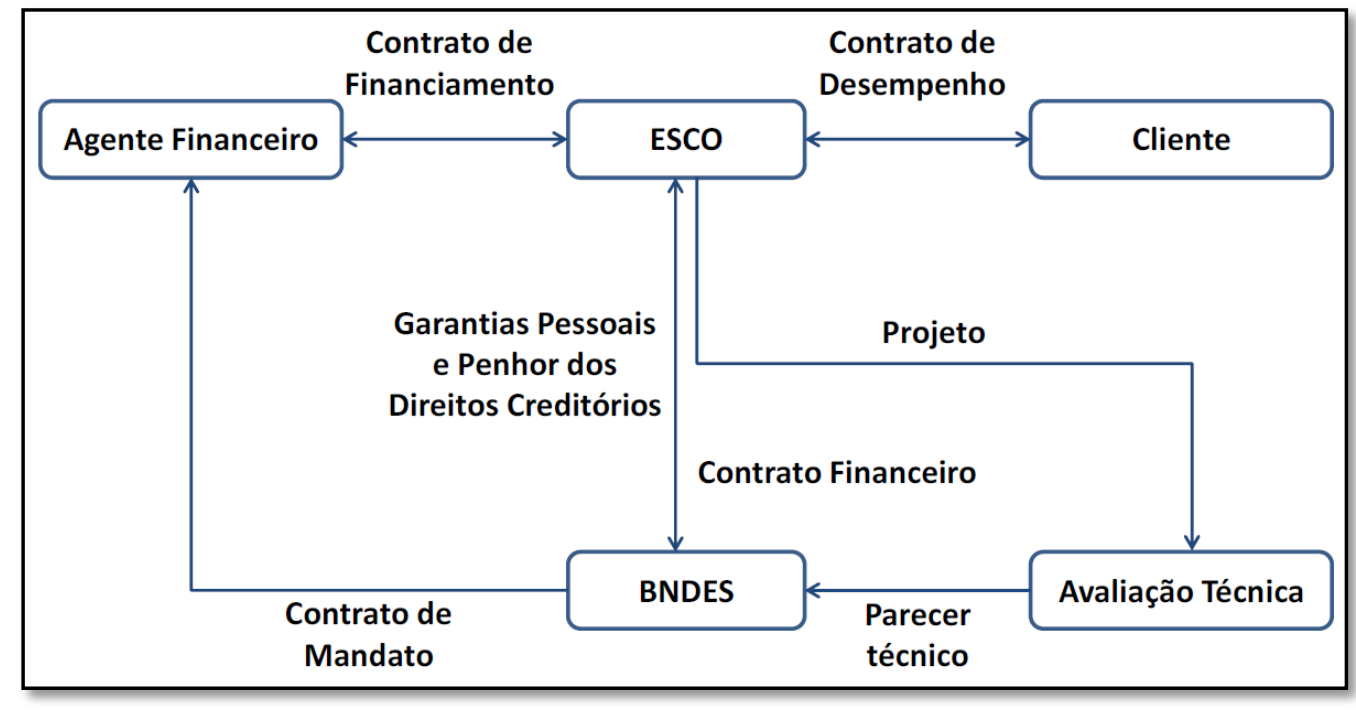

Figura 12: Funcionamento da estrutura do PROESCO

Fonte: (Calili, 2013)

Por meio de um contrato de performance, se estabelece que o financiamento do projeto será feito à partir da economia e redução do consumo de energia, podendo ser o capital utilizado de origem privada, advinda de diversas fontes de financiamento. As ESCOs oferecem projetos baseados em desempenho, sendo a remuneração paga de acordo com a economia e redução do consumo de energia obtida. Portanto, sua remuneração é de risco, uma vez que depende da efetiva redução de energia estimada (Calili, 2013).

A forma mais eficaz de reduzir os riscos, nos quais as ESCOs estão submetidas é por meio do estabelecimento de medidas eficazes de $\mathrm{M} \& \mathrm{~V}$.

Em geral, um projeto de eficiência energética apresenta alguns passos que serão apresentados a seguir, sendo a $\mathrm{M} \& \mathrm{~V}$ a etapa final do projeto, onde se fecha o ciclo para que o compromisso de redução de energia elétrica seja efetivamente medido: 


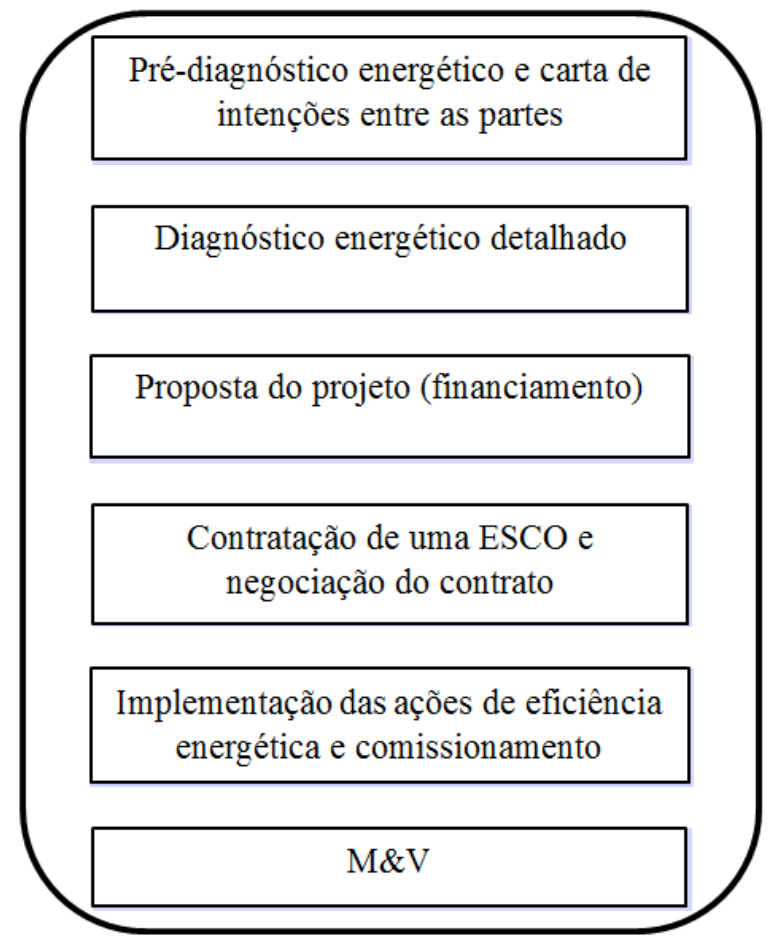

Figura 13: Passos de um PEE

Como se observa no passo a passo do processo, a primeira etapa consiste em fazer uma análise preliminar das possibilidades de redução de consumo, estabelecendo critérios de viabilidade econômica. Em posse da auditoria preliminar, pode-se fazer uma proposta preliminar ao proprietário da instalação e deste modo emitir uma carta compromisso.

Entretanto, a ESCO pode iniciar o processo fazendo um diagnóstico detalhado, onde são realizadas as medições prévias a fim de verificar o potencial de energia conservada. Nesta etapa, se faz algumas medições para ter noção do potencial de redução de energia, para que em seguida se possa calcular o fluxo de caixa do projeto e emitir a proposta.

Assim, a questão da contratação da ESCO e da negociação do contrato será realizada ao obter a proposta, pois assim poder-se-á definir qual o valor a ser financiado e quais os percentuais financeiros relativos à energia conservada, acordados entre a ESCO e ao dono da instalação. Além disso, se estabelece o termo de compromisso e a viabilização do financiamento. É importante que nesta etapa se defina claramente a responsabilidade de cada uma das partes (ESCO e proprietário da planta) e a performance que seguirão. 
Uma vez fechado o contrato, são implementadas as medidas de eficiência energética, sendo considerados nesta etapa os procedimentos de projeto executivo. Deste modo, são adotadas as ações de $\mathrm{M} \& \mathrm{~V}$ e o gerenciamento da energia reduzida a cada período contratado. Assim, as ESCOs devem definir a cada mês a economia de energia e economia monetária. Esta economia de energia deve ser estimada comparando a linha de base do uso da instalação antes da implantação da medida de EE, com uso após instalação das medidas de EE.

Finalmente, deve-se considerar que um bom plano de $M \& V$ deve medir os parâmetros chaves das ações de eficiência a serem implementadas para a construção da linha de base, assim como a avaliação dos resultados alcançados, e a comprovação do consumo de energia (Agencia Nacional de Energia Elétrica, 2012).

\section{3.}

\section{Definição de Baseline}

Conforme Calili (2013), as condições pré-contratuais (baseline ou linha de base) podem ser definidas tanto pelo cliente como pela ESCO. De qualquer forma as seguintes informações devem estar estabelecidas no contrato, para todo o período da baseline:

- Consumo e demanda de energia em cada medidor.

- Histórico do uso da instalação (por exemplo, taxa de ocupação do prédio ou instalação).

- Histórico da operação dos equipamentos (por exemplo, falhas no suprimento de energia elétrica).

- Histórico de fatores externos relevantes que influenciem o uso da energia, as variáveis explicativas (em prédios, por exemplo, são importantes as variações climáticas exteriores).

A linha de base é feita através verificação do consumo antes e a projeção do consumo depois das implementações das medidas de eficiência energética. É importante colocar, que por ser uma projeção, depois de implantadas as ações de eficiência energética se terá outra instalação, no qual os ajustes da curva de baseline devem ser previstos no contrato. Esta curva pode ser feita de diversas formas, mas dependendo do grau de complexidade das ações de eficiência 
energética adotadas, pode-se utilizar uma análise de regressão multivariada para sua elaboração.

$\mathrm{Na}$ figura 14, tem-se um exemplo de linha de base utilizando análise de regressão, onde foi ajustada uma curva aos dados medidos.

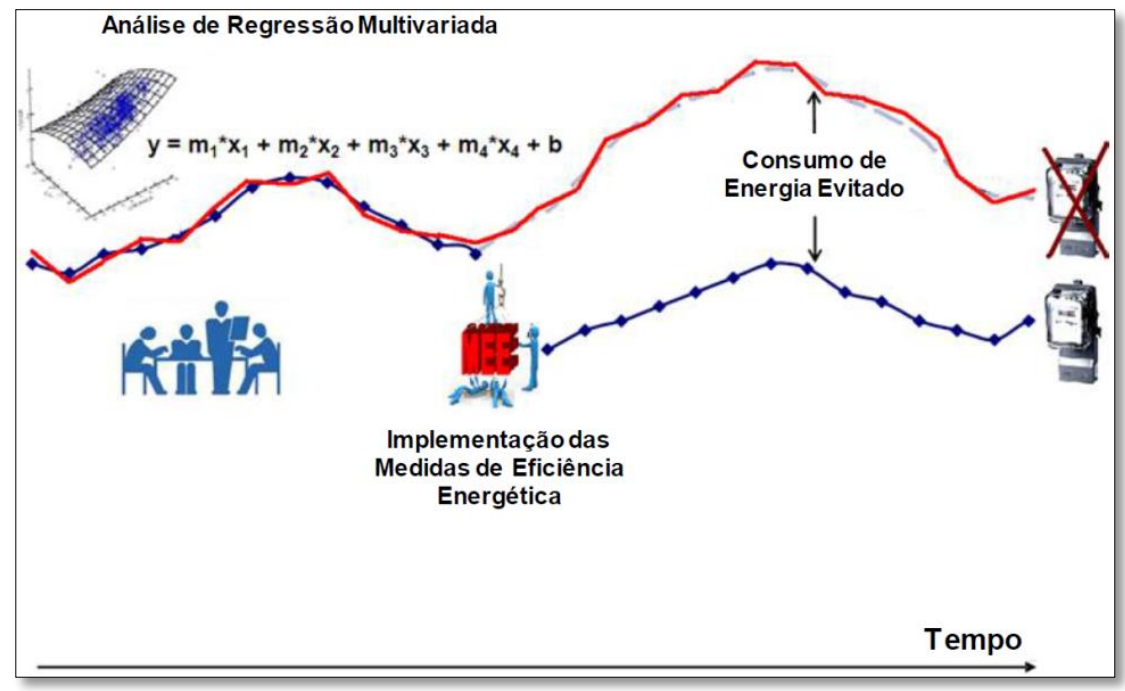

Figura 14: Descrição de Baseline

Fonte: (Calili, 2013)

$\mathrm{Na}$ figura anterior se observa uma curva ajustada (linha vermelha) e uma curva de medição (linha azul), antes da implementação das medidas de eficiência energética, para depois ser extrapolada, ou seja, após ações serem feitas (através de uma estimativa). O consumo de energia evitado ou energia reduzida com as medidas de eficiência energética é calculado pela diferença dos valores da curva de regressão extrapolada (curva vermelha) e os valores medidos após a implementação das ações (curva azul).

\subsection{1.}

\section{Contrato de performance}

As ESCOs foram organizadas para executar as AEEs sob um regime de Contrato de Performance, e por isso sua remuneração será sempre proporcional aos resultados obtidos. O PIMVP é a ferramenta que fornece resultados com uma qualidade definida pelo grau de confiança entre as partes. O Contrato de Performance é o documento utilizado para definir e quantificar a participação de cada parceiro no PEE. 
Assim, as etapas e o funcionamento de um contrato de performance são detalhadas a seguir:

- A ESCO realiza um Pré-diagnóstico sem ônus para o cliente.

- A ESCO efetiva uma Pré-viabilidade e verifica se cabe assumir o risco.

- Uma proposta é apresentada com números calcados no Pré-diagnóstico.

- O contrato é assinado com base em valores preliminares (em faixa). Serão medidos e incluídos os valores de referência (medição antes do inicio do trabalho do eficientizador).

- Realiza-se o diagnóstico detalhado e os valores preliminares transformamse em definitivos (no interior da faixa estabelecida).

- Desenvolve-se o projeto na seguinte ordem: projeto executivo, aquisição de materiais e equipamentos, instalação e montagem, comissionamento.

- Medição, a fim de verificar os resultados alcançados.

- Aceitação pelo cliente.

\section{4.}

\section{Opções de M\&V}

O objetivo de se definir as várias opções de $\mathrm{M} \& \mathrm{~V}$ é permitir ter flexibilidade no custo e no método de avaliação das economias. As quatro abordagens gerais descritas sucintamente abaixo variam em precisão e em custo de implementação. É importante lembrar que todos os métodos para determinar economias são estimados. O desempenho pode ser medido, as economias não. As opções descritas foram criadas para satisfazer as necessidades de uma grande gama de contratos que usam as economias para determinar os pagamentos de financiamentos. É importante perceber as limitações, bem como o poder de cada método apresentado (Agencia Nacional de Energia Elétrica, 2012). No quadro 1 apresenta-se as opções do PIMVP. 
Quadro 1: Opções do PIMVP

\begin{tabular}{|c|}
\hline Opção do PIMVP \\
\hline Medição Isolada das Ações de Eficiência \\
Energética (AEE): \\
Medição dos parâmetros-chave \\
Estes parâmetros definem o uso de energia
\end{tabular}

dos sistemas afetados pela ação de eficiência energética (AEE), e/ou sucesso do projeto.

Os parâmetros não selecionados para medição no campo são estimados. As estimativas podem basear-se em dados históricos, especificações do fabricante, ou avaliação de engenharia. É necessária a documentação da fonte ou a justificativa do parâmetro estimado.

O erro de economia plausível que surge da estimativa em vez da medição é avaliado.

\section{Medição isolada das AEEs:}

\section{Medição de todos os parâmetros}

A economia é determinada pela medição

\section{no campo do consumo de energia do sistema}

afetado pela AEE.

A frequência da medição vai desde o curto prazo à contínua, dependendo das variações esperadas na economia e da duração do período de determinação da economia.
Cálculo de engenharia do consumo da linha de base e do consumo do período de determinação da economia a partir de:

Medição a curto prazo ou contínuas de parâmetros-chave de funcionamento; e

Valores estimados.
A AEE da iluminação onde a potência requerida é o parâmetro-chave de desempenho energético, medido periodicamente.

Estimar as horas de funcionamento da iluminação com base nos horários do edifício e no comportamento dos ocupantes.
Medições de curto prazo ou contínuas do consumo da linha de base e consumo do período de determinação da economia, e/ou cálculos de engenharia, usando medições de representantes do consumo de energia.
Aplicação de variador de velocidade ajustável (variador de frequência) e controle de motor para ajustar o fluxo da bomba. Medir a potência elétrica com um medidor de $\mathrm{kW}$ instalado na alimentação elétrica do motor, o qual lê a potência a cada minuto. No período da linha de base este medidor permanece durante uma semana para verificar se a carga é constante. 0 medidor permanece no lugar durante o período de determinação da economia, para medir as variações da potência.

Programa de gestão de energia multifacetado, afetando muitos sistemas em uma instalação.

Medição do consumo de energia com os medidores de gás e eletricidade das concessionárias para um período da linha de base de doze meses e durante o período de determinação da economia.

Programa de gestão de energia
multifacetado, afetando muitos
sistemas em uma instalação onde não
existia nenhum medidor no período da
linha de base.
$\quad$ Medições do consumo de
energia após a instalação de
medidores de gás e de eletricidade
são usadas para calibrar a simulação.
$\quad$ Consumo de energia da linha
de base, determinado com utilização
da simulação calibrada, é comparado
à simulação do consumo de energia
do período de determinação da
economia.

Simulação do consumo de energia calibrada com dados de faturamento por hora ou mensal da concessionária (medidores de consumo de energia final podem ser usados para ajudar a refinar dados de entrada). linha de base de toda a instalação.

Ajustes de rotina como exigido, usando técnicas tais como uma regressão. economia. simulação do consumo de energia de toda a instalação.

Rotinas de simulação demonstram modela adequadamente o desempenho energético real medido na instalação.

Esta opção requer habitualmente competências consideráveis em simulação calibrada. 
Resulta complicado generalizar acerca da melhor opção de PIMVP para as diferentes situações que podem se apresentar. No entanto, algumas característicaschaves do projeto sugerem opções que normalmente são as mais favoráveis. No quadro 2 mostram-se algumas delas.

Quadro 2: Características e opções do projeto da AEE

\begin{tabular}{|c|c|c|c|c|}
\hline \multirow{2}{*}{ Características do projeto da AEE } & \multicolumn{4}{|c|}{ Opção sugerida } \\
\hline & A & B & C & D \\
\hline Necessidade de avaliar individualmente as AEEs & $x$ & $x$ & & $\mathrm{X}$ \\
\hline $\begin{array}{l}\text { Necessidade de avaliar apenas o desempenho energético } \\
\text { de toda a instalação }\end{array}$ & & & $\mathrm{X}$ & $\mathrm{x}$ \\
\hline $\begin{array}{l}\text { Economia prevista inferior a } 10 \% \text { do medidor da } \\
\text { concessionária }\end{array}$ & $\mathrm{x}$ & $x$ & & $\mathrm{x}$ \\
\hline $\begin{array}{l}\text { A importância de algumas variáveis determinantes do } \\
\text { padrão de uso da energia não é clara }\end{array}$ & & $\mathrm{X}$ & $\mathrm{X}$ & $\mathrm{x}$ \\
\hline $\begin{array}{l}\text { Os efeitos interativos da AEE são significativos ou não } \\
\text { podem ser medidos }\end{array}$ & & & $\mathrm{x}$ & $\mathrm{x}$ \\
\hline $\begin{array}{l}\text { Muitas alterações futuras previstas dentro da fronteira de } \\
\text { medição }\end{array}$ & $\mathrm{X}$ & & & $\mathrm{X}$ \\
\hline $\begin{array}{l}\text { É necessária uma avaliação do desempenho energético a } \\
\text { longo prazo }\end{array}$ & $\mathrm{X}$ & & $\mathrm{x}$ & \\
\hline Dados do período da linha de base indisponíveis & & & & $x$ \\
\hline $\begin{array}{l}\text { Pessoal sem formação técnica deve compreender os } \\
\text { relatórios }\end{array}$ & $\mathrm{X}$ & $\mathrm{X}$ & $\mathrm{X}$ & \\
\hline Competência de medição disponíveis & $\mathrm{X}$ & $\mathrm{X}$ & & \\
\hline Competências de simulação por computador disponíveis & & & & $x$ \\
\hline $\begin{array}{l}\text { Experiência de leitura das faturas de energia de } \\
\text { concessionárias e realização de análise de regressão } \\
\text { disponíveis }\end{array}$ & & & $x$ & \\
\hline
\end{tabular}

Fonte: (Agência Nacional de Energia Elétrica, 2012)

\section{5 .}

\section{Validação de M\&V}

A questão da validação poderia ser resolvida, segundo diferentes especialistas que participaram do Workshop de Medição e Verificação - M\&V 2014, através da auditoria dos procedimentos de $M \& V$, que formaria parte da iniciativa da ANEEL. Mas, a validação como tal teria que ser realizada por uma parte isenta e capacitada. A validação dos critérios adotados pela distribuidora 
para $\mathrm{M} \& \mathrm{~V}$ dos projetos ficará a cargo da $\mathrm{ANEEL}$, que poderá designar um agente credenciado para realizá-la (Instituto Nacional de Eficiência Elétrica, 2014).

A garantia de que um Projeto de Eficiência Energética tenha sido executado e de que os resultados alcançados respondam às condições definidas no Contrato de Performance, estarão na validação desses resultados que deverá ser executada por uma terceira parte, o que garantirá total isenção no processo.

Admite-se, assim, que a $\mathrm{M} \& \mathrm{~V}$ possa ser executada por uma terceira parte obedecendo a um Plano de M\&V. Ela poderá fazer intervenções eventuais durante a evolução do projeto, para correção de rumo. As intervenções serão menos necessárias quanto melhor a qualidade e maior o detalhamento do Plano de M\&V $\mathrm{e}$, fundamentalmente, quanto maior a confiança depositada no executor da $\mathrm{M} \& \mathrm{~V}$.

Entretanto, os técnicos que venham a executar a $\mathrm{M} \& \mathrm{~V}$, empregarão equipamentos de medição de propriedade de qualquer parte diretamente envolvida e que deverão possuir atestados válidos de calibração fornecidos por laboratórios credenciais pelo INMETRO (Agência Nacional de Energia Elétrica, 2012).

\section{6. \\ Considerações finais sobre o M\&V}

O objetivo da $\mathrm{M} \& \mathrm{~V}$, inclusive para o Leilão de Eficiência Energética (LEE), é garantir um montante de energia economizada a partir das ofertas. O ponto chave é a redução dos índices de $\mathrm{kWh} /$ produção no setor industrial, comercial e/ou residencial. Não apenas o sucesso do leilão depende de um bom programa de $\mathrm{M} \& \mathrm{~V}$, mas também da consolidação dos métodos de $\mathrm{M} \& \mathrm{~V}$ no Brasil.

Conforme o (Instituto Nacional de Eficiência Energética, 2014) as considerações que poderiam formar parte da $\mathrm{M} \& \mathrm{~V}$, baseadas em algumas propostas feitas no Workshop de Medição e Verificação - M\&V 2014 são as seguintes:

- Fazer um trabalho de divulgação de conceito de M\&V.

- Formar uma comissão certificada em M\&V.

- Divulgar os projetos bem sucedidos com o uso de M\&V.

- Criar um banco de dados que tenham exemplos de planos de M\&V.

- Definir o protocolo de M\&V para melhorar os projetos. 
- Ter a responsabilidade de contribuir na divulgação de M\&V.

- A M\&V deve ser executada por uma empresa neutra, não pelo executor.

- Criar uma cultura de $M \& V$ para os projetos de eficiência energética.

- Certificar profissionais e criar uma nova especialização para Engenharias (Área de eficiência energética).

- $\mathrm{A} M \& \mathrm{~V}$ pouco a pouco deve se tornar obrigatória.

- Planificação sobre o plano de M\&V por especialistas.

Pode-se concluir que as ESCOs tem participação direta no que diz respeito à aplicação da redução de consumo e gasto. O PIMVP visa o crescente investimento em eficiência energética de forma a elevar a economia e reduzir despesas com financiamentos. Para um eficiente diagnóstico devem-se fazer levantamentos de dados e medições de consumo de energia. A M\&V é um método usado para confirmar resultados de economia no que diz respeito à energia e custo. $\mathrm{A} \mathrm{M} \& \mathrm{~V}$ age como uma garantia da qualidade do uso de energia, bem como na qualificação das propostas nos leilões de energia. 


\section{Simulação do leilão de Eficiência Energética}

Ao longo dos últimos anos foram realizados diferentes leilões de energia. Assim como também foram se obtendo diversos preços de venda que permitirão simular alguns cenários.

\section{1.}

\section{Ambiente de contratação para a simulação do LEE}

O Novo Modelo do setor elétrico, estabelecido através da Lei 10.848 de 2004, determinou dois ambientes de mercado onde é concretizada a comercialização de energia elétrica, o Ambiente de Contratação Regulada (ACR) e o Ambiente de Contratação Livre (ACL).

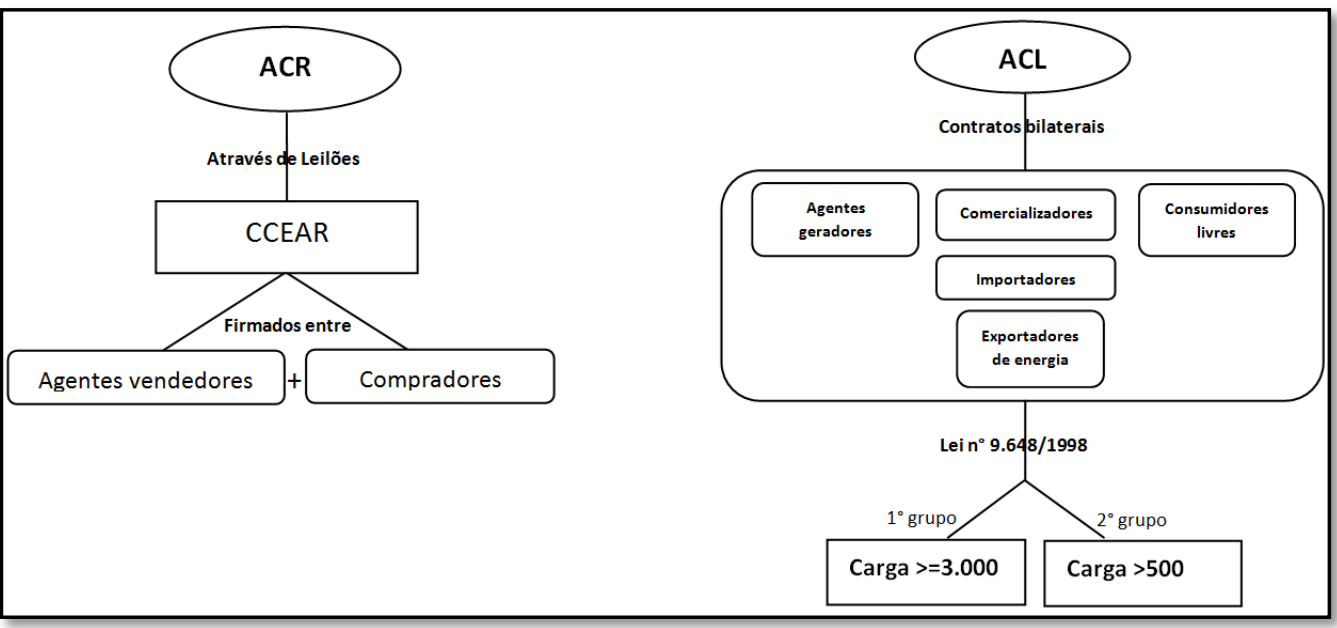

Figura 15: Resumo dos ambientes de contratação

Na figura 15, se observam os dois ambientes de contratação: regulado e livre. No ACR, os agentes de distribuição, através de leilões públicos promovidos pelo poder concedente (ANEEL) e operacionalizada pela CCEE, adquirem a energia elétrica para atender seu mercado (consumidores cativos). Já no ACL, os agentes geradores, comercializadores, produtores independente de energia, autoprodutores, e importadores de energia negociam livremente a contratação de 
energia elétrica por meio de contratos bilaterais. No ACL os consumidores "livres" podem comprar energia alternativamente ao suprimento da concessionária local. O consumidor negocia o preço da sua energia diretamente com os agentes geradores e comercializadores. Desta forma o cliente livre pode escolher qual será o seu fornecedor de energia.

Um panorama mais claro da forma se dá na comercialização de energia no Brasil, abarcando os dois ambientes de contratação, o qual é apresentado na figura 16.

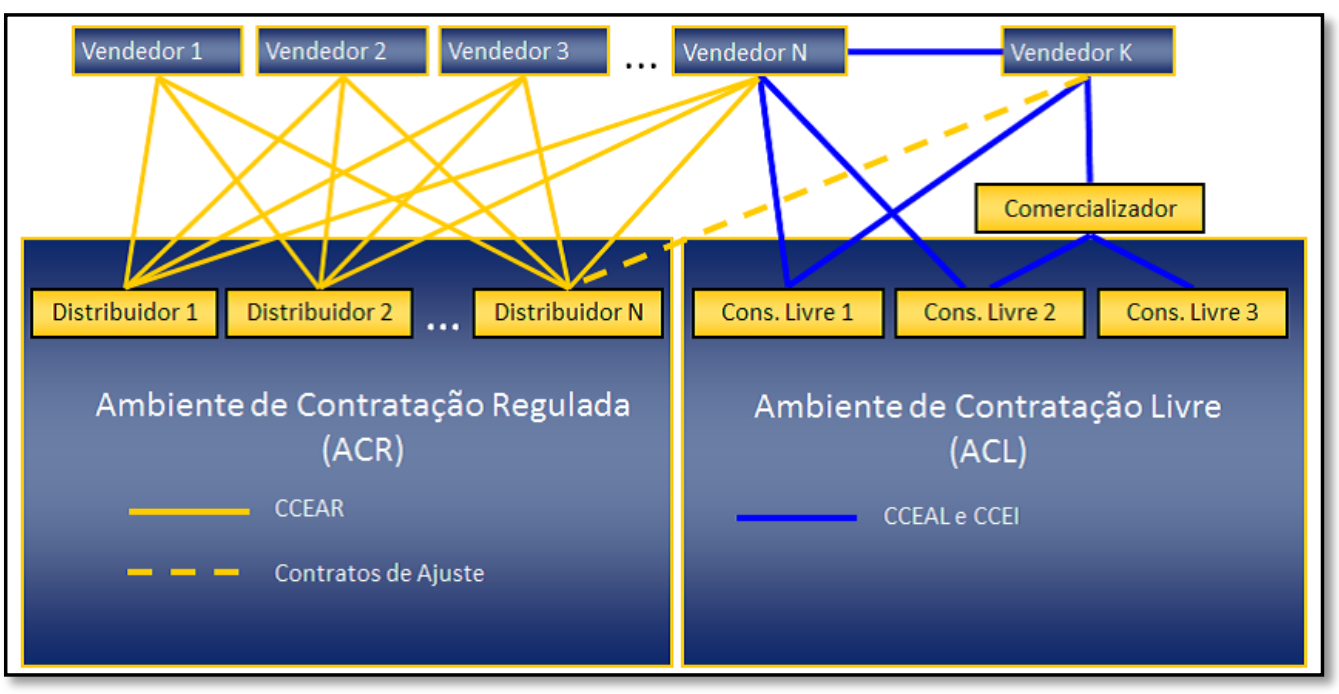

Figura 16: ACR e ACL

Fonte: (Câmara de Comercialização de Energia Elétrica, 2013)

Como se observa na figura 16, existem 2 mercados de contratação. Neste sentido, a pesquisa estará concentrada somente no mercado regulado (ambiente de contratação regulada) para analisar de maneira específica os diferentes resultados alcançados. Assim, a simulação irá considerar apenas os preços de energia do ACR, que serão uma proxy dos leilões de energia realizados pela EPE.

Nesta pesquisa esta se considerando todos os preços dos diferentes leilões: Energia nova, Fontes alternativas, Reservas e Estruturante, desde o ano 2005 até 2014. Antes de começar com as gerações dos cenários, se analisará o comportamento dos dados através de histogramas que facilitarão a obtenção e o conhecimento da distribuição que seguem. 


\section{2.}

\section{Método de Kernel}

Na hora de estimar uma função de densidade, o histograma é um estimador válido e de fácil construção e interpretação. O histograma é um dos métodos não paramétricos mais utilizados para a estimação de densidades. Normalmente, a ideia é dividir o intervalo de variação dos dados em intervalos de cumprimento h e contar o número de observações que caem em cada intervalo (Hastings, 1970).

Neste caso, o comportamento dos preços de venda do Leilão de eficiência energética, é analisado desta forma, particularmente, os preços são classificados em intervalos, e então se tentar desenhar uma função de densidade. Além disso, e sem perda de generalidade, se considera o intervalo. Com isso, a probabilidade de uma observação cair em cada intervalo é dada na eq. (1):

$$
P(X \in[-h / 2, h / 2))=\int_{-h / 2}^{h / 2} f(x) d x
$$

Onde $f$ é a densidade de $\mathrm{X}$. Naturalmente uma estimativa da densidade $f$ pode ser pensada como contar o número de observações pertencentes a cada intervalo e dividi-lo pelo número total de observações. Na eq. (2-10), dado um conjunto de observações, $X_{1}, \ldots, X_{n}$, temos:

$$
P(X \in[-h / 2, h / 2))=\frac{1}{n} \#\left\{X_{i} \in[-h / 2, h / 2)\right\}
$$

Ou seja,

$$
P(X \in[-h / 2, h / 2))=\int_{-h / 2}^{h / 2} f(x) d x=f(\xi) h
$$

Com $\xi \in[-h / 2, h / 2)$.

Daí uma estimativa para $f$ seria:

$$
\hat{f}_{h}(x)=\frac{1}{n h} \#\left\{X_{i} \in[-h / 2, h / 2)\right\}
$$

Para todo $x \in[-h / 2, h / 2)$. 
Formalmente, suponha que se observa $X_{1}, \ldots, X_{n}$, i.i.d. $f$ desconhecida. Seja $k$ o número de intervalos de comprimento $h$ e se define:

$$
C_{j}=\left[x_{0}+(j-1) h, x_{0}+j h\right)
$$

$j=1, \ldots, k$. Tome:

$$
n_{j}=\sum_{i=1}^{n} I\left(X_{i} \in C_{j}\right)
$$

Tal que:

$$
\sum_{j=1}^{n} n_{j}=n
$$

Então:

$$
\hat{f}_{h}(x)=\frac{1}{n h} \sum_{j=1}^{k} n_{j} I\left(x \in C_{j}\right)
$$

Note que a função $I(x \in A)$ é:

$$
I(x \in A)=\left\{\begin{array}{l}
1, \text { if } x \in A \\
0, \text { otherwise }
\end{array}\right\}
$$

É fácil ver que a estimativa $\hat{f}_{h}(x)$ depende fortemente da escolha de $h$, chamado de parâmetro de suavização. Neste contexto, em relação ao histograma, se sugere uma generalização considerando funções do tipo:

$$
K(x)=\left\{\begin{array}{l}
\frac{1}{2}, \text { if }|x|<1 \\
0, \text { otherwise }
\end{array}\right\}
$$

Precisar-se-á estimar uma função de densidade para a realização das simulações, em torno à dita função, dos preços do Leilão de Eficiência Energética no ambiente regulado.

Essa estimação servirá de base para o desenvolvimento e criação de diferentes cenários dos preços. No entanto, em muitos problemas pode ser bastante difícil, ou mesmo impossível, encontrar uma densidade de importância que seja simultaneamente uma boa aproximação a posteriori e fácil de ser amostrada. 
Neste sentido, e consequentemente, pode-se sugerir uma nova estimativa para $f$, o que seria a utilização do método de Kernel para cálculo da função densidade. A eq. (11), a seguir, define o método:

$$
\hat{f}(x)=\frac{1}{n h} \sum_{i=1}^{n} K\left(\frac{x-X_{i}}{h}\right)
$$

Claramente, esta nova estimativa generaliza aquela baseada no histograma.

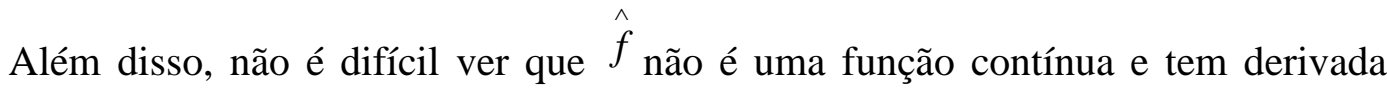
zero em todos os pontos exceto nos pontos de salto $X_{i} \pm h$. Também se deduz que h é o parâmetro de suavização, positivo e não aleatório, e K é a própria função Kernel, não negativa que satisfaz a condição $\int_{-\infty}^{+\infty} K(x) d x=1$.

Em particular quando se faz a escolha de K como sendo uma Gaussiana, $\hat{f}$ será uma curva suave com derivadas de todas as ordens. Estes estimadores conseguem funções de densidade suavizadas que são construídos em cada ponto do eixo real de acordo com os valores mais próximos ao mesmo. Nesta pesquisa, se apresenta a estimação da função de densidade mediante núcleos tendo em conta que a situação apresentada sobre o comportamento dos preços de Leilão de eficiência energética não se conseguiu ajustar utilizando técnicas tradicionais, particularmente, os métodos paramétricos.

Ademais, é importante conhecer que a estimativa é fortemente influenciada pela escolha de $h$. Sendo assim, quanto menor for o tamanho de $h$ menos suave será a estimativa, o contrario acontece quando $h$ é maior, a estimativa torna-se mais suave.

\section{3.}

\section{Aproximação por polinômios}

Uma função analítica pode ser escrita como uma série de potencias como se observa na eq. (12) a seguir:

$$
f(x)=\sum_{n=0}^{\infty} a_{n} x^{n}
$$


Que converge uniformemente à função $\mathrm{f}$ em um dado intervalo. Se se considera a sucessão ${ }^{\sigma_{n}}$ de somas parciais da série de potencias, na eq. (13) temse:

$$
p(x)=a_{n} x^{n}+a_{n-1} x^{n-1}+\ldots+a_{1} x+a_{0}
$$

Assim, dado $\in>0$ existe um número $N(\varepsilon) \in \mathrm{N}$ tal que $\left\|f-\sigma_{n}\right\|<\varepsilon$ para cada $\mathrm{n}>\mathrm{N}$. Pode se dizer então que dado um intervalo existirá um polinômio que aproxima, uniformemente, à função $f$ arbitrariamente bem.

É interessante saber se a aproximação se cumpre para a função $f$. Nesse sentido se pretende encontrar através da aproximação de polinômios a curva suavizada que permita adequar o comportamento dos preços do Leilão de eficiência energética. Deste modo se conseguiu aproximar os dados a um polinômio da ordem 17 o que apresentará uma melhor modelagem dos dados originais.

\section{4. \\ Método de Monte Carlo via cadeias de Markov}

É importante mencionar o método de Monte Carlo via Cadeias de Markov (MCMC), que permite gerar amostras de uma variável aleatória " $x$ " que possui uma distribuição de interesse qualquer.

Obtendo-se a função de densidade dos dados, procedera-se a usar o referido para simular os dados em diferentes cenários. Por outro lado, o MCMC é uma alternativa aos métodos não interativos em problemas complexos. A ideia ainda é obter uma amostra da distribuição a posteriori e calcular estimativas amostrais de características desta distribuição.

Os métodos MCMC requerem ainda que a cadeia seja:

- Homogênea, isto é, as probabilidades de transição de um estado para outro são invariantes;

- Irredutível, isto é, cada estado pode ser atingido a partir de qualquer outro em um número finito de iterações;

- Aperiódica, isto é, não haja estados absorventes.

A ideia é que a medida que o número de iterações aumente a cadeia gradualmente esquece os valores iniciais e eventualmente converge para uma 
distribuição de equilíbrio (Tierney, 1994). Em aplicações práticas é comum que as interações iniciais sejam descartadas, como se constituíssem uma amostra de aquecimento.

Os métodos de MCMC são uma útil ferramenta para resolver muitos problemas de cálculo que surgem na modelização paramétrica aplicada e que são intratáveis analiticamente.

$\mathrm{O}$ que se pretende com os algoritmos MCMC é gerar valores de uma variável aleatória $\mathrm{X}$ com distribuição de probabilidade $\pi(\mathrm{x})$, tipicamente multidimensional, e que não seja possível amostrar diretamente. Para isso se simula uma cadeia de Markov ergódiga que tem como distribuição estacionaria a distribuição objetiva $\pi(\mathrm{x})$, através de um número suficientemente grande de interações se estariam gerando mostras aproximadas de $\pi(\mathrm{x})$.

Os diferentes cenários serão simulados utilizando o MCMC. Entretanto, as amostras geradas permitirão analisar detalhadamente o comportamento dos preços do LEE, fazendo rodadas com as amostras de tamanhos diferentes $(500,1000$, 5000 e 10000) para observar o comportamento próximo da amostra original.

Uma cadeia de Markov é um processo estocástico $\left\{X_{0}, X_{1}, \ldots\right\}$ tal que a distribuição de $X_{t}$ dados todos os valores anteriores $X_{0}, \ldots, X_{t-1}$ depende apenas de $X_{t-1}$. Expressado matematicamente na eq. (14), seria:

$$
P\left(X_{t} \in A \mid X_{0}, \ldots, X_{t-1}\right)=P\left(X_{t} \in A \mid X_{t-1}\right)
$$

A densidade tentativa $\pi\left(x_{t} \mid x_{t-1}\right)$, que é uma densidade condicional dependente do estado anterior. A probabilidade de aceitação de um ponto candidato será $\mathrm{A}\left(x_{t 1}, x^{\prime}\right)$.

\section{5.}

\section{Simulação}

Neste capítulo se considerará uma das técnicas-chave para desenvolver e cumprir com um dos objetivos principais da pesquisa: a simulação dos preços de Leilões de Eficiência Energética. A simulação se destaca entre as técnicas mais usadas. Além disso, por ser uma ferramenta tão flexível e poderosa ela continua a ganhar rapidamente reconhecimento. 
Essa técnica envolve o uso de um computador para simular a operação de um inteiro processo. Por exemplo, a simulação é frequentemente usada para realizar análises de risco em projetos, imitando repetidamente a evolução dos processos envolvidos para gerar um perfil de possíveis resultados. A simulação também é amplamente usada para analisar sistemas estocásticos que continuarão a operar indefinidamente. Para tais sistemas, o computador gera e registra, aleatoriamente, as ocorrências dos vários eventos que dirigem o sistema como se eles estivessem operando fisicamente. Em virtude de sua velocidade, o computador pode simular até mesmo anos de operação em uma questão de segundos. Analisar o desempenho da operação simulada do sistema para uma série de projetos ou procedimentos operacionais alternativos habilita então a avaliação e a comparação dessas alternativas antes de escolher a melhor (Hillier e Lieberman, 2006).

Duas notáveis categorias de simulações são as simulações por eventos discretos e as simulações contínuas. A simulação por eventos discretos é aquela em que as mudanças no estado do sistema ocorrem instantaneamente em pontos aleatórios no tempo como resultado da ocorrência de eventos discretos. A maioria das aplicações de simulação, na prática, são simulações por eventos discretos. A simulação contínua é aquela na qual as mudanças no estado do sistema ocorrem continuamente ao longo do tempo.

As simulações contínuas normalmente exigem o emprego de equações diferenciais para descrever a taxa de mudança das variáveis de estado. Logo, a análise tende a ser relativamente complexa. Aproximando as mudanças contínuas do estado de um sistema por mudanças ocasionais discretas, muitas vezes é possível da simulação por eventos discretos a uma de um sistema contínuo. Isso tende a simplificar enormemente a análise.

\subsection{1. Simulação Estatística}

A simulação é uma técnica de amostragem estatística controlada (experimentação) que se usa conjuntamente com um modelo, para obter respostas aproximadas a problemas probabilísticos complexos e deve seguir as normas do desenho de experimentos para que os resultados obtidos possam conduzir a interpretações significativas das relações de interesse. A construção e a operação 
de um modelo de simulação permite a observação do comportamento dinâmico de um sistema em condições controladas, podendo-se efetuar experimentos para comprovar alguma hipótese acerca do sistema em estudo. Basicamente se relacionam três elementos: sistema (parte do mundo real que interessa estudar), modelo (representação simplificada de um sistema) e computador.

Em geral, um estudo de simulação pode dividir-se em as seguintes etapas:

- Definição do problema e planejamento do estudo inclui uma definição precisa do problema a resolver e dos objetivos de estudo.

- Coleta de dados.

- Estabelecimento do modelo de simulação inclui estabelecer as suposições que se devem fazer, e definir o modelo a utilizar.

- Execução da simulação. Consideração das técnicas e metodologias simples e avançadas requeridas para obter os resultados de programação. Isto inclui aspectos tais como geração de variáveis aleatórias, métodos para controle de variáveis, precisão dos estimadores, etc.

- Execuções do teste do modelo.

- Validação do modelo.

- Desenho do experimento de simulação

- Execução do experimento.

- Análises dos resultados. Uso das técnicas estatísticas e gráficas para interpretar os resultados.

Os problemas que se podem resolver mediante simulação se classificam em probabilísticos e determinísticos. As técnicas de re-amostragem como Bootstrap permitem comparar as estimações usando diferentes tamanhos de amostras e poucas análises, mas requerem um grande esforço computacional. Em inferência bayesiana se utilizam métodos eficientes de integração, e quando os problemas são de alta dimensão, os métodos mais eficientes de integração são os baseados em simulação. Um algoritmo probabilístico é um algoritmo que recebe como dados de entrada números aleatórios e deste modo pode produzir diferentes resultados com distintos tempos de execução. A simulação permite, por um lado a implementação de algoritmos probabilísticos, e por outro lado a análise probabilística de algoritmos. 


\subsection{2.}

\section{Simulação de Monte Carlo}

Os métodos Monte Carlo são cálculos numéricos que utilizam uma sequencia de números aleatórios para levar a cabo uma simulação estatística, com a finalidade de conhecer algumas propriedades estatísticas do sistema. Esses métodos de simulação são diferentes aos métodos numéricos discretos aplicados para resolver equações diferenciais parciais que descrevem o comportamento de algum sistema matemático. A característica essencial de Monte Carlo é o uso de técnicas de tomada de amostras aleatórias para chegar a uma solução do problema, entretanto, uma solução numérica convencional inicia com um modelo matemático do sistema, discreteando as equações diferenciais para logo resolver um grupo de equações algébricas.

Com nesses métodos somente se requer que o sistema matemático possa ser descrito mediante uma função de densidade de probabilidade, e que uma vez que seja conhecida a função, se requer uma forma rápida e efetiva para gerar números aleatórios com essa distribuição, e assim se inicia a simulação fazendo amostragens aleatórias da mesma. Depois de múltiplas simulações, o resultado desejado se toma como o valor médio dos resultados obtidos em cada simulação. Em muitas aplicações práticas se podem predizer um erro estatístico (variância, $\sigma^{2}$ ) para esse valor médio e, portanto uma estimação do número das simulações necessárias para conseguir um erro dado. Entre todos os métodos numéricos baseados em avaliações de $\mathrm{n}$ organismos em espaços de dimensão $\mathrm{r}$, os métodos de Monte Carlo têm associado um erro absoluto de estimação que decresce como $\sqrt{n}$, entretanto que para o resto de métodos tal erro decresce no melhor dos casos como $\sqrt[r]{n}$ (Drakos, 2009).

Os métodos de Monte Carlo são utilizados para simular processos aleatórios ou estocásticos, dado que eles podem ser descritos como funções de densidade de probabilidade, ainda que com algumas restrições, já que muitas aplicações não têm aparente conteúdo estocástico, tal como a inversão de um sistema de equações lineares.

Existem algumas diferencias entre simulação e simulação mediante métodos Monte Carlo. A seguir se apresentam as mais importantes: 
- No método de Monte Carlo o tempo não é importante, mas na simulação estocástica o tempo tem muita importância.

- As observações no método de Monte Carlo são independentes. Na simulação os experimentos dependem do tempo, de tal modo que as observações são correlacionais.

- No método de Monte Carlo a resposta pode-se expressar como uma simples função das variáveis aleatórias de entrada, entretanto que na simulação a resposta somente pode ser expressa explicitamente pelo próprio programa.

Nesse contexto, a resposta de um sistema pode estar determinada pela sucessão ou combinação de estados, os quais podem mudar em alguns instantes de tempo, os quais podem ser síncronos, ou assíncronos. Os métodos de Monte Carlo são aplicados a esses últimos, e dependendo da maneira como passam de um estado a outro, se classificam em:

- Métodos baseados em cadeias de Markov (o algoritmo MetropolisHastings).

- Métodos independentes (amostragem de importância e de rejeição).

Uma cadeia de Markov é uma série de eventos, na qual a probabilidade de ocorrer um evento depende do evento imediatamente anterior, é dizer, são cadeias com memória, o que condiciona as probabilidades dos eventos futuros (probabilidade de transição).

\subsection{3.}

\section{Geração de números aleatórios}

Implementar um modelo de simulação requer a geração de números aleatórios para se obter observações aleatórias a partir das distribuições de probabilidades. Uma forma para gerar números aleatórios é através do uso dos computadores como principal fonte para geração de números aleatórios. Muitos pacotes de software também possuem a capacidade de gerar números aleatórios sempre que necessário durante uma simulação.

O procedimento usado por um computador para obter números aleatórios é chamado gerador de números aleatórios, ou seja, um algoritmo que produz sequências de números que seguem uma distribuição de probabilidades especificada e possui o aspecto de aleatoriedade. 
A referência às sequências de números significa que o algoritmo produz diversos números aleatórios de uma forma serial. Embora um usuário comum normalmente possa precisar apenas de alguns números, geralmente o algoritmo deve ser capaz de produzir muitos números. A distribuição de probabilidades implica que a declaração de probabilidade possa ser associada à ocorrência de cada número produzido pelo algoritmo (Hillier e Lieberman, 2006).

Reservar-se-á o termo número aleatório para significar uma observação aleatória de alguma forma de distribuição uniforme, de modo que todos os possíveis números sejam igualmente prováveis. 


\section{5 \\ Metodologia}

\section{1. \\ Considerações iniciais}

Este capítulo apresenta a metodologia utilizada para avaliação e análise dos preços da energia nos diferentes leilões. São descritos os procedimentos necessários para o desenvolvimento da simulação no ambiente de contratação regulada a partir da modelagem do comportamento dos dados de preços.

Com o auxílio da metodologia proposta, se criará condições para que os planejadores e controladores do possível Leilão de Eficiência Energética possam gerenciar melhor os preços, sabendo que a metodologia pode ser usada em qualquer cenário ou realidade. Dependendo de como se comporta o preço ao longo do tempo, a metodologia oferece garantia de conseguir-se adaptar.

Desse modo, o escopo desse capítulo apresenta a metodologia e as contribuições feitas nesta dissertação. Primeiramente, é descrita um método para se aproximar uma função de densidade adequada ao comportamento dos dados originais (preços do Leilão de Eficiência Energética). Em seguida, é apresentado o método de MCMC que permitirá gerar amostras da distribuição de interesse. O algoritmo de MCMC utilizado foi o de Metropolis-Hastings, que permitirá obter diferentes amostras para analisar cenários diferentes com os preços de um possível leilão de eficiência energética no Brasil.

\section{2.}

\section{Simulação no ambiente de contratação regulado}

Os procedimentos apresentados podem ser utilizados para ter uma clara noção do enfoque que a pesquisa tenta dar. Utilizando-se as informações necessárias se classificou em 3 seções que abarcarão o núcleo deste capítulo. 
5.2.1.

\section{A distribuição dos dados foi obtida usando o método Kernel e aproximação polinomial}

Os dados de negociações dos preços de Leilões de Eficiência Energética foram obtidos de leilões anteriores, no período de 2005 até 2014. O objetivo deste estudo foi avaliar o comportamento dos preços de energia entre $\mathrm{R} \$ 110 \mathrm{MWh}$ e R\$140 MWh, como sugerido por (Calili, 2013).

A distribuição dos dados no intervalo de interesse (Figura 17) é desconhecida. Neste contexto, o método não paramétrico de Kernel foi utilizado para obter a estimativa da função de densidade dos dados dos preços de energia. $\mathrm{O}$ método pode ser interpretado como uma generalização do histograma.

Em seguida, a estimativa da função de densidade obtida pelo método de Kernel foi aproximada por um polinômio de ordem 17 (Figura 19). Os coeficientes do polinômio foram obtidos usando o método de mínimos quadrados.

\subsection{2. Utilização do MCMC}

A partir da estimativa da densidade obtida pelo método de Kernel e aproximação polinomial, tem-se a suposta distribuição de interesse e pode-se utilizar o método de MCMC para gerar amostras.

O método de MCMC permite gerar amostras de uma distribuição de interesse qualquer. $\mathrm{O}$ algoritmo de MCMC adotado foi o Metropolis-Hastings (MH) com distribuição de interesse sendo o polinômio obtido na aproximação.

$\mathrm{Na}$ verdade, o que se fez com o MCMC foram gerar valores da variável aleatória dos preços de energia através da distribuição de probabilidade obtida pelo método de Kernel.

\subsection{3.}

\section{Geração de amostras usando o algoritmo de Metropolis-Hastings}

$\mathrm{O}$ algoritmo de Metropolis-Hastings $(\mathrm{MH})$ foi desenvolvido inicialmente por Metropolis (1953) e generalizado por (Hastings, 1970). Na verdade, a ideia do algoritmo é obter a distribuição desejada, através de uma distribuição proposta. Neste caso, a distribuição dos dados que se utiliza para gerar uma realização 
depende da simulação anterior. A distribuição proposta adotada neste estudo foi a distribuição Uniforme.

O algoritmo conseguiu fazer as simulações e criar cenários com diferentes tamanhos de amostras. As amostras geradas seguem o comportamento dos dados originais. Sendo assim, podemos usar as amostras geradas para compreender o comportamento da distribuição dos preços de energia. E assim, as amostras permitiram obter a distribuição de probabilidade do preço proposto do Leilão de Eficiência Energética encontrado entre R \$ 110 MWh e R \$ 140 MWh, como foi sugerido na pesquisa de (Calili, 2013). 


\section{6 Resultados}

Através de exemplos numéricos, conforme Calili (2013) apresenta, se observará os ambientes de contratação e também uma possível formação dos preços de venda no leilão de eficiência energética (preços estáticos). Para isso, se analisará o balanço energético e a liquidação financeira que o LEE propõe dentro do mercado de energia real e virtual. Feito isso, se simulará a formação dos preços que seriam aceitos dentro do ambiente de contratação regulada (preços dinâmicos), levando em consideração tanto para os compradores quanto para os vendedores que utilizam diferentes medidas de eficiência energética.

\section{1. Funcionamento do Leilão de Eficiência Energética}

Para contextualizar o funcionamento do Leilão de eficiência energética, se levará em consideração um exemplo do mercado de energia, que estará composto por três consumidores livres e duas distribuidoras de energia, ambas as partes consumindo um total de $2.000 \mathrm{MW}$ med no ano t. O mercado contará com seis usinas geradoras que suprirão os consumidores (consumidores livres e distribuidores). Esse exemplo foi retirado da tese de Calili (2013) que ilustra o funcionamento do mercado de energia no Brasil na ocorrência de um possível Leilão de Eficiência Energética. A tabela 1 mostra o exemplo didático no tempo t. De maneira didática, não se considerou as perdas na rede (técnicas e comerciais). 
Tabela 1: Geração total, preços e arranjo contratual no ano t

\begin{tabular}{|c|c|c|c|c|c|c|c|c|c|c|c|c|}
\hline \multicolumn{13}{|l|}{ Tempot } \\
\hline & Demanda & Energia Gerada & Preço & Custo & Contratos & & & & & & & \\
\hline & Consumidor livre 1 & 100 & 120 & 12000 & Energia Gerada & Usina 1 & Usina 2 & Usina 3 & Usina 4 & Usina 5 & Usina 6 & \\
\hline & Consumidor livre 2 & 200 & 110 & 22000 & Consumidor livre 1 & & & & & 100 & & 100 \\
\hline & Consumidor livre 3 & 300 & 100 & 30000 & \begin{tabular}{|l|} 
Consumidor livre 2 \\
\end{tabular} & & 200 & & & & & 200 \\
\hline & Distribuidora 1 & 100 & 90 & 9000 & \begin{tabular}{|l|} 
Consumidor livre 3 \\
\end{tabular} & & & 300 & & & & 300 \\
\hline & 800 & 300 & 110 & 33000 & Distribuidora 1 & 100 & & & 300 & 400 & & 800 \\
\hline & & 400 & 120 & 48000 & \begin{tabular}{|l|} 
Distribuidora 2 \\
\end{tabular} & & & & 100 & & 500 & 600 \\
\hline & Distribuidora 2 & 100 & 110 & 11000 & & 100 & 200 & 300 & 400 & 500 & 500 & \\
\hline & 600 & 500 & 100 & 50000 & & & & & & & & \\
\hline & Total Mercado & 2000 & & 215000 & & & & & & & & \\
\hline & & & & & Monetário & Usina 1 & Usina 2 & Usina 3 & Usina 4 & Usina 5 & Usina 6 & \\
\hline & Suprimento & Energia Gerada & Preço & Receita & \begin{tabular}{|l|} 
Consumidor livre 1 \\
\end{tabular} & & & & & 12000 & & 12000 \\
\hline & Gerador 1 & 100 & 90 & 9000 & \begin{tabular}{|l|} 
Consumidor livre 2 \\
\end{tabular} & & 22000 & & & & & 22000 \\
\hline & Gerador 2 & 200 & 110 & 22000 & \begin{tabular}{|l|} 
Consumidor livre 3 \\
\end{tabular} & & & 30000 & & & & 30000 \\
\hline & Gerador 3 & 300 & 100 & 30000 & \begin{tabular}{|l|} 
Distribuidora 1 \\
\end{tabular} & 9000 & & & 33000 & 48000 & & 90000 \\
\hline & Gerador 4 & 400 & 110 & 44000 & \begin{tabular}{|l|} 
Distribuidora 2 \\
\end{tabular} & & & & 11000 & & 50000 & 61000 \\
\hline & Gerador 5 & 500 & 120 & 60000 & & 9000 & 22000 & 30000 & 44000 & 60000 & 50000 & \\
\hline & Gerador 6 & 500 & 100 & 50000 & & & & & & & & \\
\hline & Total Suprimento & 2000 & & 215000 & & & & & & & & \\
\hline & Preço médio & 107,50 & & & & & & & & & & \\
\hline
\end{tabular}

Fonte: Adaptada de (Calili, 2013) 
Deste modo os preços de energia que o mercado da demanda pagará, serão fixados pelos preços de energia que cada gerador decide vender através dos contratos estabelecidos. Assim mesmo, os contratos ficarão estabelecidos entre os geradores e o mercado da demanda igualando a energia demandada e a energia suprida como pode ser observado na tabela 1.

Na tabela 2 observa-se que o mercado de energia cresceu em um tempo $t+1$, ou seja, o consumo de energia aumentou neste mercado. Assim, o consumo passou de 2000 MW med para 2100 MW med., levando em consideração que o mercado observado na tabela não faz o uso de eficiência energética.

Ademais, o consumidor livre 1 passou de $100 \mathrm{MW}$ med para $120 \mathrm{MW}$ med (20\% de crescimento), o consumidor livre 3, passou de $300 \mathrm{MW}$ med para 330 MW med (10\% de crescimento), a distribuidora 1 passou de 800 MW med para $820 \mathrm{MW}$ med (2,5\% de crescimento), e a distribuidora 2 passou de $600 \mathrm{MW}$ med para $630 \mathrm{MW}$ med (5\% de crescimento).

Entretanto, para suprir a nova necessidade de energia, sem o uso de eficiência energética, se construíram 2 (Gerador 7 e 8) novos geradores. Além disso, se observa que o preço da energia também aumenta quando comparado aos outros geradores.

Também se observa os diferentes contratos estabelecidos entre geradores e consumidores, igualando a quantidade de energia e o preço que requer cada um entre ambas as partes.

Assim, percebe-se que o preço médio tem um aumento de 1,2\% em comparação ao preço médio no ano $\mathrm{t}$ (preço ano $\mathrm{t}=107,50$; preço ano $\mathrm{t}+1=$ 108,76). Em termos gerais o mercado em $\mathrm{t}+1$ aumentou em um 5\% quando comparado com o mercado do tempo t. 
Tabela 2: Geração total, preços e arranjo contratual no ano $t+1$ sem EE

\begin{tabular}{|c|c|c|c|c|c|c|c|c|c|c|c|c|c|c|}
\hline \multicolumn{15}{|c|}{ Tempo $t+1$ sem EE } \\
\hline & & Energia Gerada & Preço & Custo & Contratos & & & & & & & & & \\
\hline & \multirow{2}{*}{ Consumidor livre 1} & 100 & 120 & 12000 & Energia Gerada & Usina 1 & Usina 2 & Usina 3 & Usina 4 & Usina 5 & Usina 6 & Usina 7 & Usina 8 & \\
\hline & & 20 & 140 & 2800 & Consumidor livre 1 & & & & & 100 & & 20 & & 120 \\
\hline & \multirow{3}{*}{\begin{tabular}{|l} 
Consumidor live 2 \\
Consumidor livre 3
\end{tabular}} & 200 & 110 & 22000 & \begin{tabular}{|l} 
Consumidor livre 2 \\
\end{tabular} & & 200 & & & & & & & 200 \\
\hline & & 300 & 100 & 30000 & Consumidor livre 3 & & & 300 & & & & & 30 & 330 \\
\hline & & 30 & 130 & 3900 & \begin{tabular}{|l|} 
Distribuidora 1 \\
\end{tabular} & 100 & & & 300 & 400 & & 20 & & 820 \\
\hline & \multirow[t]{4}{*}{ Distribuidora 1} & 100 & 90 & 9000 & \begin{tabular}{|l|} 
Distribuidora 2 \\
\end{tabular} & & & & 100 & & 500 & & 30 & 630 \\
\hline & & 300 & 110 & 33000 & & 100 & 200 & 300 & 400 & 500 & 500 & 40 & 60 & \\
\hline & & 400 & 120 & 48000 & & & & & & & & & & \\
\hline & & 20 & 140 & 2800 & & & & & & & & & & \\
\hline & \multirow[t]{3}{*}{ Distribuidora 2} & 100 & 110 & 11000 & Monetário & Usina 1 & Usina 2 & Usina 3 & Usina 4 & Usina 5 & Usina 6 & Usina 7 & Usina 8 & \\
\hline & & 500 & 100 & 50000 & Consumidor livre 1 & & & & & 12000 & & 2800 & & 14800 \\
\hline & & 30 & 130 & 3900 & Consumidor livre 2 & & 22000 & & & & & & & 22000 \\
\hline & \multirow[t]{2}{*}{ Total Mercado } & 2100 & & 228400 & Consumidor livre 3 & & & 30000 & & & & & 3900 & 33900 \\
\hline & & & & & Distribuidora 1 & 9000 & & & 33000 & 48000 & & 2800 & & 92800 \\
\hline & Suprimento & Energia Gerada & Preço & Receita & \begin{tabular}{|l|} 
Distribuidora 2 \\
\end{tabular} & & & & 11000 & & 50000 & & 3900 & 64900 \\
\hline & Gerador 1 & & 90 & 9000 & & 9000 & 22000 & 30000 & 44000 & 60000 & 50000 & 5600 & 7800 & \\
\hline & Gerador 2 & 200 & 110 & 22000 & & & & & & & & & & \\
\hline & Gerador 3 & 300 & 100 & 30000 & & & & & & & & & & \\
\hline & Gerador 4 & 400 & 110 & 44000 & & & & & & & & & & \\
\hline & Gerador 5 & 500 & 120 & 60000 & & & & & & & & & & \\
\hline & Gerador 6 & 500 & 100 & 50000 & & & & & & & & & & \\
\hline \multirow{4}{*}{$\begin{array}{l}\text { Nova } \\
\text { Nova }\end{array}$} & Gerador 7 & 40 & 140 & 5600 & \multicolumn{2}{|c|}{ Expansão do sistema elétrico } & Energia Gerad & & \multirow{3}{*}{\multicolumn{2}{|c|}{140}} & & & & \\
\hline & Gerador 8 & 60 & 130 & 7800 & & & & & & & & & & \\
\hline & Total Suprimento & 2100 & & 228400 & Preço médio & 108,76 & & & & & & & & \\
\hline & Preço médio & 108,76 & $1,2 \%$ & & & & & & & & & & & \\
\hline
\end{tabular}

Fonte: Adaptada de (Calili, 2013) 
Tabela 3: Geração total, preços e arranjo contratual no ano $t+1$ com EE (Real)

\begin{tabular}{|c|c|c|c|c|c|c|c|c|c|c|c|c|c|c|}
\hline \multirow{2}{*}{$\begin{array}{l}\text { Tempo tt+ } \\
\text { Real }\end{array}$} & \multicolumn{14}{|l|}{ com EE } \\
\hline & \multicolumn{2}{|l|}{ Demanda } & Energia Gerada & Preço & Custo & Contratos & \multirow[b]{2}{*}{ Usina 1} & \multirow[b]{2}{*}{ Usina 2} & \multirow[b]{2}{*}{ Usina 3} & \multirow[b]{2}{*}{ Usina 4} & \multirow[b]{2}{*}{ Usina 5} & \multirow[b]{2}{*}{ Usina 6} & & \multirow[b]{2}{*}{ Usina 8} \\
\hline & \multirow{2}{*}{\multicolumn{2}{|c|}{ Consumidor livre 1}} & 100 & 120 & 12000 & Energia Gerada & & & & & & & & \\
\hline & & & 20 & 110 & 2200 & \begin{tabular}{|l} 
Consumidor livre 1 \\
\end{tabular} & & 20 & & & 100 & & & \\
\hline & Consumidor livre 2 & & 160 & 110 & 17600 & \begin{tabular}{|l} 
Consumidor livre 2 \\
\end{tabular} & & 160 & & & & & & \\
\hline & \multirow{2}{*}{\multicolumn{2}{|c|}{ Consumidor livre 3}} & 300 & 100 & 30000 & \begin{tabular}{|l|} 
Consumidor livre 3 \\
\end{tabular} & & & 300 & & & & & 30 \\
\hline & & & 30 & 130 & 3900 & \begin{tabular}{|l|} 
Distribuidora 1 \\
\end{tabular} & 100 & 20 & & 300 & 400 & & & \\
\hline & \multirow[t]{4}{*}{ Distribuidora 1} & & 100 & 90 & 9000 & \begin{tabular}{|l} 
Distribuidora 2 \\
\end{tabular} & & & & 100 & & 500 & & 30 \\
\hline & & \multirow[t]{3}{*}{820} & 300 & 110 & 33000 & & 100 & 200 & 300 & 400 & 500 & 500 & 0 & 60 \\
\hline & & & 400 & 120 & 48000 & & & & & & & & & \\
\hline & & & 20 & 110 & 2200 & & & & & & & & & \\
\hline & \multirow[t]{3}{*}{ Distribuidora 2} & & 100 & 110 & 11000 & Monetário & Usina 1 & Usina 2 & Usina 3 & Usina 4 & Usina 5 & Usina 6 & & Usina 8 \\
\hline & & \multirow[t]{2}{*}{630} & 500 & 100 & 50000 & \begin{tabular}{|l} 
Consumidor livre 1 \\
\end{tabular} & & 2200 & & & 12000 & & & \\
\hline & & & 30 & 130 & 3900 & \begin{tabular}{|l} 
Consumidor livre 2 \\
\end{tabular} & & 17600 & & & & & & \\
\hline & \multirow[t]{2}{*}{ Total Mercado } & & 2060 & & 222800 & \begin{tabular}{|l} 
Consumidor livre 3 \\
\end{tabular} & & & 30000 & & & & & 3900 \\
\hline & & & & & & \begin{tabular}{|l} 
Distribuidora 1 \\
\end{tabular} & 9000 & 2200 & & 33000 & 48000 & & & \\
\hline & Suprimento & & Energia Gerada & Preço & Receita & \begin{tabular}{|l|} 
Distribuidora 2 \\
\end{tabular} & & & & 11000 & & 50000 & & 3900 \\
\hline & Gerador 1 & & 100 & 90 & 9000 & & 9000 & 22000 & 30000 & 44000 & 60000 & 50000 & & 7800 \\
\hline & Gerador 2 & & 200 & 110 & 22000 & & & & & & & & & \\
\hline & Gerador 3 & & 300 & 100 & 30000 & & & & & & & & & \\
\hline & Gerador 4 & & 400 & 110 & 44000 & \multicolumn{9}{|c|}{ Gerador 2 vai continuar a gerar a mesma quantidade de Energia Gerada, que continuará a ser comprada pelo Consumidor Livre 2.} \\
\hline & Gerador 5 & & 500 & 120 & 60000 & \multirow{2}{*}{\multicolumn{2}{|c|}{ 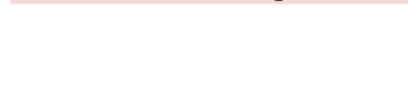 }} & & & & \multicolumn{3}{|c|}{ mprada pelo Consumidor Livre 2.} & \\
\hline & \multirow{2}{*}{\multicolumn{2}{|c|}{ Gerador 8}} & 500 & 100 & 50000 & & & & & & & & & \\
\hline \multirow[t]{4}{*}{ Nova } & & & 60 & 130 & 7800 & \multirow{2}{*}{\multicolumn{2}{|c|}{ Expansão do sistema elétrico }} & & & & & & & \\
\hline & \multirow{2}{*}{\multicolumn{2}{|c|}{ Total Suprimento }} & 2060 & & 222800 & & & & & & & & & \\
\hline & & & & & & Preço médio & 108,16 & & Ganho para a & dade & 0,61 & & & \\
\hline & Preço médio & & 108,16 & $0,6 \%$ & & & & & & & & & & \\
\hline
\end{tabular}

Fonte: Adaptada de (Calili, 2013) 
Depois de ter analisado o mercado sem eficiência energética, a tabela 3 apresenta o mesmo mercado, mas com o uso de eficiência energética, neste contexto se mostrará 2 cenários que o Leilão de eficiência energética propõe: ambiente real e ambiente virtual. Na tabela a seguir, pode-se verificar o comportamento dos participantes no ambiente real.

No mesmo tempo $t+1$, se observa que o Consumidor Livre 2 conseguiu reduzir o seu consumo de energia até $160 \mathrm{MW}$ med, é dizer, diminuiu $40 \mathrm{MW}$ med dos 200 MW med que tinha, através do uso de medidas de eficiência energética. É importante observar que a diferença deste mercado em relação ao mercado sem eficiência energética é que se conseguiu evitar a construção do gerador 7, mostrado na tabela 2. Ademais, o preço médio diminuiu ( $\mathrm{R} \$ 108,16)$ em comparação ao mercado sem eficiência energética ( $\mathrm{R}$ \$ 108,76), mostrando assim que existe um ganho com eficiência energética. Espera-se que isto aconteça no mercado real que é proposto pelo leilão de eficiência energética. Da mesma maneira, os contratos ficam igualados segundo a energia demandada e a energia suprida pelos diferentes participantes.

Assim, se analisará o mercado usando eficiência energética no ambiente virtual, que é o ambiente no qual se analisa como o consumidor que consegue economizar a energia pode vendê-la aos demais consumidores.

Como se observa na tabela 4 , o Consumidor livre 2 reduz o seu consumo a 160 MW med, economizando $40 \mathrm{MW}$ med, o que poderia vender tanto ao consumidor livre 1 quanto à distribuidora 1, já que ambos aumentaram seu consumo de energia. Se levará em consideração que o contrato que o consumidor livre 2 tinha com o gerador 2 ainda continua, isso não tem sido modificado apesar da redução do consumo. Sendo assim, o consumidor livre 2 tem que levar em conta o preço que deverá usar na hora de vender a energia que conseguiu economizar. Terá que analisar que o preço ideal que poderia usar para vender a energia deve ser maior do que o preço contratado com o gerador 2 (preço piso $\mathrm{R} \$ 110,00)$ e também deve considerar que o preço que ele tenta usar tem que ser menor do que o preço que demanda construir o gerador 7 ( $\mathrm{R} \$ 140,00)$. Deste modo o consumidor 2 obterá ganho na hora de vender a energia. Segundo o exemplo utilizado o preço que o consumidor livre 2 está utilizando é de $\mathrm{R} \$ 125,00$ por MWh (valor da energia entre R\$ 110,00 e R\$ 140,00 o MWh). 
Tabela 4: Geração total, preços e arranjo contratual no ano $t+1$ com EE (Virtual)

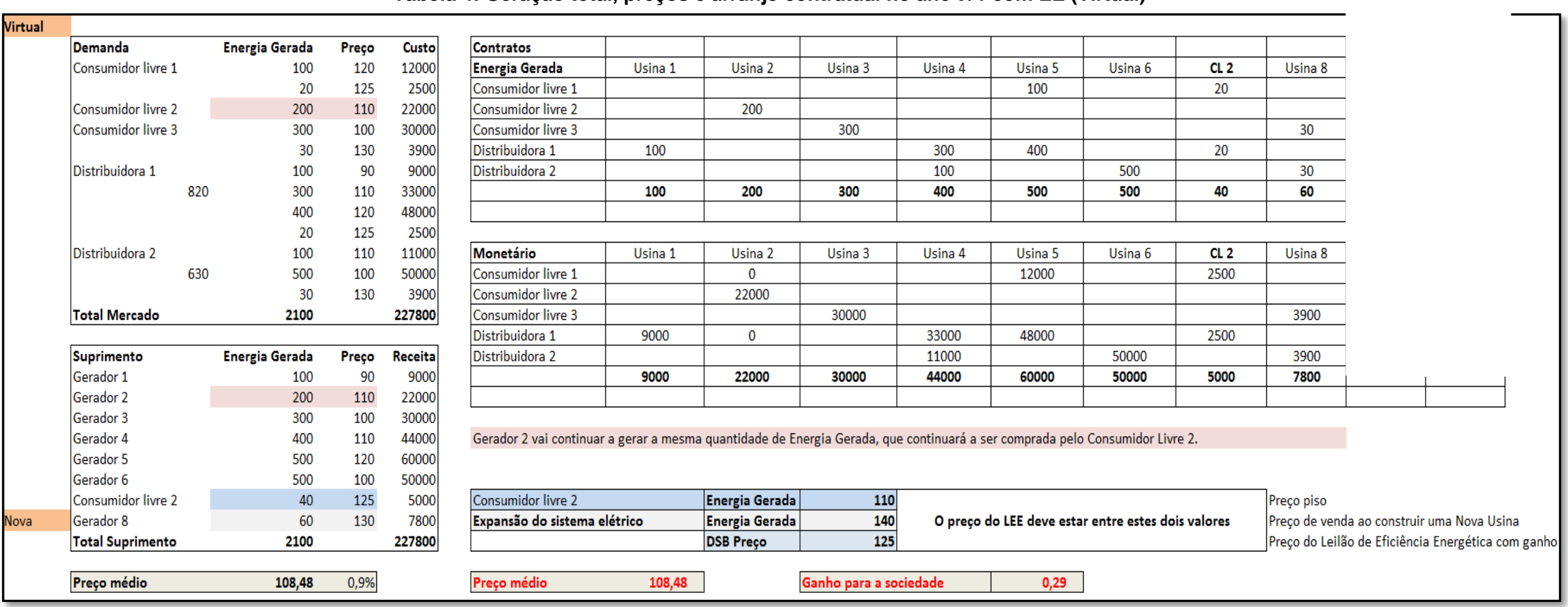

Fonte: Adaptada de (Calili, 2013) 
Também pode se observar que o preço médio diminuiu para $\mathrm{R} \$ 108,48 \mathrm{em}$ comparação ao preço médio do mercado sem o uso de eficiência energética $(\mathrm{R} \$ 108,76)$.

Tudo indica que o uso da eficiência energética, como propõe o Leilão de Eficiência Energética, traz ganho para a sociedade, não só em termos econômicos, mas também em termos ambientais.

\section{2.}

\section{Resultados das rodadas para o ambiente regulado}

Para conseguir obter os resultados mais importantes, teve-se que trabalhar com algumas correções do preço de venda (PLD) aplicando a inflação desde o ano que começaram os leilões no Brasil. Neste caso, se aplicou a inflação sobre os preços desde o ano 2005 até 2014. A seguir, na tabela 5 mostra o comportamento dos preços antes de aplicar a inflação, índice geral de preços do mercado (IPG-M), desde o começo dos leilões, e a figura 17 mostra o histograma.

Tabela 5: Preços sem inflação

\begin{tabular}{ccc}
\hline Data & Preço de Venda (R\$/MWh) & Total dos dados \\
\hline $16 / 12 / 2005-06 / 06 / 2014$ & $58,35-154,49$ & 322 \\
\hline
\end{tabular}

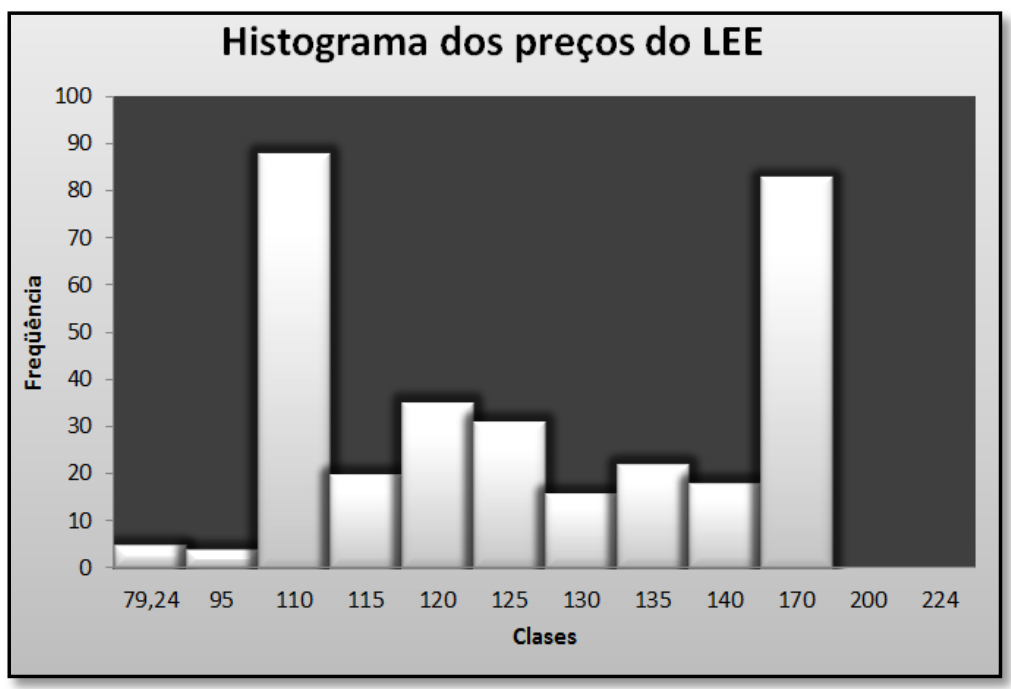

Figura 17: Histograma dos dados originais sem aplicar a inflação

Além disso, se realizou a análise descritiva dos preços dos leilões ocorrido no Brasil de 2005 a 2014, na tabela 6 pode se observar os resultados. 
Tabela 6: Análise descritiva do preço sem inflação

\begin{tabular}{ll}
\hline & Preço de venda (R\$/MW) \\
\hline \hline Média & 123,64 \\
Erro padrão & 1,10 \\
Mediana & 121,25 \\
Moda & 116,00 \\
Desvio padrão & 19,78 \\
Variância da amostra & 391,25 \\
Curtose & $-0,70$ \\
Assimetria & $-0,11$ \\
Intervalo & 96,14 \\
Mínimo & 58,35 \\
Máximo & 154,49 \\
Soma & 39813,49 \\
Contagem & 322 \\
\hline
\end{tabular}

Na tabela 7, se observará como se comportaram os dados depois de ter aplicado o índice de inflação aos preços que serão simulados.

Tabela 7: Preços com inflação

\begin{tabular}{|c|c|c|}
\hline Data & Preço de Venda (R\$/MWh) & Total dos dados \\
\hline $16 / 12 / 2005-06 / 06 / 2014$ & $79,24-223,01$ & 322 \\
\hline
\end{tabular}

Ademais, se realizou a análise descritiva dos preços de energia que permitirão obter as diferentes simulações para avaliar o comportamento de um possível preço do Leilão de eficiência energética, a seguir pode se observar os resultados obtidos.

Tabela 8: Análise descritiva do preço sem inflação

\begin{tabular}{ll}
\hline & Preço de venda (R\$/MWh) \\
\hline \hline Média & 162,08 \\
Erro padrão & 2,12 \\
Mediana & 165,92 \\
Moda & 114,11 \\
Desvio padrão & 38,02 \\
Variância da amostra & 1445,16 \\
Curtose & $-1,63$ \\
Assimetria & $-0,10$ \\
Intervalo & 143,77 \\
Mínimo & 79,24 \\
Máximo & 223,01 \\
Soma & 52188,92 \\
Contagem & 322 \\
\hline
\end{tabular}


Analisando os diferentes cenários de simulação de preços se observa que a proposta inicial faz sentido em relação ao preço de venda da energia economizada utilizando eficiência energética. Neste caso, se analisou o comportamento dos preços em função dos intervalos de interesse, especificamente, os preços compreendidos entre R\$ 110 e R\$ 140 MWh.

A seguir se observa, na figura 18, o histograma dos preços de energia corrigidos, é dizer, aqueles preços sobre os quais se aplicou a inflação desde o mesmo ano que começaram os diferentes leilões, o mesmo que representa o comportamento dos dados classificados.

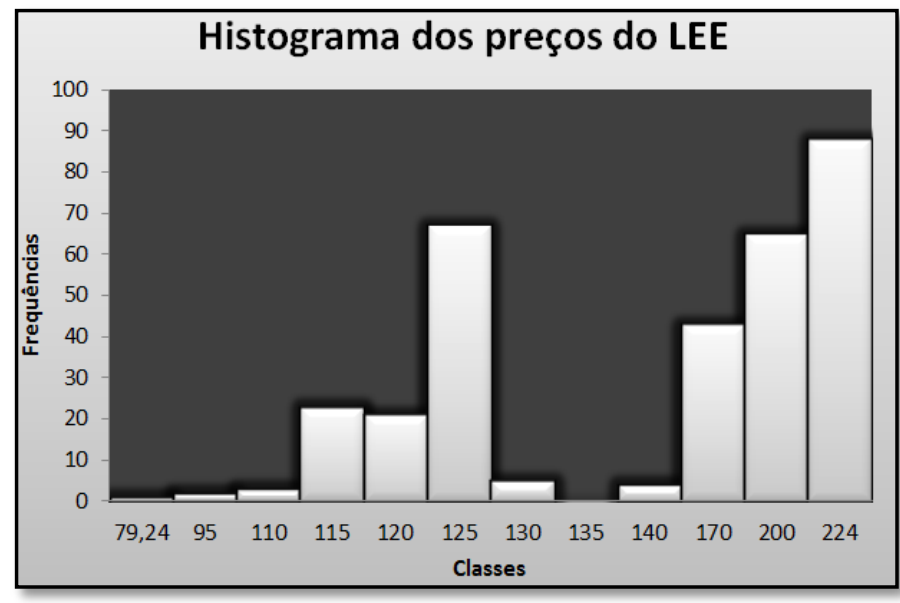

Figura 18: Histograma dos dados originais aplicando a inflação

Conforme se observa na figura 18 e na tabela 9, se realizou uma distribuição de frequências para analisar e identificar os preços de leilões que estariam entre $\mathrm{R} \$ 110$ e R\$ $140 \mathrm{MWh}$ segundo a proposta de (Calili, 2013).

Tabela 9: Resultados dos preços originais

\begin{tabular}{cccc}
\hline Classes & Contagem & Probabilidade & $\%$ \\
\hline \hline 79.24 & 1 & 0.0031 & $0.31 \%$ \\
95 & 2 & 0,0062 & $0,62 \%$ \\
\hline 110 & 3 & 0,0093 & $0,93 \%$ \\
115 & 23 & 0.0714 & $7.14 \%$ \\
120 & 21 & 0,0652 & $6,52 \%$ \\
125 & 67 & 0,2081 & $20,81 \%$ \\
130 & 5 & 0,0155 & $1,55 \%$ \\
135 & 0 & 0,0000 & $0,00 \%$ \\
-140 & 4 & 0,0124 & $1.24 \%$ \\
170 & 43 & 0.1335 & $13.35 \%$ \\
200 & 43 & 0,2019 & $20,19 \%$ \\
224 & 65 & 0,2733 & $27,33 \%$ \\
\hline & 88 & 1 & $100 \%$ \\
\hline
\end{tabular}


Deste modo, se consegue visualizar o comportamento dos dados, que aparentemente não descrevem nenhuma distribuição tradicional para poder ajustar a função de densidade. Sendo esse o contexto, através do método não paramétrico de Kernel, se conseguiu ajustar a uma função de densidade com polinômio da ordem 17. A seguir se observa a figura que descreve melhor a função obtida.

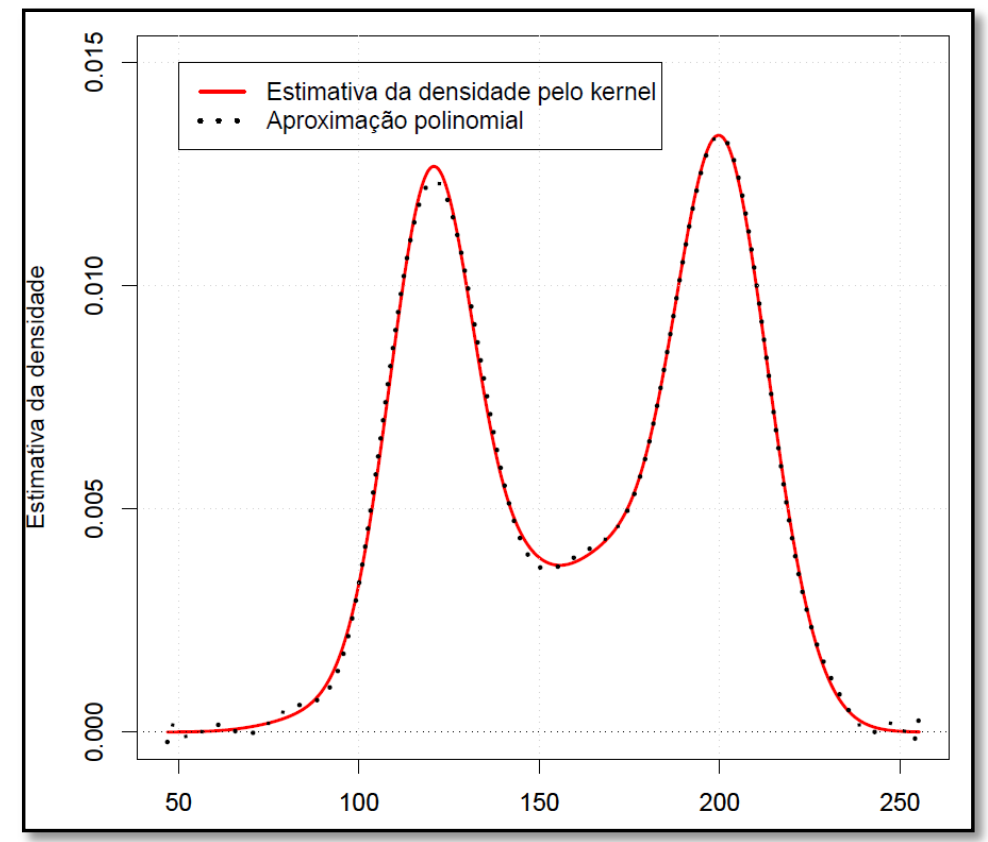

Figura 19: Estimativa da densidade pelo Kernel

Com a estimativa conseguida, resultam mais simples poder adequar o comportamento dos dados e gerar simulações seguindo a ordem do polinômio. Além disso, foram geradas algumas amostras de diversos tamanhos para ver as ligeiras diferenças existentes, levando em consideração que, neste caso, quanto maior é a amostra melhor é a aproximação com os dados originais.

Nesse aspecto, é importante mencionar que tanto o uso do método Kernel quanto o uso do MCMC são determinantes e conseguem se ajustar muito bem para fornecer aproximações dos dados originais e analisar claramente o impacto que tem as amostras ao ser analisadas. A seguir, se observa o comportamento dos dados em cada histograma com amostras de 500, 1000, 5000, 10000, considerando somente um cenário, já que não existirá muita diferença à medida que o tamanho vai crescendo (neste caso um cenário é composto por rodadas de 500, 1000, 5000 e 10000). 


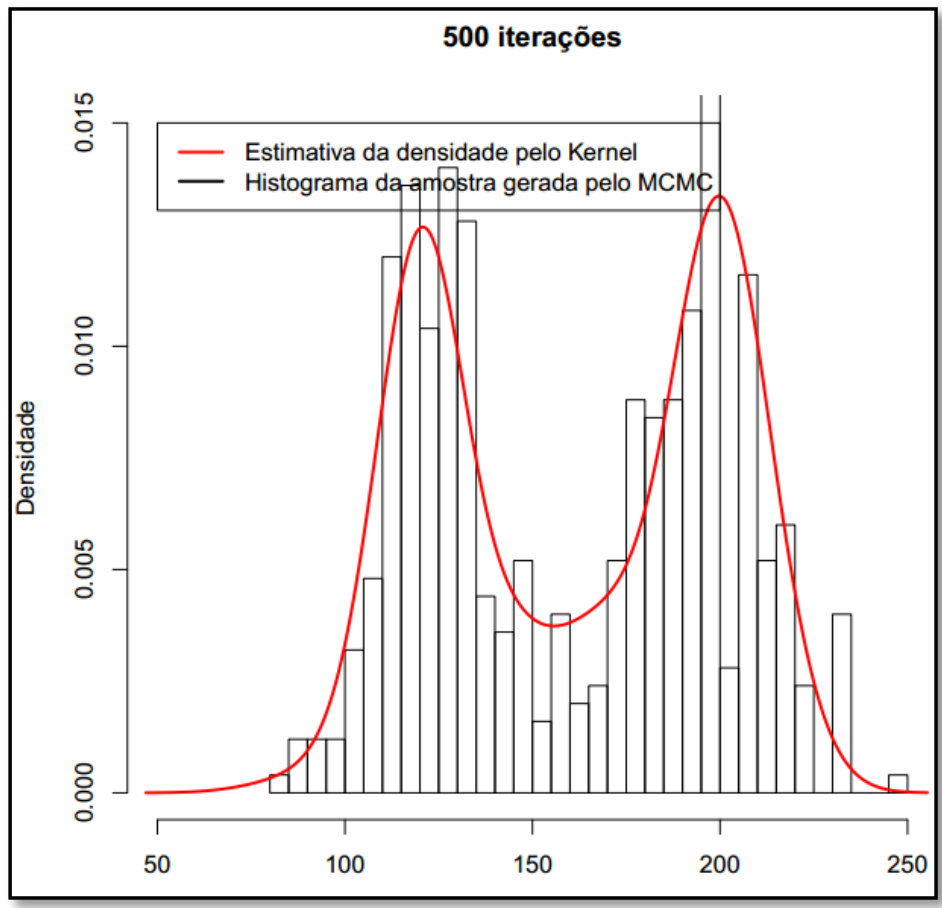

Figura 20: Histograma com Kernel e MCMC de 500 iterações

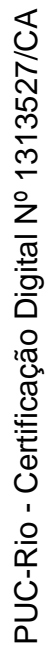

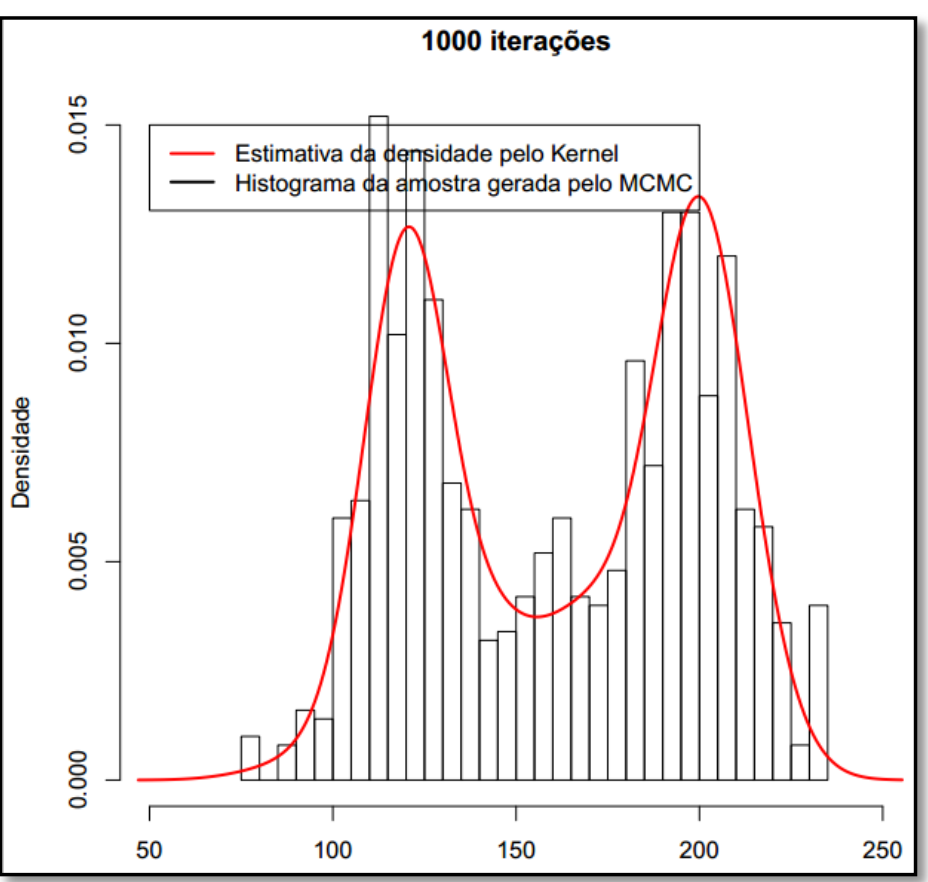

Figura 21: Histograma com Kernel e MCMC de 1000 iterações 


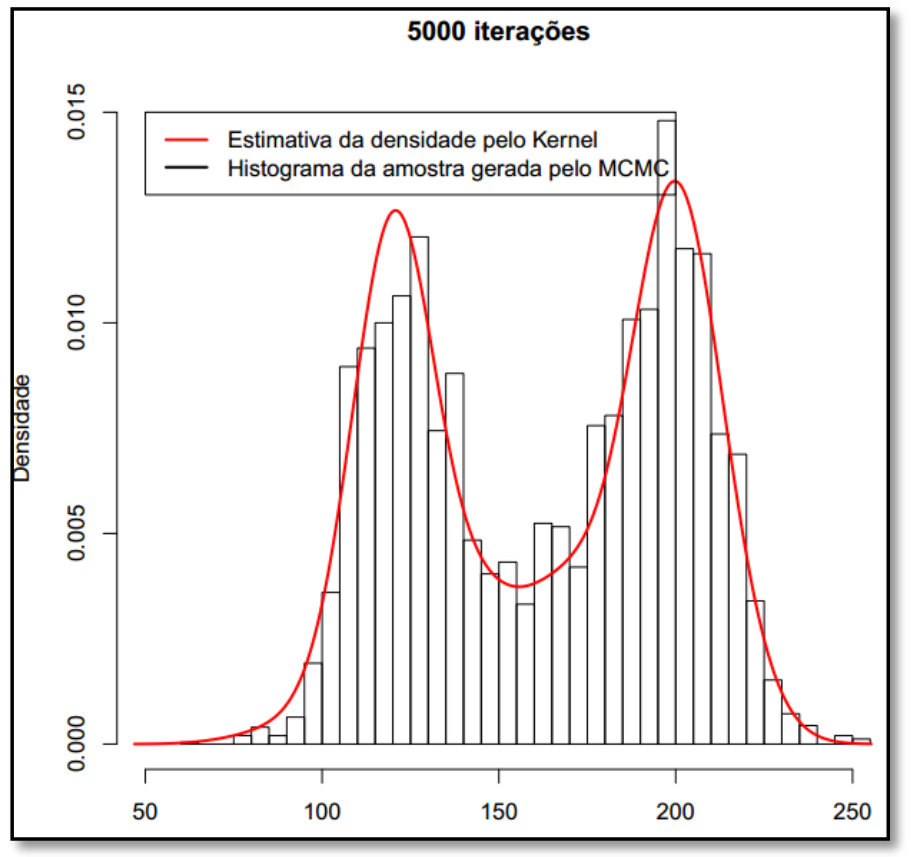

Figura 22: Histograma com Kernel e MCMC de 5000 iterações

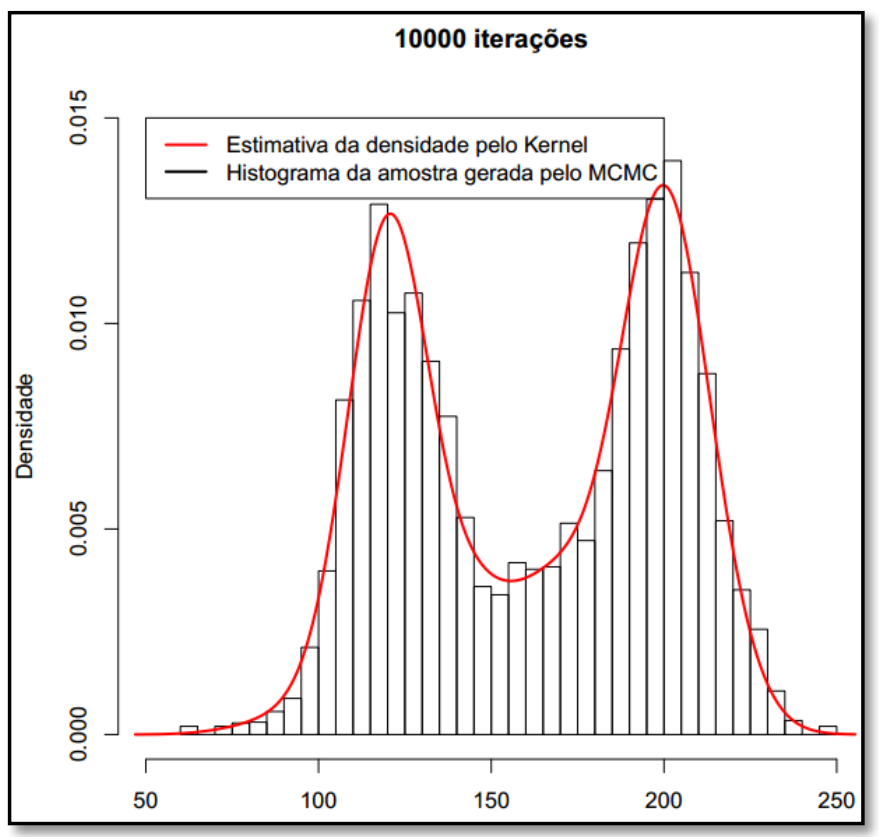

Figura 23: Histograma com Kernel e MCMC de 10000 iterações

Observa-se que a amostra que melhor se aproxima aos dados originais segundo os histogramas gerados, é a de tamanho 10000, apresentando consistência e proximidade no comportamento dos dados. A seguir se apresentam diferentes cenários com amostras de 500, 1000, 5000 e 10000 que foram geradas com o MCMC, e se analisam os resultados conseguidos em cada um. 
Tabela 10: Cenário 1 (A500)

\begin{tabular}{lr}
\hline \multicolumn{2}{c}{ Preços } \\
\hline \hline \\
Média & $\mathbf{1 6 6 , 1 7 3}$ \\
Erro padrão & 1,650 \\
Mediana & 178,297 \\
Moda & 189,354 \\
Desvio padrão & $\mathbf{3 6 , 8 9 9}$ \\
Variância da amostra & 1361,560 \\
Curtose & $-1,316$ \\
Assimetria & $-0,299$ \\
Intervalo & 161,689 \\
Mínimo & 86,094 \\
Máximo & 247,783 \\
Soma & 83086,584 \\
Contagem & $\mathbf{5 0 0}$ \\
\hline & $27,80 \%$
\end{tabular}

Tabela 11: Cenário 1 (A1000)

\begin{tabular}{lr}
\hline \multicolumn{2}{c}{ Preço } \\
\hline \hline \\
Média & $\mathbf{1 6 7 , 2 5 9}$ \\
Erro padrão & 1,258 \\
Mediana & 179,842 \\
Moda & 220,362 \\
Desvio padrão & $\mathbf{3 9 , 7 6 6}$ \\
Variância da amostra & 1581,360 \\
Curtose & $-1,315$ \\
Assimetria & $-0,252$ \\
Intervalo & 161,572 \\
Mínimo & $\mathbf{7 4 , 0 4 3}$ \\
Máximo & 235,616 \\
Soma & 167259,12 \\
Contagem & $\mathbf{1 0 0 0}$ \\
\hline & $26,10 \%$
\end{tabular}

Tabela 12: Cenário 1 (A5000)

\begin{tabular}{lr}
\hline \multicolumn{2}{c}{ Preços } \\
\hline \hline \\
Média & $\mathbf{1 6 2 , 6 4 8}$ \\
Erro padrão & 0,550 \\
Mediana & 167,194 \\
Moda & 133,964 \\
Desvio padrão & $\mathbf{3 8 , 8 9 7}$ \\
Variância da amostra & 1512,965 \\
Curtose & $-1,366$ \\
Assimetria & $-0,111$ \\
Intervalo & 189,658 \\
Mínimo & 59,317 \\
Máximo & 248,975 \\
Soma & 813238,085 \\
Contagem & $\mathbf{5 0 0 0}$ \\
\hline & $29,66 \%$
\end{tabular}

Tabela 13: Cenário 1 (A10000)

\begin{tabular}{lr}
\hline \multicolumn{2}{c}{ Preços } \\
\hline \hline \\
Média & $\mathbf{1 6 2 , 3 2 2}$ \\
Erro padrão & 0,400 \\
Mediana & 168,218 \\
Moda & 128,898 \\
Desvio padrão & $\mathbf{4 0 , 0 3 7}$ \\
Variância da amostra & 1602,959 \\
Curtose & $-1,364$ \\
Assimetria & $-0,134$ \\
Intervalo & 200,213 \\
Mínimo & 49,295 \\
Máximo & 249,508 \\
Soma & 1623223,601 \\
Contagem & $\mathbf{1 0 0 0 0}$ \\
\hline & $30,86 \%$
\end{tabular}

Como se observa no cenário 1 , os resultados que mais se aproximam aos originais é amostra de tamanho 10000 (preço médio próximo do original). 
Tabela 14: Cenário 2 (A500)

\begin{tabular}{lr}
\hline \multicolumn{2}{c}{ Preços } \\
\hline \hline \\
Média & $\mathbf{1 6 5 , 9 0 3}$ \\
Erro padrão & 1,677 \\
Mediana & 176,189 \\
Moda & 174,991 \\
Desvio padrão & $\mathbf{3 7 , 4 9 3}$ \\
Variância da amostra & 1405,709 \\
Curtose & $-1,248$ \\
Assimetria & $-0,195$ \\
Intervalo & 156,906 \\
Mínimo & 79,403 \\
Máximo & 236,310 \\
Soma & 82951,696 \\
Contagem & $\mathbf{5 0 0}$ \\
\hline & $28,60 \%$
\end{tabular}

Tabela 15: Cenário 2 (A1000)

\begin{tabular}{lr}
\hline \multicolumn{2}{c}{ Preços } \\
\hline \hline \\
Média & $\mathbf{1 5 8 , 8 8 4}$ \\
Erro padrão & 1,249 \\
Mediana & 155,815 \\
Moda & 127,562 \\
Desvio padrão & $\mathbf{3 9 , 4 9 1}$ \\
Variância da amostra & 1559,574 \\
Curtose & $-1,600$ \\
Assimetria & 0,016 \\
Intervalo & 143,453 \\
Mínimo & 82,232 \\
Máximo & 225,685 \\
Soma & 158884,245 \\
Contagem & $\mathbf{1 0 0 0}$ \\
\hline & $31,40 \%$
\end{tabular}

Tabela 16: Cenário 2 (A5000)

\begin{tabular}{lr}
\hline \multicolumn{2}{c}{ Preços } \\
\hline \hline \\
Média & $\mathbf{1 6 3 , 0 6 2}$ \\
Erro padrão & 0,565 \\
Mediana & 171,710 \\
Moda & 128,805 \\
Desvio padrão & $\mathbf{3 9 , 9 5 6}$ \\
Variância da amostra & 1596,520 \\
Curtose & $-1,419$ \\
Assimetria & $-0,096$ \\
Intervalo & 193,178 \\
Mínimo & 57,567 \\
Máximo & 250,745 \\
Soma & 815311,808 \\
Contagem & $\mathbf{5 0 0 0}$ \\
\hline & $30,00 \%$
\end{tabular}

Tabela 17: Cenário 2 (A10000)

\begin{tabular}{lr}
\hline \multicolumn{2}{c}{ Preços } \\
\hline \hline \\
Média & $\mathbf{1 6 2 , 0 0 4}$ \\
Erro padrão & 0,396 \\
Mediana & 165,812 \\
Moda & 155,826 \\
Desvio padrão & $\mathbf{3 9 , 6 4 2}$ \\
Variância da amostra & 1571,485 \\
Curtose & $-1,394$ \\
Assimetria & $-0,074$ \\
Intervalo & 199,750 \\
Mínimo & 49,548 \\
Máximo & 249,297 \\
Soma & 1620038,976 \\
Contagem & $\mathbf{1 0 0 0 0}$ \\
\hline & $31,61 \%$
\end{tabular}

No cenário 2, os resultados que mais se aproximam aos originais é amostra de tamanho 10000, como aconteceu no cenário 1 (preço médio próximo do original). 
Tabela 18: Cenário 3 (A500)

\begin{tabular}{lr}
\hline \multicolumn{2}{c}{ Preços } \\
\hline \hline \\
Média & $\mathbf{1 6 0 , 7 1 2}$ \\
Erro padrão & 1,793 \\
Mediana & 173,796 \\
Moda & 191,623 \\
Desvio padrão & $\mathbf{4 0 , 0 9 6}$ \\
Variância da amostra & 1607,719 \\
Curtose & $-1,407$ \\
Assimetria & $-0,081$ \\
Intervalo & 170,003 \\
Mínimo & 77,491 \\
Máximo & 247,494 \\
Soma & 80355,864 \\
Contagem & $\mathbf{5 0 0}$ \\
\hline & $31,80 \%$
\end{tabular}

Tabela 19: Cenário 3 (A1000)

\begin{tabular}{lr}
\hline \multicolumn{2}{c}{ Preços } \\
\hline \hline \\
Média & $\mathbf{1 6 2 , 1 2 0}$ \\
Erro padrão & 1,185 \\
Mediana & 162,241 \\
Moda & 189,031 \\
Desvio padrão & $\mathbf{3 7 , 4 6 6}$ \\
Variância da amostra & 1403,710 \\
Curtose & $-1,349$ \\
Assimetria & $-0,072$ \\
Intervalo & 155,870 \\
Mínimo & 83,048 \\
Máximo & 238,919 \\
Soma & 162119,895 \\
Contagem & $\mathbf{1 0 0 0}$ \\
\hline & $29,10 \%$
\end{tabular}

Tabela 20: Cenário 3 (A5000)

\begin{tabular}{lr}
\hline \multicolumn{2}{c}{ Preços } \\
\hline \hline \\
Média & $\mathbf{1 6 2 , 3 1 0}$ \\
Erro padrão & 0,558 \\
Mediana & 165,919 \\
Moda & 192,470 \\
Desvio padrão & $\mathbf{3 9 , 4 5 1}$ \\
Variância da amostra & 1556,387 \\
Curtose & $-1,357$ \\
Assimetria & $-0,066$ \\
Intervalo & 192,594 \\
Mínimo & 57,969 \\
Máximo & 250,563 \\
Soma & 811552,210 \\
Contagem & $\mathbf{5 0 0 0}$ \\
\hline & $30,94 \%$
\end{tabular}

Tabela 21: Cenário 3 (A10000)

\begin{tabular}{lr}
\hline \multicolumn{2}{c}{ Preços } \\
\hline \hline \\
Média & $\mathbf{1 6 1 , 8 3 8}$ \\
Erro padrão & 0,396 \\
Mediana & 166,644 \\
Moda & 187,805 \\
Desvio padrão & 39,575 \\
Variância da amostra & 1566,156 \\
Curtose & $-1,365$ \\
Assimetria & $-0,100$ \\
Intervalo & 190,362 \\
Mínimo & 59,699 \\
Máximo & 250,061 \\
Soma & 1618383,842 \\
Contagem & $\mathbf{1 0 0 0 0}$ \\
\hline & $30,07 \%$
\end{tabular}

No cenário 3, os resultados que mais se aproximam aos originais é amostra de tamanho 1000 (preço médio próximo do original). 
Tabela 22: Cenário 4 (A500)

\begin{tabular}{lr}
\hline \multicolumn{2}{c}{ Preços } \\
\hline \hline Média & \\
Erro padrão & $\mathbf{1 6 2 , 2 1 2}$ \\
Mediana & 1,783 \\
Moda & 167,786 \\
Desvio padrão & 199,637 \\
Variância da amostra & $\mathbf{3 9 , 8 7 7}$ \\
Curtose & $-159,183$ \\
Assimetria & $-0,098$ \\
Intervalo & 150,453 \\
Mínimo & 87,873 \\
Máximo & 238,326 \\
Soma & 81105,769 \\
Contagem & $\mathbf{5 0 0}$ \\
\hline & $25,80 \%$
\end{tabular}

Tabela 23: Cenário 4 (A1000)

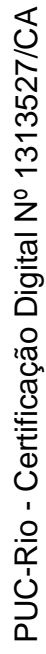

\begin{tabular}{lr}
\hline \multicolumn{2}{c}{ Preços } \\
\hline \hline Média & $\mathbf{1 6 3 , 3 6 1}$ \\
Erro padrão & 1,234 \\
Mediana & 165,521 \\
Moda & 215,580 \\
Desvio padrão & 39,014 \\
Variância da amostra & 1522,069 \\
Curtose & $-1,412$ \\
Assimetria & $-0,079$ \\
Intervalo & 156,687 \\
Mínimo & 79,090 \\
Máximo & 235,777 \\
Soma & 163361,487 \\
Contagem & $\mathbf{1 0 0 0}$ \\
\hline
\end{tabular}

Tabela 24: Cenário 4 (A5000)

\begin{tabular}{lr}
\hline \multicolumn{2}{c}{ Preços } \\
\hline Média & $\mathbf{1 6 0 , 1 7 0}$ \\
Erro padrão & 0,571 \\
Mediana & 160,841 \\
Moda & 108,244 \\
Desvio padrão & $\mathbf{4 0 , 4 0 1}$ \\
Variância da amostra & 1632,279 \\
Curtose & $-1,316$ \\
Assimetria & $-0,033$ \\
Intervalo & 199,559 \\
Mínimo & 49,793 \\
Máximo & 249,352 \\
Soma & 800847,827 \\
Contagem & $\mathbf{5 0 0 0}$ \\
\hline
\end{tabular}

Tabela 25: Cenário 4 (10000)

\begin{tabular}{lr}
\hline \multicolumn{2}{c}{ Preços } \\
\hline \hline Média & $\mathbf{1 6 2 , 7 0 0}$ \\
Erro padrão & 0,396 \\
Mediana & 168,390 \\
Moda & 199,569 \\
Desvio padrão & $\mathbf{3 9 , 5 8 1}$ \\
Variância da amostra & 1566,681 \\
Curtose & $-1,403$ \\
Assimetria & $-0,113$ \\
Intervalo & 178,133 \\
Mínimo & 58,262 \\
Máximo & 236,395 \\
Soma & 1626998,004 \\
Contagem & $\mathbf{1 0 0 0 0}$ \\
\hline & $29,88 \%$
\end{tabular}

No cenário 4, os resultados que mais se aproximam aos originais é amostra de tamanho 500 (preço médio próximo do original). 
Tabela 26: Cenário 5 (A500)

\begin{tabular}{lr}
\hline \multicolumn{2}{c}{ Preços } \\
\hline \hline \\
Média & $\mathbf{1 6 0 , 6 9 9}$ \\
Erro padrão & 1,718 \\
Mediana & 167,033 \\
Moda & 201,665 \\
Desvio padrão & $\mathbf{3 8 , 4 1 7}$ \\
Variância da amostra & 1475,869 \\
Curtose & $-1,468$ \\
Assimetria & $-0,048$ \\
Intervalo & 141,239 \\
Mínimo & 93,663 \\
Máximo & 234,902 \\
Soma & 80349,712 \\
Contagem & $\mathbf{5 0 0}$ \\
\hline & $34,60 \%$
\end{tabular}

Tabela 27: Cenário 5 (A1000)

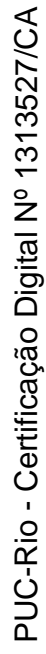

\begin{tabular}{lr}
\hline \multicolumn{2}{c}{ Preços } \\
\hline \hline \\
Média & $\mathbf{1 6 2 , 8 1 5}$ \\
Erro padrão & 1,254 \\
Mediana & 171,544 \\
Moda & 129,892 \\
Desvio padrão & $\mathbf{3 9 , 6 5 9}$ \\
Variância da amostra & 1572,876 \\
Curtose & $-1,253$ \\
Assimetria & $-0,221$ \\
Intervalo & 169,275 \\
Mínimo & 74,300 \\
Máximo & 243,575 \\
Soma & 162815,198 \\
Contagem & $\mathbf{1 0 0 0}$ \\
\hline & $27,80 \%$
\end{tabular}

Tabela 28: Cenário 5 (A5000)

\begin{tabular}{lr}
\hline \multicolumn{2}{c}{ Preços } \\
\hline \hline \\
Média & $\mathbf{1 6 1 , 2 1 8}$ \\
Erro padrão & 0,568 \\
Mediana & 163,371 \\
Moda & 237,449 \\
Desvio padrão & $\mathbf{4 0 , 1 9 6}$ \\
Variância da amostra & 1615,712 \\
Curtose & $-1,433$ \\
Assimetria & $-0,064$ \\
Intervalo & 178,780 \\
Mínimo & 58,670 \\
Máximo & 237,449 \\
Soma & 806088,719 \\
Contagem & $\mathbf{5 0 0 0}$ \\
\hline & $30,20 \%$
\end{tabular}

Tabela 29: Cenário 5 (A10000)

\begin{tabular}{lr}
\hline \multicolumn{2}{c}{ Preços } \\
\hline Média & $\mathbf{1 6 0 , 0 7 4}$ \\
Erro padrão & 0,401 \\
Mediana & 159,250 \\
Moda & 198,572 \\
Desvio padrão & $\mathbf{4 0 , 0 6 6}$ \\
Variância da amostra & 1605,304 \\
Curtose & $-1,395$ \\
Assimetria & $-0,001$ \\
Intervalo & 193,771 \\
Mínimo & 57,021 \\
Máximo & 250,792 \\
Soma & 1600736,363 \\
Contagem & $\mathbf{1 0 0 0 0}$ \\
\hline & $32,18 \%$
\end{tabular}

No cenário 5, os resultados que mais se aproximam aos originais é amostra de tamanho 5000 (preço médio próximo do original). 
Tabela 30: Cenário 6 (A500)

\begin{tabular}{lr}
\hline \multicolumn{2}{c}{ Preços } \\
\hline \hline \\
Média & $\mathbf{1 6 0 , 3 2 0}$ \\
Erro padrão & 1,794 \\
Mediana & 163,496 \\
Moda & 117,301 \\
Desvio padrão & $\mathbf{4 0 , 1 0 6}$ \\
Variância da amostra & 1608,507 \\
Curtose & $-1,446$ \\
Assimetria & 0,030 \\
Intervalo & 147,303 \\
Mínimo & 88,803 \\
Máximo & 236,106 \\
Soma & 80160,025 \\
Contagem & $\mathbf{5 0 0}$ \\
\hline & $27,80 \%$
\end{tabular}

Tabela 31: Cenário 6 (A1000)

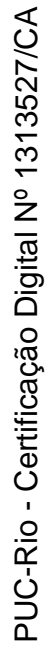

\begin{tabular}{lr}
\hline \multicolumn{2}{c}{ Preços } \\
\hline \hline Média & $\mathbf{1 6 2 , 1 3 5}$ \\
Erro padrão & 1,262 \\
Mediana & 167,657 \\
Moda & 192,358 \\
Desvio padrão & $\mathbf{3 9 , 9 0 9}$ \\
Variância da amostra & 1592,750 \\
Curtose & $-1,402$ \\
Assimetria & $-0,117$ \\
Intervalo & 157,588 \\
Mínimo & $\mathbf{7 7 , 8 8 1}$ \\
Máximo & 235,469 \\
Soma & 162134,752 \\
Contagem & $\mathbf{1 0 0 0}$ \\
\hline & $31,30 \%$
\end{tabular}

Tabela 32: Cenário 6 (A5000)

\begin{tabular}{lr}
\hline \multicolumn{2}{c}{ Preços } \\
\hline \hline \\
Média & $\mathbf{1 6 0 , 7 6 6}$ \\
Erro padrão & 0,556 \\
Mediana & 165,007 \\
Moda & 182,486 \\
Desvio padrão & $\mathbf{3 9 , 3 1 6}$ \\
Variância da amostra & 1545,741 \\
Curtose & $-1,405$ \\
Assimetria & $-0,058$ \\
Intervalo & 192,681 \\
Mínimo & 57,698 \\
Máximo & 250,379 \\
Soma & 803830,991 \\
Contagem & $\mathbf{5 0 0 0}$ \\
\hline & $31,28 \%$
\end{tabular}

Tabela 33: Cenário 6 (A10000)

\begin{tabular}{lr}
\hline \multicolumn{2}{c}{ Preços } \\
\hline \hline \\
Média & $\mathbf{1 6 1 , 5 7 4}$ \\
Erro padrão & 0,401 \\
Mediana & 166,119 \\
Moda & 150,660 \\
Desvio padrão & $\mathbf{4 0 , 1 0 9}$ \\
Variância da amostra & 1608,738 \\
Curtose & $-1,369$ \\
Assimetria & $-0,069$ \\
Intervalo & 201,181 \\
Mínimo & 49,860 \\
Máximo & 251,041 \\
Soma & 1615737,054 \\
Contagem & $\mathbf{1 0 0 0 0}$ \\
\hline & $30,84 \%$
\end{tabular}

No cenário 6 , os resultados que mais se aproximam aos originais é amostra de tamanho 1000 (preço médio próximo do original). 
Tabela 34: Cenário 7 (A500)

\begin{tabular}{lr}
\hline \multicolumn{2}{c}{ Preços } \\
\hline \hline Média & $\mathbf{1 5 7 , 5 6 8}$ \\
Erro padrão & 1,781 \\
Mediana & 149,740 \\
Moda & 131,947 \\
Desvio padrão & $\mathbf{3 9 , 8 2 7}$ \\
Variância da amostra & 1586,182 \\
Curtose & $-1,426$ \\
Assimetria & 0,089 \\
Intervalo & 160,653 \\
Mínimo & 75,603 \\
Máximo & 236,257 \\
Soma & 78783,780 \\
Contagem & $\mathbf{5 0 0}$ \\
\hline & $35,20 \%$
\end{tabular}

Tabela 35: Cenário 7 (A1000)

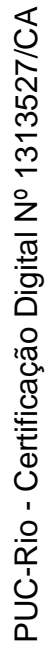

\begin{tabular}{lr}
\hline \multicolumn{2}{c}{ Preços } \\
\hline \hline Média & \\
Erro padrão & $\mathbf{1 5 8 , 3 5 8}$ \\
Mediana & 1,270 \\
Moda & 155,846 \\
Desvio padrão & 183,276 \\
Variância da amostra & $\mathbf{4 0 , 1 4 6}$ \\
Curtose & 1611,664 \\
Assimetria & $-1,338$ \\
Intervalo & $-0,028$ \\
Mínimo & 167,510 \\
Máximo & 60,090 \\
Soma & 227,600 \\
Contagem & 158357,778 \\
\hline & $\mathbf{1 0 0 0}$ \\
\hline
\end{tabular}

Tabela 36: Cenário 7 (A5000)

\begin{tabular}{lr}
\hline \multicolumn{2}{c}{ Preços } \\
\hline \hline Média & \\
Erro padrão & $\mathbf{1 6 2 , 8 4 1}$ \\
Mediana & 0,561 \\
Moda & 170,770 \\
Desvio padrão & 213,930 \\
Variância da amostra & $\mathbf{3 9 , 6 8 5}$ \\
Curtose & 1574,937 \\
Assimetria & $-1,400$ \\
Intervalo & $-0,142$ \\
Mínimo & 191,073 \\
Máximo & 57,339 \\
Soma & 248,412 \\
Contagem & 814205,845 \\
\hline & $\mathbf{5 0 0 0}$ \\
\hline
\end{tabular}

Tabela 37: Cenário 7 (A10000)

\begin{tabular}{lr}
\hline \multicolumn{2}{c}{ Preços } \\
\hline \hline Média & $\mathbf{1 6 1 , 9 5 0}$ \\
Erro padrão & 0,395 \\
Mediana & 166,044 \\
Moda & 101,929 \\
Desvio padrão & 39,519 \\
Variância da amostra & 1561,791 \\
Curtose & $-1,350$ \\
Assimetria & $-0,120$ \\
Intervalo & 199,752 \\
Mínimo & 49,755 \\
Máximo & 249,506 \\
Soma & 1619504,500 \\
Contagem & $\mathbf{1 0 0 0 0}$ \\
\hline & $28,66 \%$
\end{tabular}

No cenário 7, os resultados que mais se aproximam aos originais é amostra de tamanho 10000, como aconteceu nos cenários 1 e 2 (preço médio próximo do original). 
Tabela 38: Cenário 8 (A500)

\begin{tabular}{lr}
\hline \multicolumn{2}{c}{ Preços } \\
\hline \hline \\
Média & $\mathbf{1 6 4 , 3 1 4}$ \\
Erro padrão & 1,765 \\
Mediana & 175,177 \\
Moda & 201,421 \\
Desvio padrão & $\mathbf{3 9 , 4 7 4}$ \\
Variância da amostra & 1558,213 \\
Curtose & $-1,514$ \\
Assimetria & $-0,215$ \\
Intervalo & 148,708 \\
Mínimo & 77,577 \\
Máximo & 226,285 \\
Soma & 82157,088 \\
Contagem & $\mathbf{5 0 0}$ \\
\hline & $28,40 \%$
\end{tabular}

Tabela 39: Cenário 8 (A1000)

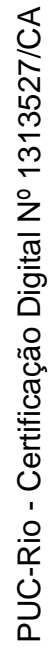

Tabela 40: Cenário 8 (A5000)

\begin{tabular}{lr}
\hline \multicolumn{2}{c}{ Preços } \\
\hline \hline \\
Média & $\mathbf{1 6 1 , 6 3 3}$ \\
Erro padrão & 0,546 \\
Mediana & 166,299 \\
Moda & 183,459 \\
Desvio padrão & $\mathbf{3 8 , 6 2 6}$ \\
Variância da amostra & 1491,952 \\
Curtose & $-1,364$ \\
Assimetria & $-0,091$ \\
Intervalo & 189,931 \\
Mínimo & 57,292 \\
Máximo & 247,222 \\
Soma & 808166,410 \\
Contagem & $\mathbf{5 0 0 0}$ \\
\hline & $28,60 \%$
\end{tabular}

Tabela 41: Cenário 8 (A10000)

\begin{tabular}{lr}
\hline \multicolumn{2}{c}{ Preços } \\
\hline \hline \\
Média & $\mathbf{1 6 3 , 1 2 1}$ \\
Erro padrão & 0,392 \\
Mediana & 168,578 \\
Moda & 160,991 \\
Desvio padrão & $\mathbf{3 9 , 2 4 1}$ \\
Variância da amostra & 1539,879 \\
Curtose & $-1,355$ \\
Assimetria & $-0,110$ \\
Intervalo & 185,867 \\
Mínimo & 60,271 \\
Máximo & 246,138 \\
Soma & 1631211,177 \\
Contagem & $\mathbf{1 0 0 0 0}$ \\
\hline & $28,50 \%$
\end{tabular}

No cenário 8, os resultados que mais se aproximam aos originais é amostra de tamanho 5000, como aconteceu no cenário 5 (preço médio próximo do original). 
Tabela 42: Cenário 9 (A500)

\begin{tabular}{lr}
\hline \multicolumn{2}{c}{ Preços } \\
\hline \hline \\
Média & $\mathbf{1 6 2 , 3 9 8}$ \\
Erro padrão & 1,828 \\
Mediana & 172,526 \\
Moda & 149,883 \\
Desvio padrão & $\mathbf{4 0 , 8 7 2}$ \\
Variância da amostra & 1670,527 \\
Curtose & $-1,449$ \\
Assimetria & $-0,122$ \\
Intervalo & 149,094 \\
Mínimo & 85,755 \\
Máximo & 234,849 \\
Soma & 81199,210 \\
Contagem & $\mathbf{5 0 0}$ \\
\hline & $30,40 \%$
\end{tabular}

Tabela 43: Cenário 9 (A1000)

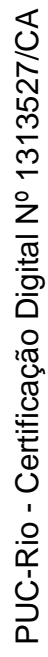

\begin{tabular}{lr}
\hline \multicolumn{2}{c}{ Preços } \\
\hline \hline \\
Média & $\mathbf{1 6 3 , 1 1 8}$ \\
Erro padrão & 1,167 \\
Mediana & 166,824 \\
Moda & 209,942 \\
Desvio padrão & $\mathbf{3 6 , 9 1 2}$ \\
Variância da amostra & 1362,490 \\
Curtose & $-1,189$ \\
Assimetria & $-0,184$ \\
Intervalo & 175,102 \\
Mínimo & 61,296 \\
Máximo & 236,398 \\
Soma & 163118,390 \\
Contagem & $\mathbf{1 0 0 0}$ \\
\hline & $26,20 \%$
\end{tabular}

Tabela 44: Cenário 9 (A5000)

\begin{tabular}{lr}
\hline \multicolumn{2}{c}{ Preços } \\
\hline \hline \\
Média & $\mathbf{1 6 3 , 3 6 2}$ \\
Erro padrão & 0,568 \\
Mediana & 170,178 \\
Moda & 131,927 \\
Desvio padrão & $\mathbf{4 0 , 1 3 3}$ \\
Variância da amostra & 1610,625 \\
Curtose & $-1,378$ \\
Assimetria & $-0,112$ \\
Intervalo & 186,271 \\
Mínimo & 64,711 \\
Máximo & 250,983 \\
Soma & 816810,368 \\
Contagem & $\mathbf{5 0 0 0}$ \\
\hline & $30,04 \%$
\end{tabular}

Tabela 45: Cenário 9 (A10000)

\begin{tabular}{lr}
\hline \multicolumn{2}{c}{ Preços } \\
\hline \hline \\
Média & $\mathbf{1 6 0 , 7 3 3}$ \\
Erro padrão & 0,395 \\
Mediana & 163,617 \\
Moda & 201,039 \\
Desvio padrão & $\mathbf{3 9 , 5 2 0}$ \\
Variância da amostra & 1561,796 \\
Curtose & $-1,392$ \\
Assimetria & $-0,043$ \\
Intervalo & 199,543 \\
Mínimo & 50,214 \\
Máximo & 249,757 \\
Soma & 1607331,905 \\
Contagem & $\mathbf{1 0 0 0 0}$ \\
\hline & $31,07 \%$
\end{tabular}

No cenário 9, os resultados que mais se aproximam aos originais é amostra de tamanho 500, como aconteceu no cenário 4 (preço médio próximo do original). 
Tabela 46: Cenário 10 (A500)

\begin{tabular}{lr}
\hline \multicolumn{2}{c}{ Preço } \\
\hline \hline \\
Média & $\mathbf{1 6 1 , 2 1 8}$ \\
Erro padrão & 1,929 \\
Mediana & 167,255 \\
Moda & 133,870 \\
Desvio padrão & $\mathbf{4 3 , 1 3 4}$ \\
Variância da amostra & 1860,506 \\
Curtose & $-1,356$ \\
Assimetria & $-0,127$ \\
Intervalo & 165,937 \\
Mínimo & 80,316 \\
Máximo & 246,254 \\
Soma & 80608,909 \\
Contagem & $\mathbf{5 0 0}$ \\
\hline
\end{tabular}

$28,20 \%$

Tabela 47: Cenário 10 (A1000)

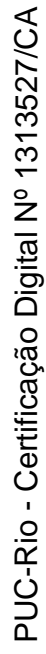

\begin{tabular}{lr}
\hline \multicolumn{2}{c}{ Preços } \\
\hline \hline \\
Média & $\mathbf{1 5 9 , 1 6 9}$ \\
Erro padrão & 1,214 \\
Mediana & 160,381 \\
Moda & 187,487 \\
Desvio padrão & $\mathbf{3 8 , 4 0 6}$ \\
Variância da amostra & 1474,991 \\
Curtose & $-1,334$ \\
Assimetria & 0,065 \\
Intervalo & 182,891 \\
Mínimo & 63,365 \\
Máximo & 246,256 \\
Soma & 159168,984 \\
Contagem & $\mathbf{1 0 0 0}$ \\
\hline & $33,00 \%$
\end{tabular}

Tabela 48: Cenário 10 (A5000)

\begin{tabular}{lr}
\hline \multicolumn{2}{c}{ Preços } \\
\hline \hline \\
Média & $\mathbf{1 6 1 , 9 2 0}$ \\
Erro padrão & 0,557 \\
Mediana & 169,279 \\
Moda & 209,920 \\
Desvio padrão & $\mathbf{3 9 , 3 8 1}$ \\
Variância da amostra & 1550,865 \\
Curtose & $-1,286$ \\
Assimetria & $-0,130$ \\
Intervalo & 192,918 \\
Mínimo & 57,040 \\
Máximo & 249,958 \\
Soma & 809601,877 \\
Contagem & $\mathbf{5 0 0 0}$ \\
\hline & $29,96 \%$
\end{tabular}

Tabela 49: Cenário 10 (10000)

\begin{tabular}{lr}
\hline \multicolumn{2}{c}{ Preços } \\
\hline Média & $\mathbf{1 6 0 , 6 3 9}$ \\
Erro padrão & 0,399 \\
Mediana & 162,515 \\
Moda & 186,949 \\
Desvio padrão & $\mathbf{3 9 , 8 9 4}$ \\
Variância da amostra & 1591,524 \\
Curtose & $-1,377$ \\
Assimetria & $-0,038$ \\
Intervalo & 188,964 \\
Mínimo & 61,870 \\
Máximo & 250,834 \\
Soma & 1606391,476 \\
Contagem & $\mathbf{1 0 0 0 0}$ \\
\hline & $32,36 \%$
\end{tabular}

No cenário 10, os resultados que mais se aproximam aos originais é amostra de tamanho 5000, como aconteceu nos cenários 5 e 8 (preço médio próximo do original). 
Depois de ter visto e analisado os resultados em diferentes cenários (nas 10 rodadas) do comportamento dos preços do Leilão de Eficiência Energética, ademais dos histogramas apresentados acima, se constata que as amostras que conseguem se aproximar muito melhor do comportamento original dos dados são as de 5000 e 10000 , seguindo certa regularidade e continuidade respeito aos dados que inicialmente foram mostrados. Nesse contexto da geração de amostras do preço do LEE através do MCMC, se verifica, segundo os resultados, que quanto maior é a amostra o resultado se aproxima à amostra original. A seguir, o quadro 3 apresenta os resultados de forma geral e a tabela 50 as conclusões.

Quadro 3: Comparações entre os cenários

\begin{tabular}{|c|c|c|c|c|}
\hline Rodada & Amostra 500 & Amostra 1000 & Amostra 5000 & Amostra 10000 \\
\hline $\mathrm{R} 1$ & $x$ & $x$ & $\mathrm{x}$ & Mais próximo \\
\hline $\mathrm{R} 2$ & $x$ & $x$ & $x$ & Mais próximo \\
\hline R3 & $x$ & Mais próximo & $\mathrm{x}$ & $x$ \\
\hline R4 & Mais próximo & $x$ & $x$ & $x$ \\
\hline R5 & $x$ & $x$ & Mais próximo & $x$ \\
\hline R6 & $x$ & Mais próximo & $x$ & $x$ \\
\hline R7 & $x$ & $x$ & $\mathrm{x}$ & Mais próximo \\
\hline R8 & $x$ & $x$ & Mais próximo & $x$ \\
\hline R9 & Mais próximo & $x$ & $\mathrm{x}$ & $x$ \\
\hline R10 & $x$ & $x$ & Mais próximo & $\mathrm{x}$ \\
\hline
\end{tabular}

Tabela 50: Conclusões das amostras

\begin{tabular}{|c|c|}
\hline Amostras & Conclusão \\
\hline A500 & $\begin{array}{l}\text { Em duas das dez rodadas propostas se conseguiu aproximar ao comportamento } \\
\text { dos dados originais, que representam o } 20 \% \text {. }\end{array}$ \\
\hline A1000 & $\begin{array}{l}\text { Em duas das dez rodadas propostas se conseguiu aproximar ao comportamento } \\
\text { dos dados originais, que representam o } 20 \% \text {. }\end{array}$ \\
\hline A5000 & $\begin{array}{l}\text { Em três das dez rodadas se conseguiu aproximar ao comportamento dos dados } \\
\text { originais, que representam o } 30 \% \text {. }\end{array}$ \\
\hline A10000 & $\begin{array}{l}\text { Em três das dez rodadas se conseguiu aproximar ao comportamento dos dados } \\
\text { originais, que representam o } 30 \% \text {. }\end{array}$ \\
\hline
\end{tabular}

Ademais, uma vez conseguida a curva mais bem ajustada se realizou a análise de cada cenário com cada amostra para encontrar a probabilidade dos preços ficarem entre o intervalo de $\mathrm{R} \$ 110$ e $\mathrm{R} \$ 140$. A seguir se apresenta os diferentes resultados com cada probabilidade obtida. 
Tabela 51: Probabilidade no Cenário 1

\begin{tabular}{cc}
\hline Tamanho da amostra & Probabilidade \\
\hline 500 & $27,80 \%$ \\
\hline 1000 & $26,10 \%$ \\
\hline 5000 & $29,66 \%$ \\
\hline 10000 & $30,86 \%$ \\
\hline
\end{tabular}

Como se observa na tabela 51 em relação ao cenário 1 , a probabilidade do preço ficar no intervalo de $\mathrm{R} \$ 110$ e $\mathrm{R} \$ 140$ na amostra de 500 dados é de 27,80\%, na amostra de 1000 é de $26,10 \%$, na amostra de 5000 é de $29,66 \%$ e de 10000 é de $30,86 \%$.

Tabela 52: Probabilidade no Cenário 2

\begin{tabular}{cc}
\hline Tamanho da amostra & Probabilidade \\
\hline 500 & $28,60 \%$ \\
\hline 1000 & $31,40 \%$ \\
\hline 5000 & $30,00 \%$ \\
\hline 10000 & $31,61 \%$ \\
\hline
\end{tabular}

Como se observa na tabela 52 em relação ao cenário 2, a probabilidade do preço ficar no intervalo de $\mathrm{R} \$ 110$ e $\mathrm{R} \$ 140$ na amostra de 500 dados é de 28,60\%, na amostra de 1000 é de $31,40 \%$, na amostra de 5000 é de $30,00 \%$ e de 10000 é de $31,61 \%$.

Tabela 53: Probabilidade no Cenário 3

\begin{tabular}{cc}
\hline Tamanho da amostra & \multicolumn{1}{c}{ Probabilidade } \\
\hline \hline 500 & $31,80 \%$ \\
\hline 1000 & $29,10 \%$ \\
\hline 5000 & $30,94 \%$ \\
\hline 10000 & $30,07 \%$ \\
\hline
\end{tabular}

Como se observa na tabela 53 em relação ao cenário 3, a probabilidade do preço ficar no intervalo de $\mathrm{R} \$ 110$ e $\mathrm{R} \$ 140$ na amostra de 500 dados é de 31,80\%, 
na amostra de 1000 é de $29,10 \%$, na amostra de 5000 é de $30,94 \%$ e de 10000 é de $30,07 \%$.

Tabela 54: Probabilidade no Cenário 4

\begin{tabular}{cc}
\hline Tamanho da amostra & Probabilidade \\
\hline 500 & $25,80 \%$ \\
\hline 1000 & $30,80 \%$ \\
\hline 5000 & $30,90 \%$ \\
\hline 10000 & $29,88 \%$ \\
\hline
\end{tabular}

Como se observa na tabela 54 em relação ao cenário 4, a probabilidade do preço ficar no intervalo de $\mathrm{R} \$ 110$ e $\mathrm{R} \$ 140$ na amostra de 500 dados é de 25,80\%, na amostra de 1000 é de $30,80 \%$, na amostra de 5000 é de $30,90 \%$ e de 10000 é de $29,88 \%$.

Tabela 55: Probabilidade no Cenário 5

\begin{tabular}{cr}
\hline Tamanho da amostra & Probabilidade \\
\hline 500 & $34,60 \%$ \\
\hline 1000 & $27,80 \%$ \\
\hline 5000 & $30,20 \%$ \\
\hline 10000 & $32,18 \%$ \\
\hline
\end{tabular}

Como se observa na tabela 55 em relação ao cenário 5 , a probabilidade do preço ficar no intervalo de $\mathrm{R} \$ 110$ e $\mathrm{R} \$ 140$ na amostra de 500 dados é de 34,60\%, na amostra de 1000 é de $27,80 \%$, na amostra de 5000 é de $30,20 \%$ e de 10000 é de $32,18 \%$.

Tabela 56: Probabilidade no Cenário 6

\begin{tabular}{cr}
\hline Tamanho da amostra & Probabilidade \\
\hline 500 & $27,80 \%$ \\
\hline 1000 & $31,30 \%$ \\
\hline 5000 & $31,28 \%$ \\
\hline 10000 & $30,84 \%$ \\
\hline
\end{tabular}


Como se observa na tabela 56 em relação ao cenário 6, a probabilidade do preço ficar no intervalo de $\mathrm{R} \$ 110$ e $\mathrm{R} \$ 140$ na amostra de 500 dados é de 27,80\%, na amostra de 1000 é de $31,30 \%$, na amostra de 5000 é de $31,28 \%$ e de 10000 é de $30,84 \%$.

Tabela 57: Probabilidade no Cenário 7

\begin{tabular}{cr}
\hline Tamanho da amostra & Probabilidade \\
\hline 500 & $35,20 \%$ \\
\hline 1000 & $32,10 \%$ \\
\hline 5000 & $29,42 \%$ \\
\hline 10000 & $28,66 \%$ \\
\hline
\end{tabular}

Como se observa na tabela 57 em relação ao cenário 7, a probabilidade do preço ficar no intervalo de $\mathrm{R} \$ 110$ e $\mathrm{R} \$ 140$ na amostra de 500 dados é de 35,20\%, na amostra de 1000 é de $32,10 \%$, na amostra de 5000 é de $29,42 \%$ e de 10000 é de $28,66 \%$.

Tabela 58: Probabilidade no Cenário 8

\begin{tabular}{cr}
\hline Tamanho da amostra & Probabilidade \\
\hline 500 & $28,40 \%$ \\
\hline 1000 & $30,20 \%$ \\
\hline 5000 & $28,60 \%$ \\
\hline 10000 & $28,50 \%$ \\
\hline
\end{tabular}

Como se observa na tabela 58 em relação ao cenário 8 , a probabilidade do preço ficar no intervalo de $\mathrm{R} \$ 110$ e $\mathrm{R} \$ 140$ na amostra de 500 dados é de $28,40 \%$, na amostra de 1000 é de 30,20\%, na amostra de 5000 é de 28,60\% e de 10000 é de $28,50 \%$.

Tabela 59: Probabilidade no Cenário 9

\begin{tabular}{cc}
\hline Tamanho da amostra & Probabilidade \\
\hline 500 & $30,40 \%$ \\
\hline 1000 & $26,20 \%$ \\
\hline 5000 & $30,04 \%$ \\
\hline 10000 & $31,07 \%$ \\
\hline
\end{tabular}


Como se observa na tabela 59 em relação ao cenário 9, a probabilidade do preço ficar no intervalo de $\mathrm{R} \$ 110$ e $\mathrm{R} \$ 140$ na amostra de 500 dados é de 30,40\%, na amostra de 1000 é de 26,20\%, na amostra de 5000 é de 30,04\% e de 10000 é de $31,07 \%$.

Tabela 60: Probabilidade no Cenário 10

\begin{tabular}{cc}
\hline Tamanho da amostra & Probabilidade \\
\hline 500 & $28,20 \%$ \\
\hline 1000 & $33,00 \%$ \\
\hline 5000 & $29,96 \%$ \\
\hline 10000 & $32,36 \%$ \\
\hline
\end{tabular}

Como se observa na tabela 60 em relação ao cenário 10, a probabilidade do preço ficar no intervalo de $\mathrm{R} \$ 110$ e $\mathrm{R} \$ 140$ na amostra de 500 dados é de 28,20\%, na amostra de 1000 é de 33,00\%, na amostra de 5000 é de $29,96 \%$ e de 10000 é de $32,36 \%$.

As probabilidades apresentadas nos diferentes cenários variam entre 25,80\% mostrada no cenário 4 e 35,20\% mostrada no cenário 7 . 


\section{Conclusões e recomendações}

Quando o modelo matemático, para o método analítico, não captura todas as características importantes do sistema estocástico, a simulação é uma aplicação a ser utilizada para incorporar todas as características do sistema estocástico e então obter informações detalhadas sobre as medidas de desempenho de alguns candidatos em potencial para a configuração final do sistema. Esta pesquisa tratou da simulação dos preços de energia no ambiente de contratação regulado do possível leilão de eficiência energética no Brasil. Analisando os diferentes leilões realizados desde anos anteriores, especificamente os preços que foram tratados em cada um deles.

A simulação forneceu uma forma de experimentação com políticas propostas utilizando teoria estatística sólida. Normalmente foram necessários processamentos longos de simulação para obter resultados significativos em termos estatísticos.

Ademais, foram analisadas e também comparadas as diversas experiências que outros países têm em relação ao leilão de eficiência energética, tentando adaptar para Brasil aqueles modelos que vem trazendo sucesso em outros lugares.

Por outro lado, se conseguiu adaptar os preços de energia de um possível leilão de eficiência energética a uma curva através do método Kernel (obtendo um polinômio da ordem 17), além disso, se realizou as simulações aplicando Monte Carlo via cadeia de Markov, e usando o algoritmo de Metropolis-Hastings se gerou amostras para poder analisar melhor o comportamento dos preços.

$\mathrm{O}$ uso de ferramentas computacionais e modelos estatísticos permitiram simular e obter as probabilidades dos futuros preços do possível Leilão de Eficiência Energética em diversos cenários apresentados.

Além disso, se conseguiu estabelecer a partir das propostas de leilão de eficiência energética de diferentes países as melhores características para um possível Leilão no Brasil. 
O fator do mecanismo de Medição e Verificação no Leilão de Eficiência Energética também foi estudado, levando em conta a importância que terá na hora de ser implantado, sabendo que os participantes buscarão garantia no processo.

Como futuro trabalho de pesquisa relacionado ao Leilão de eficiência Energética, se recomenda a otimização dos preços que o processo do Leilão teria ao ser implementado. Desse modo, o preço seria conhecido com mais exatidão já que o comportamento dos dados foi ajustado claramente com diferentes técnicas matemáticas e estatísticas, neste caso, o método Kernel e Monte Carlo foram chaves para conseguir isso.

Além disso, sugere-se a simulação no ambiente livre, que tem como proxy de preço o PLD (Preço de Liquidação das Diferenças). Todavia, uma outra metodologia que permita obter, de forma similar, os diferentes cenários que foram obtidos no ambiente de contratação regulado feito nesta pesquisa devem ser testados. Assim, poderá ter-se uma visão mais ampla do contexto do Leilão de Eficiência Energética nos dois ambientes de contratação brasileiros. 


\section{8 \\ Referências bibliográficas}

AGÊNCIA NACIONAL DE ENERGIA ELÉTRICA. Efficiency Valuation Organization. Brasilia: ANEEL: v. 1, p. 125, 2012.

Resolução Normativa $\mathbf{N}^{\mathbf{0}}$ 492/2002. Estabelece os critérios para aplicação de recursos em Programas de Eficiência Energética (PEE). 2002.

Resolução Normativa No 300/2008. Define o Manual para Elaboração do Programa de Eficiência Energética (PEE). 2008.

Resolução Normativa $\mathbf{N}^{\mathbf{0}} \mathbf{5 5 6 / 2 0 1 3}$. Aprovar os Procedimentos do Programa de Eficiência Energética (PROPEE). 2013.

ATZENI, I. et al. Noncooperative Day-Ahead Bidding Strategies for DemandSide Expected Cost Minimization With Real-Time Adjustments: A GNEP Approach. IEEE Transactions on Signal Processing, v. 62, n. 9, p. 2397-2412, May 2014. ISSN 1053-587X.

BOMPARD, E. et al. The impacts of price responsiveness on strategic equilibrium in competitive electricity markets. International Journal of Electrical Power \& Energy Systems, v. 29, n. 5, p. 397-407, Jun 2007. ISSN 0142-0615.

CALILI, R. F. Políticas de Eficiência Energética no Brasil: uma abordagem em um Ambiente Econômico sob incerteza. Tese de doutorado. 2013. 184. Departamento de Engenharia Elétrica da Pontifícia Universidade Católica do Rio de Janeiro.

DRAKOS, K. Competition and contestability in transition banking: an empirical analysis. South-Eastern Europe Journal of Economics, v. 2, p. 183-209, 2009.

EARLE, R.; FARUQUI, A. Measuring the capacity impacts of demand response. The Electricity Journal, 22, Issue 6, p. 47-58, 2008.

FURIO, D.; LUCIA, J. J. Congestion management rules and trading strategies in the Spanish electricity market. Energy Economics, v. 31, n. 1, p. 48-60, Jan 2009. ISSN 0140-9883.

FURUSAWA, K.; SUGIHARA, H.; TSUJI, K. Economic evaluation of Demandside energy storage systems by using a multi-agent-based electricity market. Electrical Engineering in Japan, v. 167, n. 3, p. 36-45, May 2009. ISSN 04247760 . 
GARCIA, A. G. P. Leilão de Eficiência Energética no Brasil. Tese de doutorado. 2008. 175. Pós-Graduação no Programa de Planejamento Energético da Universidade Federal do Rio de Janeiro.

GARCIA, A. G. P. Leilões de Eficiência Energética no Brasil. Rio de Janeiro: Synergia, 2009. p. 229, n. 1. ISBN: 8561325070.

GROVER, H. K.; PRETORIUS, M. W. The technology assessment of demand side bidding within the South African context. Journal of Industrial Engineering, v. 19, n. 2, p. 93-108, 2007.

HASTINGS, W. K. Monte Carlo Sampling Methods using Markov Chains and their applications. Biometrika, v. 57, p. 97-109, 1970.

HILLIER, F.; LIEBERMAN, G. Introdução à pesquisa operacional. McGrawHill. São Paulo. p. 811. ISBN 85-868046-81. 2006.

IGNATIEVA, K. A nonparametric model for spot price dynamics and pricing of futures contracts in electricity markets. Studies in Nonlinear Dynamics and Econometrics, v. 18, n. 5, p. 483-505, Dec 2014. ISSN 1081-1826.

INSTITUTO NACIONAL DE EFICIÊNCIA ENERGÉTICA. Medição e Verificação. Rio de Janeiro, 2014. Disponível em: http://www.inee.org.br/.

MAURER T. A., L.; BARROSO, L. A.. Electricity Auctions: An overview of efficient practices. A World Bank Study. Washington, DC: World Bank. 2011. p. 152. ISBN: 978-0-8213-8822-8.

METROPOLIS, N., A.W., ROSENBLUTH, M.N. ROSENBLUTH, A.H. TELLER, AND E. TELLER. Equations of State Calculations by Fast Computing Machines. Journal of Chemical Physics, v. 21, p. 1087-1092, 1953.

MINISTÉRIO DE MINAS E ENERGIA. Plano Nacional de Energia 2030 Programa Nacional de Eficiência Energética 2030. Brasilia. 2014.

OH, H.; THOMAS, R. J. Demand-Side Bidding Agents: Modeling and Simulation. IEEE Transactions on Power Systems, IEEE. v. 23, p. 1050-1056. 2008 .

OPERADOR NACIONAL DO SISTEMA ELÉTRICO. Plano da Operação Energética 2014/2016 - Plano Nacional de Energia. Departamento de Desenvolvimento Energético: Brasil, v. 1, p. 133. 2014.

PHILPOTT, A. B.; PETTERSEN, E. Optimizing demand-side bids in day-ahead electricity markets. IEEE Transactions on Power Systems, v. 21, n. 2, p. 488498, May 2006. ISSN 0885-8950.

PRABAVATHI, M.; GNANADASS, R. Energy bidding strategies for restructured electricity market. Electrical Power \& Energy Systems, v. 64, p. 956-966, 2015. 
SCHAEFFER, R. Energia é refém do jogo político. Entrevista à revista Brasil Energia, $n^{\circ} 284$, julho, 2004, p. 20-24.

TIERNEY, L. Markov chains for exploring posterior distributions. The Annals of Statistics, v. 22, p. 1701-1728, 1994.

TYLER, E.; DU TOIT, M.; BURCHELL, Z. White certificates and white certificate trading schemes as greenhouse gas mitigation policy options for South Africa. Journal of Energy in Southern Africa, v. 22, n. 1, p. 18-25, Feb 2011. ISSN 1021-447X.

ZHANG, N. Generators' bidding behavior in the NYISO day-ahead wholesale electricity market. Energy Economics, v. 31, n. 6, p. 897-913, Nov 2009. ISSN 0140-9883. 